UNIVERSIDADE DE SÃO PAULO ESCOLA DE ENGENHARIA DE SÃO CARLOS

DEPARTAMENTO DE ENGENHARIA ELÉTRICA E COMPUTAÇÃO PROGRAMA DE PÓS-GRADUAÇÃO EM ENGENHARIA ELÉTRICA

SÉRGIO AUGUSTO DE MORAIS FILHO

\title{
Métodos para Alocação de Sistemas de Armazenamento de Energia em Redes de Distribuição de Energia Elétrica
}




\section{SÉRGIO AUGUSTO DE MORAIS FILHO}

\section{Métodos para Alocação de Sistemas de Armazenamento de Energia em Redes de Distribuição de Energia Elétrica}

Dissertação apresentada à Escola de Engenharia de São Carlos da Universidade de São Paulo, como requisito para a obtenção do título de Mestre em Ciências pelo Programa de Pós-Graduação em Engenharia Elétrica.

Área de Concentração: Sistemas Elétricos de Potência

Orientador: Prof. Dr. José Carlos de Melo Vieira Júnior

VERSÃO CORRIGIDA

São Carlos

2020 
AUTORIZO A REPRODUÇÃO TOTAL OU PARCIAL DESTE TRABALHO, POR QUALQUER MEIO CONVENCIONAL OU ELETRÔNICO, PARA FINS DE ESTUDO E PESQUISA, DESDE QUE CITADA A FONTE.

Ficha catalográfica elaborada pela Biblioteca Prof. Dr. Sérgio Rodrigues Fontes da EESC/USP com os dados inseridos pelo(a) autor(a).

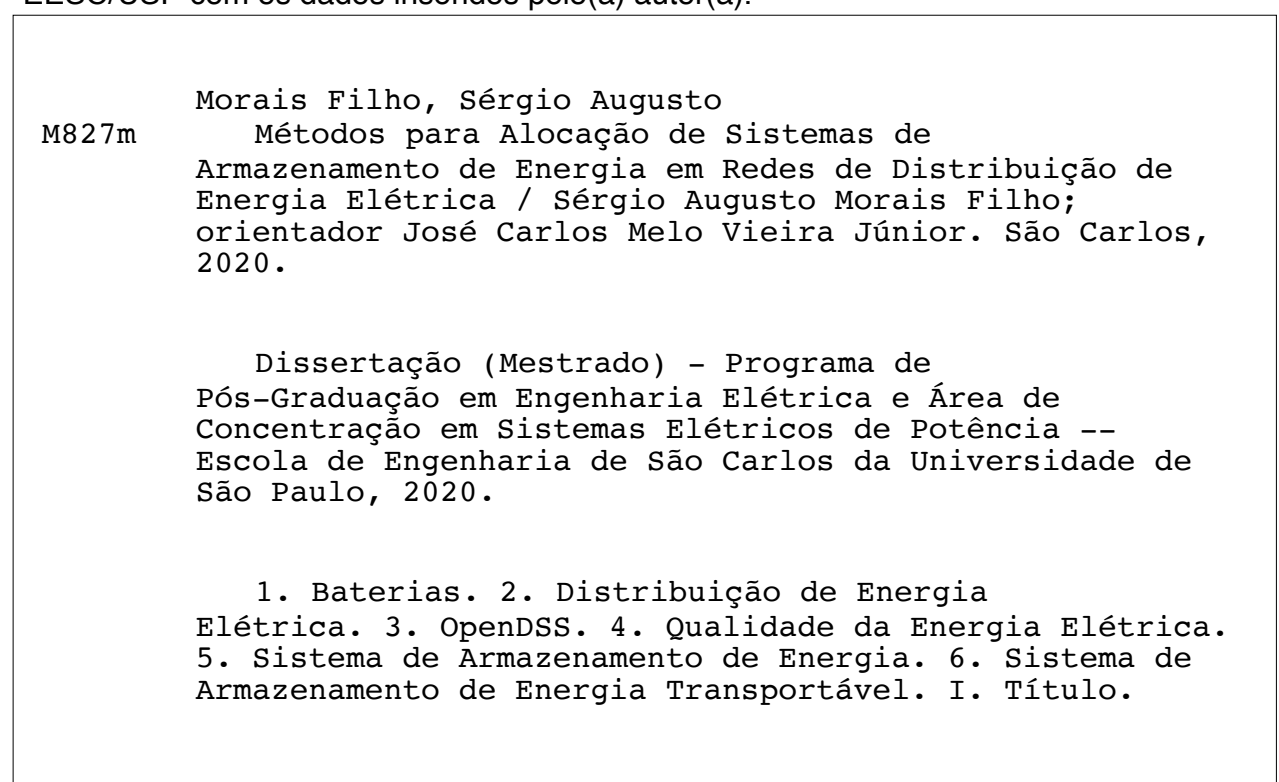

Eduardo Graziosi Silva - CRB - 8/8907 


\section{FOLHA DE JULGAMENTO}

Candidato: Engenheiro SÉRGIO AUGUSTO DE MORAIS FILHO.

Título da dissertação: "Métodos para alocação de sistemas de armazenamento de energia em redes de distribuição de energia elétrica".

Data da defesa: 08/07/2020

Comissão Julgadora:

Resultado:

Prof. Associado José Carlos de Melo Vieira Júnior

APROVADO (Orientador)

(Escola de Engenharia de São Carlos - EESC/USP)

Prof. Dr. Danilo Hernane Spatti APROVADO

(Instituto de Ciências Matemáticas e de Computação/ICMC-USP)

Prof. Dr. Madson Cortes de Almeida APROVADO

(Universidade Estadual de Campinas/UNICAMP)

Coordenador do Programa de Pós-Graduação em Engenharia Elétrica: Prof. Titular Ivan Nunes da Silva

Presidente da Comissão de Pós-Graduação:

Prof. Titular Murilo Araujo Romero 


\section{Agradecimentos}

Agradeço ao professor José Carlos pela orientação que obtive também durante esse tempo de estudo dedicado ao mestrado, por sua constante paciência para comigo, companheirismo e atenção solícita sempre que possível. Sempre me lembrarei da dedicação e seriedade com que o vi trabalhar e de sua simplicidade como pessoa. Também agradeço à (com crase) minha prima de consideração, Fernanda Trindade, pelos conselhos e suportes frequentes mesmo que à distância.

Sou grato também aos meus colegas, que contribuíram para que esse período e esse trabalho fossem os melhores possíveis. Dentre eles, destaco o Eduardo Gomes (Dudão), Vinícius Albernaz, Rodrigo Bataglioli, Jeovane Souza, Leandro Dias, Rui Bertho, Daniel Ferreira, Renan Furlan, André Pessoa e Yan Vilela, pelos momentos de distrações e pela disposição em ajudar várias vezes em meus estudos.

Também não poderia deixar de reconhecer o amor e apoio sempre presentes da minha família: pai, mãe, irmã e avó. Sem os quais dificilmente teria condições de completar esta etapa. Graças ao Senhor por cada um que ele colocou ao meu redor nessa caminhada, porque estou certo que cooperaram para o meu bem.

Por fim, destaco que este trabalho foi fruto do Programa de Pesquisa e Desenvolvimento Tecnológico do Setor de Energia Elétrica da Agência Nacional de Energia Elétrica (PD-2866-0454/2016) - Sistema de Armazenamento Transportável para Suporte a Contingências Programadas em SEs, desenvolvido em conjunto com CPqD, a COPEL Distribuição S.A. e COPEL Geração e Transmissão S.A., sendo estas últimas as responsáveis pelo suporte financeiro para a sua realização. 
"Disse Daniel: Seja bendito o nome de Deus para todo o sempre, porque são dele a sabedoria e a força. Ele muda os tempos e as estações; ele remove os reis e estabelece os reis; é ele quem dá a sabedoria aos sábios e o entendimento aos entendidos."

Daniel 2:20-22 


\section{Resumo}

MORAIS, S. A. Métodos para Alocação de Sistemas de Armazenamento de Energia em Redes de Distribuição de Energia Elétrica. 2020. Dissertação (Mestrado) - Escola de Engenharia de São Carlos, Universidade de São Paulo, São Carlos, 2020.

Em um mercado de energia com evidentes mudanças em sua regulamentação, sistemas de armazenamento de energia transportáveis surgem como equipamentos importantes capazes de prestar vários serviços aos sistemas de distribuição. A alocação dos sistemas de armazenamento de energia está intimamente relacionada com o sucesso de suas aplicações, sejam estes transportáveis ou estacionários. Neste trabalho, um índice ponderado e um método baseado em sensibilidades de tensão são propostos para otimizar a alocação de sistemas de armazenamento de energia em redes de distribuição de energia elétrica. O sistema teste IEEE 34 barras foi utilizado para validar as ferramentas mencionadas. O MATLAB e o OpenDSS foram os programas usados nas análises em regime permanente de horizonte diário. Sendo assim, a interação entre o perfil de carga e o controle de carga/descarga do armazenador de energia foi analisada. O estudo endossa o índice proposto como uma ferramenta útil na otimização da alocação de um sistema de armazenamento de energia para a operação do sistema, no que diz respeito às perdas de energia e outros impactos. Ademais, o método baseado em sensibilidades de tensão foi capaz de calcular tanto o aumento de tensão devido às injeções de potência quanto a máxima injeção de potência para cada barra do sistema, facilitando assim a alocação de sistemas de armazenamento de energia.

Palavras-chave: baterias, distribuição de energia elétrica, OpenDSS, qualidade da energia elétrica, sistema de armazenamento de energia, sistema de armazenamento de energia transportável. 


\section{Abstract}

MORAIS, S. A. Allocation Methods for Storage Energy Systems in Power Distribution Networks. 2020. Thesis (Masters) - São Carlos School of Engineering, University of São Paulo, 2020.

In an energy market with notorious changes in regulation, transportable energy storage emerges as important equipment capable of supplying many services to electric power distribution systems. Energy storage allocation is intrinsically related to the success of energy storage systems applications, whether they are stationary or transportable. In this work, an average weighted index and a voltage sensibility-based method are proposed to optimize the allocation of energy storage systems in energy distribution. The IEEE 34 bus test system was used to validate the proposed approach. MATLAB and OpenDSS were the software employed in steady-state analyses on a daily horizon. Correspondingly, the interaction between load shape and control of charge/discharge for the energy storage system is analyzed. The study endorses that the proposed index is a useful tool for optimizing the energy storage system allocation for system operation, regarding power losses and other impacts. Additionally, the voltage sensitivity-based method was able to calculate the voltage rise due to power injection as well as the maximum power injection allowed for each system bus, thus facilitating the allocation of energy storage systems.

Keywords: battery, distribution power system, energy storage system, OpenDSS, power quality, transportable energy storage system. 


\section{Lista de Ilustrações}

FIGURA 1 - ARMAZENAMENTO DE ENERGIA VIA BOMBEAMENTO HIDRÁULICO ..................... 21

FIGURA 2 - ARMAZENAMENTO DE ENERGIA VIA AR COMPRIMIDO ......................................... 22

FIGURA 3 - ARMAZENAMENTO DE ENERGIA VIA VOLANTE DE INÉRCIA................................. 22

FIGURA 4 - ARMAZENADOR DE ENERGIA COMPOSTO DE SUPERCAPACITORES ........................22

FIGURA 5 - ARMAZENADOR DE ENERGIA VIA BATERIA DE ÍONS DE LÍTIO INSTALADA EM

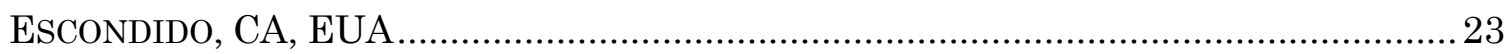

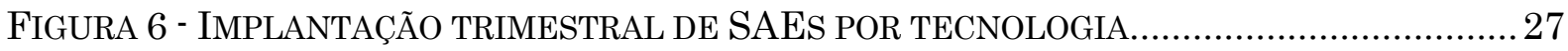

FIGURA 7 - ESTRUTURA DE LOCOMOÇÃO DE UM SAET …................................................. 38

FIGURA 8 - SiSTEMA IEEE 34 BARRAS, COM BARRAS DE CARGA DESTACADAS EM VER......... 46

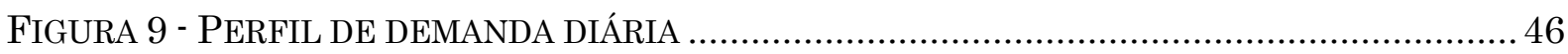

FigURA 10 - SisTEMA IEEE 123 BARRAS, COM BARRAS DE CARGA DESTACADAS EM VERDE 47

FIGURA 11 - INTERFACE GRÁFICA OPENDSS .............................................................. 48

FIGURA 12 - MODELO DE SAE DO OPENDSS ................................................................. 55

Figura 13 - CURVA DE CONTROLE APLiCADA AO SAET COM TAXA DE DESCARGA $1 \mathrm{C}$.........58

Figura 14 - CuRVA DE CONTROLE APLICADA AO SAET COM TAXA DE DESCARGA 0,5 C ......59

Figura 15 - CURVA DE CONTROLE APLICADA AO SAET COM TAXA DE DESCARGA 0,33 C .... 59

Figura 16 - CuRVA DE CONTROLE APLICADA AO SAET COM TAXA DE DESCARGA 0,2 C ...... 59

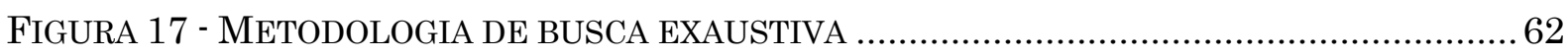

FiguRA 18 - TOTAL DE ATUAÇÃo DOS REGULADORES DE TENSÃO POR ALOCAÇÃO DO SAET69

FIGURA 19 - PERDAS DE ENERGIA (KWH) POR ALOCAÇÃO DO SAET EM UM DIA DE OPERAÇÃO

FIGURA 20 - SISTEMA IEEE 34 BARRAS, COM BARRAS AGRUPADAS DE ACORDO COM OS

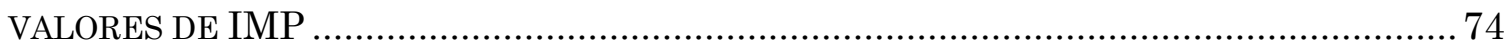

FIGURA 21 - CLASSIFICAÇÃO DE ALOCAÇÕES DO SAET POR IMP PARA DIFERENTES CENÁRIOS NO SISTEMA IEEE 34 BARRAS .............................................................. 75

FIGURA 22 - SISTEMA IEEE 123 BARRAS, COM BARRAS AGRUPADAS DE ACORDO COM OS VALORES DE IMP.

FIGURA 23 - CLASSIFICAÇÃO DE ALOCAÇÕES DO SAET POR IMP PARA DIFERENTES CENÁRIOS NO SISTEMA IEEE 123 BARRAS (10 MELHORES ALOCAÇÕES PARA CADA CENÁRIO)

FigURA 24 - PoTÊNCIA NA SUBESTAÇÃO DO SISTEMA AO LONGO DO DIA, DESCONSIDERANDO

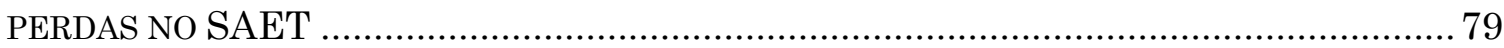

FIGURA 25 - ESTADO DE CARGA DO SAET OPERANDO COM DIFERENTES TAXAS DE DESCARGA, DESCONSIDERANDO PERDAS NO SAET 80

FIGURA 26 - POTÊNCIA NA SUBESTAÇÃO DO SISTEMA AO LONGO DO DIA, CONSIDERANDO PERDAS NO SAET

FIGURA 27 - ESTADO DE CARGA DO SAET OPERANDO COM DIFERENTES TAXAS DE DESCARGA, CONSIDERANDO PERDAS NO SAET 81

FIGURA 28 - CLASSIFICAÇÃO DE ALOCAÇÕES DO SAET POR IMP PARA DIFERENTES TAXAS DE DESCARGA, SISTEMA IEEE 34 BARRAS 
Figura 29 - ERRo ENTRE MÉTOdo De SENSIBILIDAdes E MÉTOdo DE NR, FASE A (PSAE = $-1000 \mathrm{~kW})$ 100

FiguRA 30 - ERRo ENTRE MÉTOdo De SENSIBILIDAdEs E MÉTOdo DE NR, FASE B (PSAE = $-1000 \mathrm{~kW})$ 100

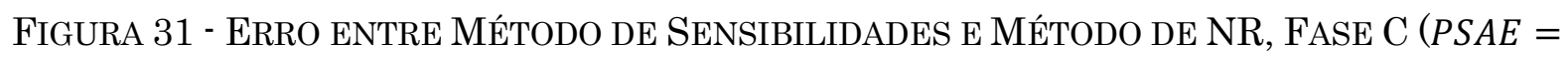
$-1000 \mathrm{~kW})$ 101

FiguRA 32 - ERRO ENTRE MÉTOdo DE SENSIBILIDADES E MÉTODO DE NR (DEMANDA MÁXIMA) 102

Figura 33 - ERro entre MÉtodo de SEnsibilidades E MÉtodo DE NR (DEMANDA MÍNIMA).

FIGURA 34 - TENSÕES NODAIS EM FUnÇÃO DA ALOCAÇÃo DO SAET (FASE A) - CARGA EM DEMANDA MÍNIMA 103

FigurA 35 - TENSÕES NODAIS PARA SAET NA BARRA 848 (FASE A) - CARGA EM DEMANDA MÍNIMA 104

Figura 36 - TENSÕES NODAIS EM FUnÇÃO DA ALOCAÇÃO DO SAET (FASE A) - DESCARGA EM DEMANDA MÍNIMA 105

FIGURA 37 - TENSÕES NODAIS EM FUNÇÃO DA ALOCAÇÃO DO SAET (FASE A) - CARGA EM DEMANDA MÁXIMA . 106

FIGURA 38 - TENSÕES NODAIS EM FUNÇÃO DA ALOCAÇÃO DO SAET (FASE A) - DESCARGA EM DEMANDA MÁXIMA.

FIGURA 39 - MÁXIMA INJEÇÃo DE POTÊNCIA ATIVA VIA MÉTODO DE SENSIBILIDADES E NR

FIGURA 40 - ERRO ABSOLUTO PARA MÁXIMA INJEÇÃO DE POTÊNCIA VIA MÉTODO DE NR E MÉTODO DE SENSIBILIDADES

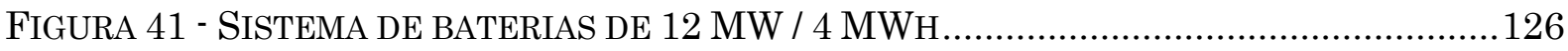

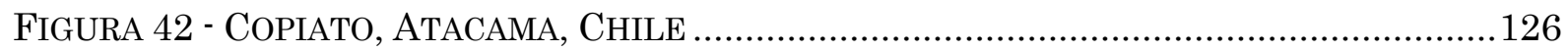

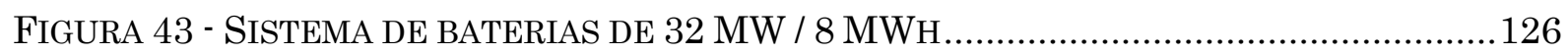

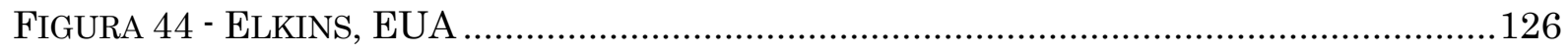

Figura 45 - COMPONENTES DA MICRORREDE PERTENCENTE À PENITENCIÁRIA DE SANTA RITA

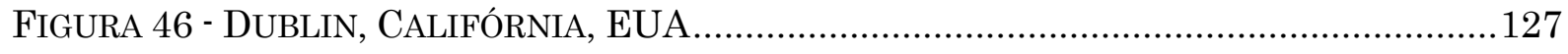

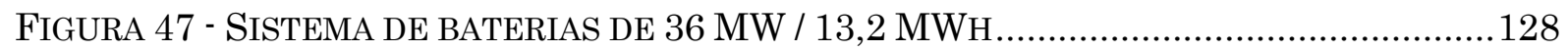

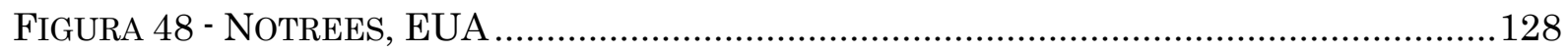

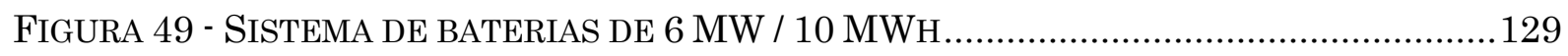

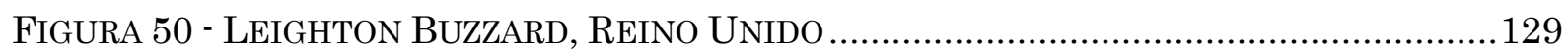

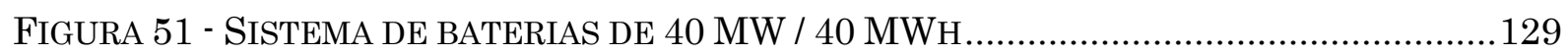

FIGURA 52 - MINAMISOMA, JAPÃO ............................................................................... 129

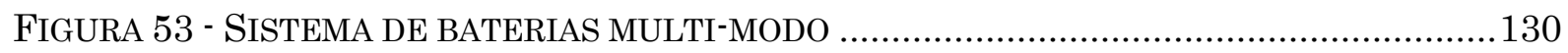

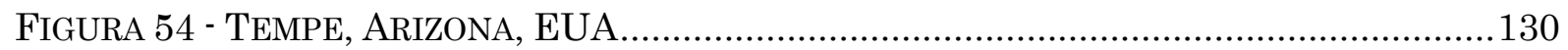

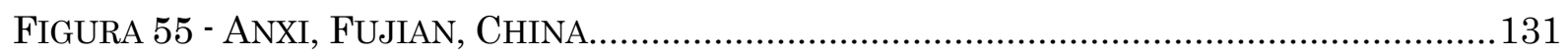

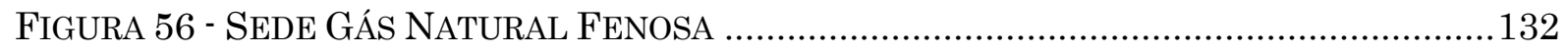

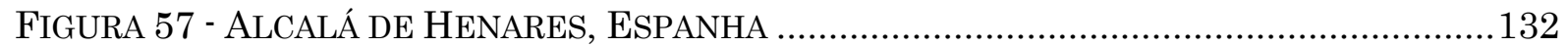

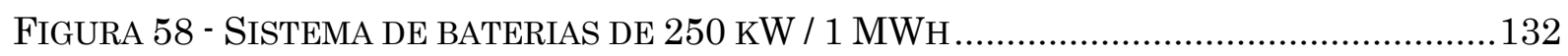

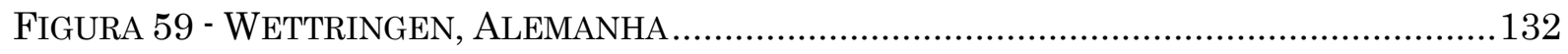

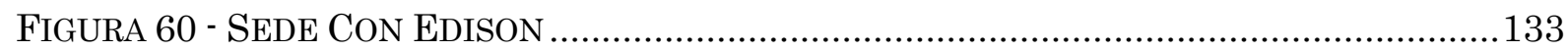

FIGURA 61 - LOCALIZAÇÃO - SEDE CON EDISON................................................................. 133 


\section{Lista de Tabelas}

TABELA 1 - TECNOLOGIAS DE BATERIA: CARACTERÍSTICAS E UNIDADES COMERCIAIS

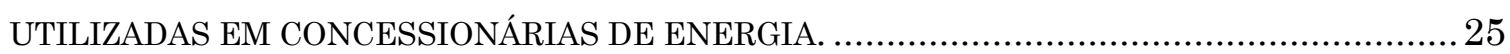

TABELA 2 - PRINCIPAIS PARÂMETROS DO ELEMENTO CIRCUIT …....................................... 50

TABELA 3 - PRINCIPAIS PARÂMETROS DO ELEMENTO LINE ............................................... 51

TABELA 4 - PRINCIPAIS PARÂMETROS DO ELEMENTO LINECODE ......................................... 51

TABELA 5 - PRINCIPAIS PARÂMETROS DO ELEMENTO LOAD .................................................. 52

TABELA 6 - PRINCIPAIS PARÂMETROS DO ELEMENTO LOADSHAPE …..................................... 53

TABELA 7 - PRINCIPAIS PARÂMETROS DO ELEMENTO TRANSFORMER ................................... 53

TABELA 8 - PRINCIPAIS PARÂMETROS DO ELEMENTO REGCONTROL ..................................... 54

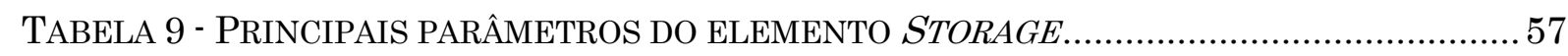

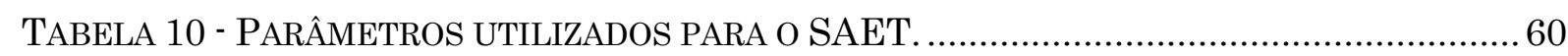

TABELA 11 - LIMITES DE AMPACIDADE DAS LINHAS DO SISTEMA IEEE 34 BARRAS.............. 68

TABELA 12 - VALORES MÍNIMO E MÁXIMO DE TENSÃO PARA CADA ALOCAÇÃO DO SAET...... 72

TABELA 13 - ÍNDICE IMP PARA TAXA DE DESCARGA 1 C, SISTEMA IEEE 34 BARRAS............. 74

TABELA 14 - CENÁRIOS DE PESOS PARA CÁlCULO DO IMP .............................................. 75

TABELA 15 - ÍNDICE IMP PARA TAXA DE DESCARGA 1 C, SISTEMA IEEE 123 BARRAS........... 77

TABELA 16 - ÍNDICE IMP PARA TAXA DE DESCARGA 0,5 C, SISTEMA IEEE 34 BARRAS.......... 82

TABELA 17 - ÍNDICE IMP PARA TAXA DE DESCARGA 0,33 C, SISTEMA IEEE 34 BARRAS........ 84

TABELA 18 - ÍNDICE IMP PARA TAXA DE DESCARGA 0,2 C, SISTEMA IEEE 34 BARRAS.......... 85

TABELA 19 - PESOS DO IMP PARA OS DIVERSOS CENÁRIOS EM ESTUDO ............................. 107

TABELA 20 - VALORES DE IMP PARA OS CENÁRIOS DE MANDA MÁXIMA E MÍNIMA, CONSIDERANDO OPERAÇÕES DE CARGA E DESCARGA DO SAET. 108

TABELA 21 - COMPARAÇÃO DE CUSTO COMPUTACIONAL ENTRE ÍNDICE IMP E MÉTODO DE SENSIBILIDADES NO ESTUDO DA ALOCAÇÃO DE UM SAET.......................................... 109

TABELA 22 - COMPARAÇÃo DE CUSTO COMPUTACIONAL ENTRE MÉTODO DE SENSIBILIDADES E o MÉTODo NR NO CÁlCULO DA MÁXIMA INJEÇÃO DE POTÊNCIA NODAL................... 112 


\section{Sumário}

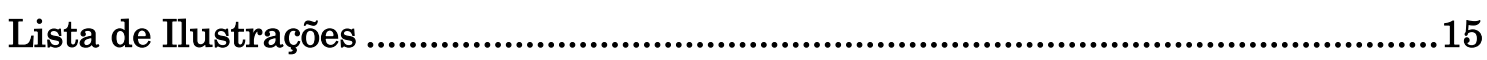

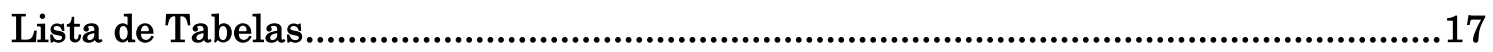

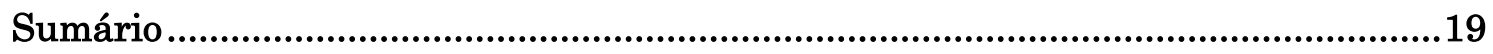

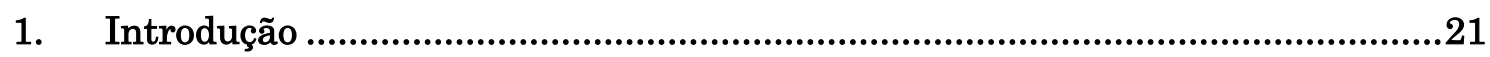

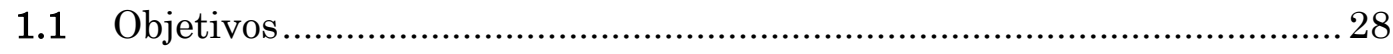

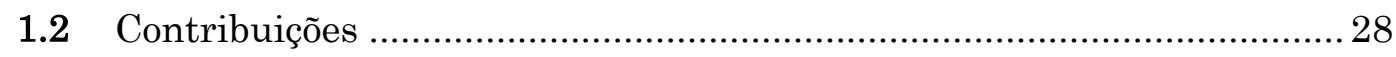

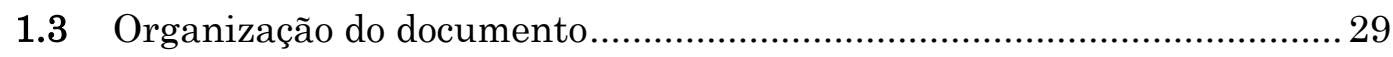

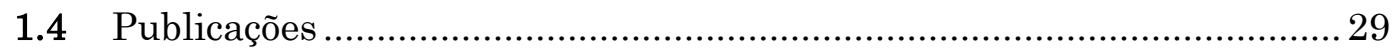

2. Aplicações de sistemas de armazenamento de energia em redes elétricas .....31

2.1 Aplicações, dimensionamento e alocação................................................. 31

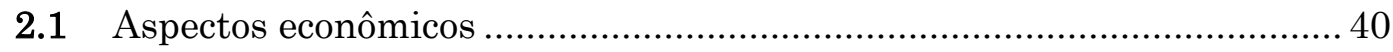

2.2 Considerações Finais do Capítulo ............................................................ 41

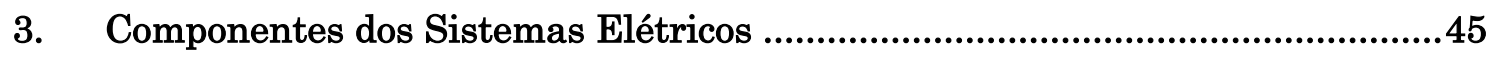

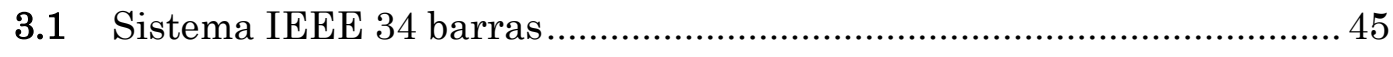

3.2 Sistema IEEE 123 barras........................................................ 47

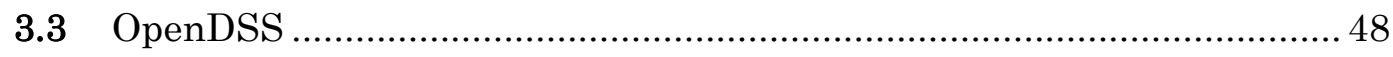

3.3.1 Equivalente de Thévenin...................................................... 50

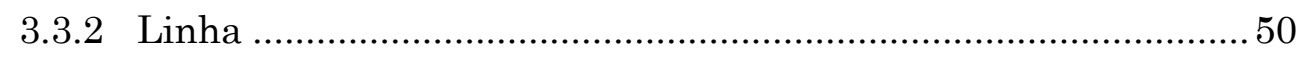

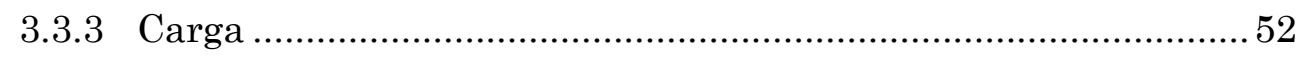

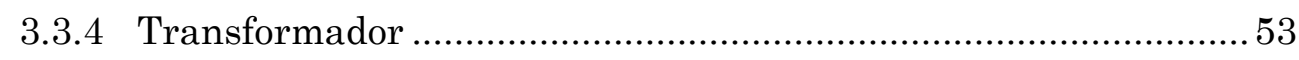

3.3.5 Regulador automático de tensão .............................................. 54

3.3.6 Sistema de armazenamento de energia.................................... 54

4. Método do Índice Médio Ponderado ............................................................61

4.1 Análise de impacto em regime permanente ....................................... 61

4.2 Índices de impacto em regime permanente ...........................................6 63

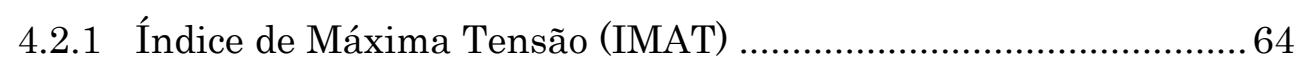

4.2.2 Índice de Mínima Tensão (IMIT) .................................................. 64

4.2.3 Índice de Chaveamento (ICH) ................................................. 64 
4.2.4 Índice de Perdas de Energia (IPE) .............................................65

4.2.5 Índice Médio Ponderado (IMP) ...................................................65

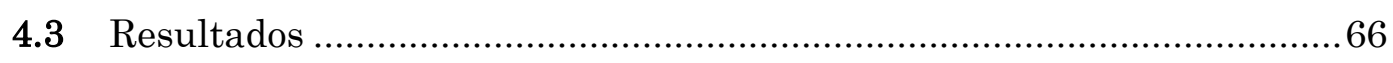

4.3.1 Análise de impacto em regime permanente ..............................66

4.3.2 Aplicação dos índices de impacto em regime permanente ...........72

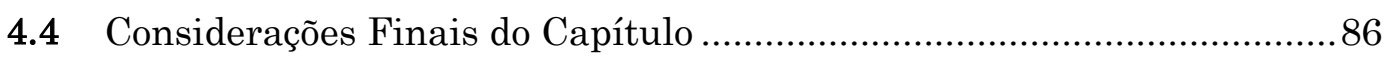

5. Método de Análise via Sensibilidades Estendido para Sistemas Trifásicos ... 89

5.1 Método de Análise via Sensibilidades. .89

5.2 Método de Análise via Sensibilidades Estendido para Sistemas Trifásicos

5.2.1 Aplicação do Método de Sensibilidades na alocação de um SAET 95

5.2.2 Aplicação do Método de Sensibilidades na determinação da máxima injeção de potência ativa de um SAET ..........................96

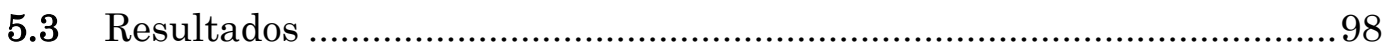

5.3.1 Sistema IEEE 34 barras modificado ..........................................98

5.3.2 Validação do Método de Sensibilidades ......................................98

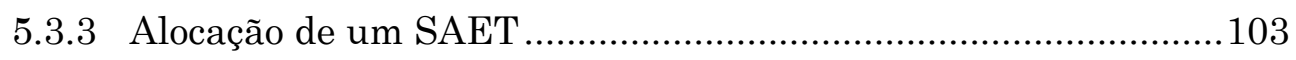

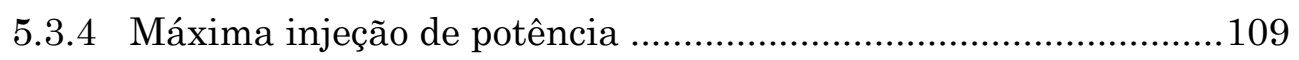

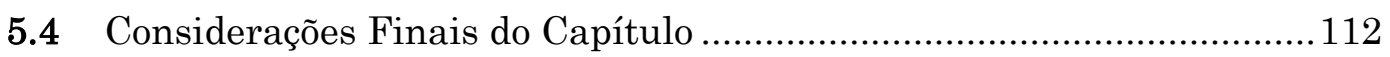

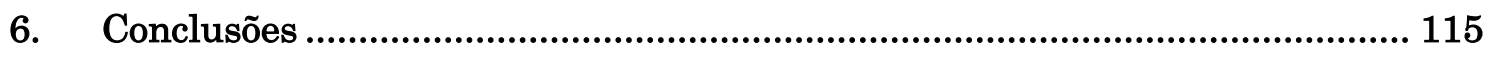

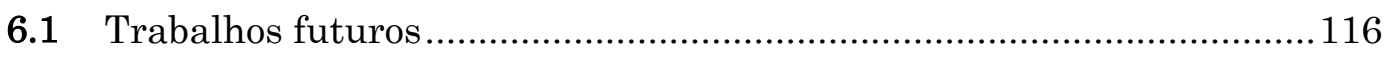

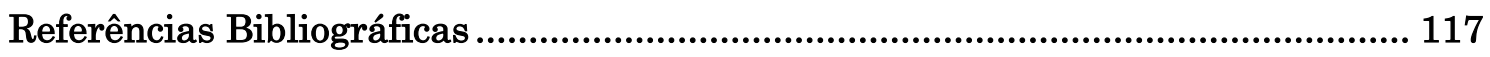

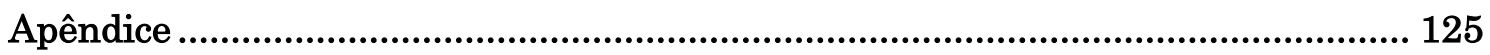

A. Instalações de sistemas de baterias - Estado da arte..........................125

1) Instalações de sistemas de baterias não transportáveis............125

2) Instalações de sistemas de baterias transportáveis ..................130 


\section{Capítulo 1}

\section{Introdução}

Sistemas de armazenamento de energia são responsáveis por armazenar energia em uma forma alternativa e transformá-la em energia elétrica sempre que necessário. Para tanto, diversas tecnologias têm sido empregadas, cada uma com suas respectivas vantagens e desvantagens. Sendo assim, o conhecimento detalhado de cada uma destas formas de armazenamento é de fundamental importância na busca pela tecnologia que mais se adequa ao problema que se deseja mitigar. Dentre as principais tecnologias de armazenamento de energia, destacam־se:

Bombeamento hidráulico: esta tecnologia de armazenamento de energia baseia-se na diferença de energia potencial entre dois reservatórios de água localizados a alturas diferentes, como pode ser observado na Figura 1.

A ideia consiste em utilizar uma máquina elétrica para impulsionar água do reservatório mais baixo para o reservatório mais alto, quando o preço da energia elétrica for baixo, geralmente durante horários fora de pico. Já em horários com maior demanda de energia a água é liberada do reservatório mais alto para o reservatório mais baixo, passando pela máquina elétrica que movida pela energia potencial cinética do fluido passa a gerar energia elétrica.

Figura 1 - Armazenamento de energia via bombeamento hidráulico

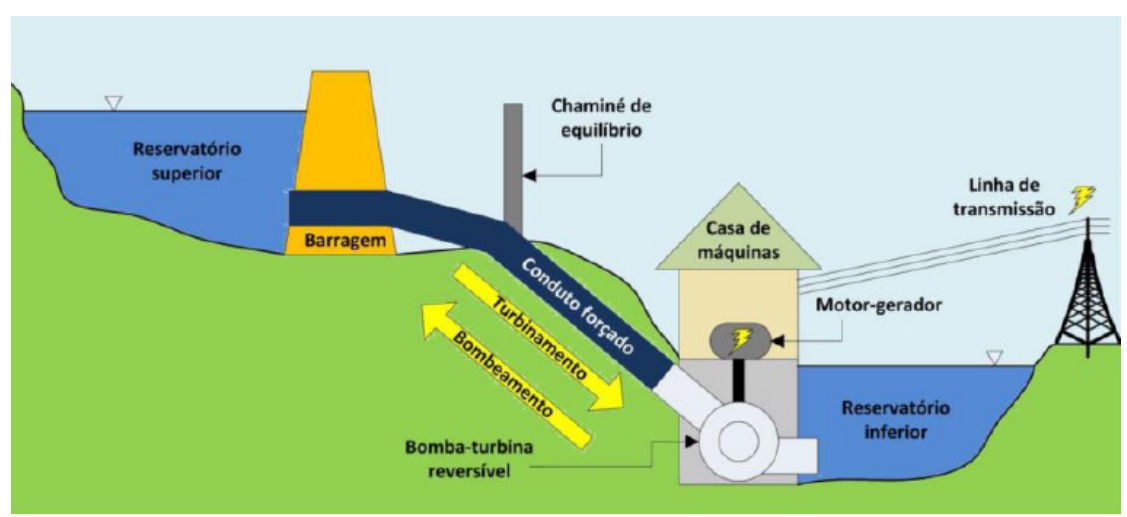

Fonte: (CANALES; BELUCO; MENDES, 2015) 
Ar Comprimido: de maneira análoga ao que acontece no uso de bombas hídricas de potência, neste tipo de tecnologia a energia é armazenada em um reservatório de ar que é comprimido utilizando um compressor nas horas em que o preço da energia elétrica é baixo. Quando há a necessidade de geração de energia, o reservatório é esvaziado fazendo com que o ar comprimido acione a mesma turbina usada como compressor, que agora atuará como gerador de energia elétrica. O funcionamento do sistema mencionado está ilustrado na Figura 2.

Figura 2 - Armazenamento de energia via ar comprimido

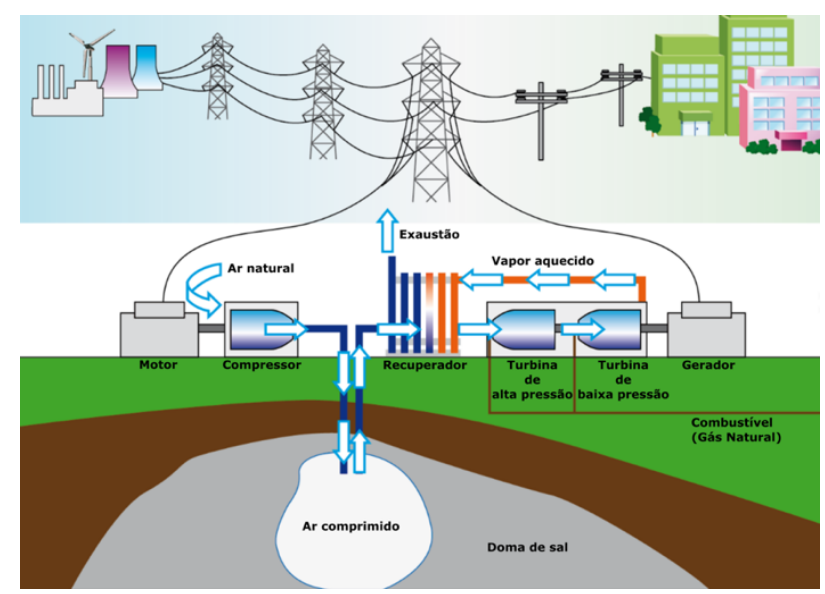

Fonte: (BELFORTE; GUZZONI, 2013)

Volantes de inércia ou Flywheels: o armazenamento de energia em flywheels ocorre baseado na inércia de uma grande roda acoplada a uma máquina elétrica. A máquina é acionada eletricamente e assim armazena energia na forma de inércia. Posteriormente, a máquina é usada como gerador, transformando a inércia em energia elétrica. A Figura 3 apresenta um armazenador de energia que utiliza a tecnologia de volante de inércia.

Figura 3 - Armazenamento de energia via volante de inércia

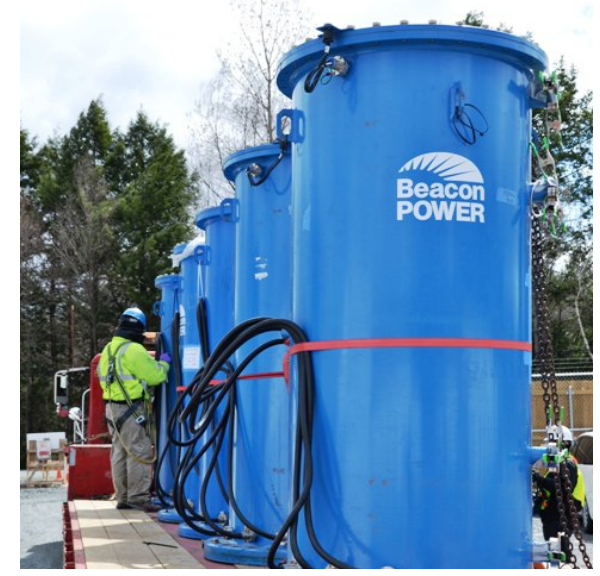

Fonte: (ENGADGET, 2018) 
Supercapacitores: este tipo de dispositivo, que pode ser visto na Figura 4, é composto por dois eletrodos carregados com cargas de polaridade opostas, um separador, um eletrólito e coletores de correntes. A energia é armazenada por íons em uma bateria. Entretanto, diferente do que ocorre em uma bateria convencional, não ocorrem reações químicas quando há fornecimento da energia armazenada.

Figura 4 - Armazenador de energia composto de supercapacitores

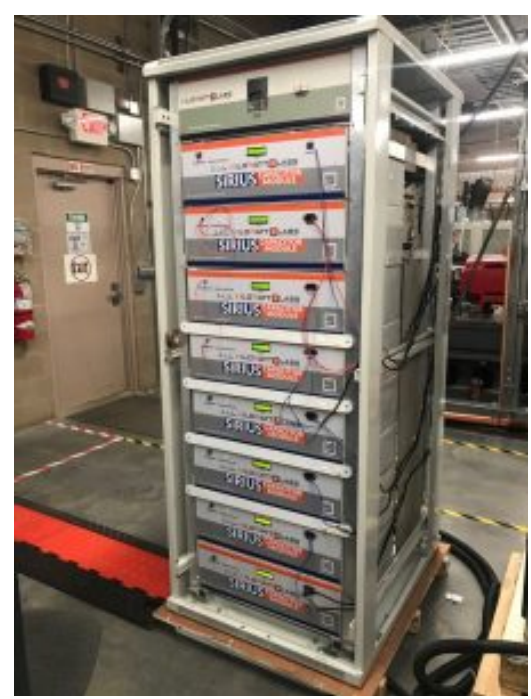

Fonte: (COHN, 2018)

Baterias: a bateria é definida como um dispositivo constituído de células armazenadoras de energia em que a energia química é transformada em energia elétrica. As baterias fornecem energia na forma de corrente contínua e podem ser agrupadas de modo a se obter os níveis de tensão e corrente desejados. A Figura 5 mostra um banco de baterias de íons de Lítio.

Figura 5 - Armazenador de energia via bateria de íons de Lítio instalada em Escondido, CA, EUA

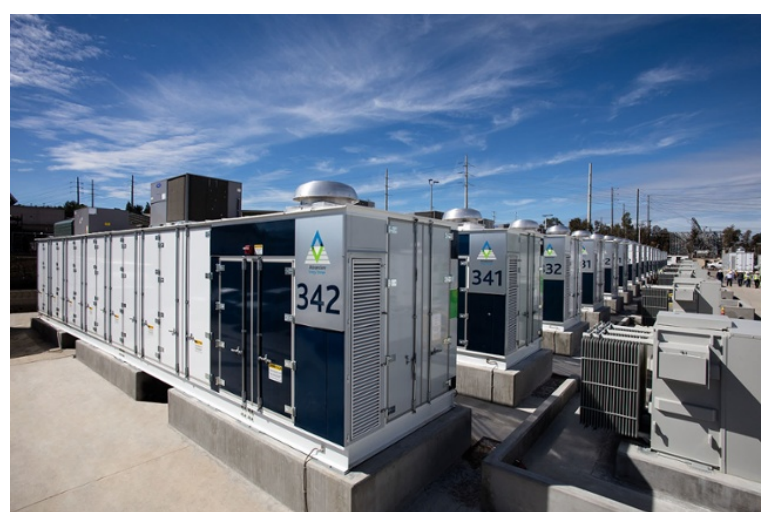

Fonte: (GOLDMAN, 2017) 
De acordo com (ZHENG et al., 2014), comparado aos outros tipos de sistema de armazenamento de energia (SAE), o sistema que é constituído por baterias é o mais economicamente viável para aplicações em sistemas de distribuição de energia elétrica. Dentre as suas aplicações estão: contribuição para o aumento da penetração de geração renovável, nivelamento de curva de demanda, controle da frequência do sistema e postergação de investimentos em melhorias da rede elétrica.

É necessário destacar que há atualmente uma variedade de tipos de baterias, cada um com seus aspectos construtivos, tais como capacidade de potência, capacidade de armazenamento, vida útil, eficiência, temperatura de operação, profundidade de descarga, densidade energética e a taxa de auto descarregamento, que conferem vantagens em determinadas aplicações. A Tabela 1 apresenta um resumo das características dos vários tipos de baterias, incluindo o preço estimado por kWh para alguns deles.

Em 2009 a bateria de chumbo ácido foi considerada a tecnologia mais madura e a mais utilizada em aplicações voltadas ao sistema elétrico (DIVYA; ØSTERGAARD, 2009). Entretanto, atualmente as baterias de íons de Lítio são as de maior destaque no que diz respeito às aplicações de larga escala de armazenamento de energia (EPRI, 2017). Várias destas são apresentadas no Apêndice. A partir da análise da Tabela 1 é possível constatar que as baterias de íons de Lítio desempenham melhor do que as baterias de chumbo ácido tradicionais no que diz respeito à energia específica, ciclo de vida e eficiência (EPRI, 2017). Adicionalmente, as baterias de íons de Lítio se sobressaem com relação às de chumbo ácido visto que estas demandam manutenção a cada 3 a 6 meses, além de serem negativamente afetadas por carga incompleta. Este efeito não é significante em certas baterias de Lítio (DIOUF; PODE, 2015; KRIEGER; CANNARELLA; ARNOLD, 2013).

O destaque das baterias de íons de Lítio se deve ao declínio no preço e ao desenvolvimento desta tecnologia. A primeira aplicação significativa de baterias de Lítio no sistema elétrico ocorreu em 2008, visando à prestação do serviço de regulação de frequência. Esta tarefa requer uma alta taxa de carga/descarga e precisão, características peculiares de armazenadores de energia via baterias. Já no fim de 2015, o interesse em grandes sistemas conectados à rede começou a aumentar, fomentado pelos seguintes acontecimentos (EPRI, 2017):

- Em setembro de 2015, uma concessionária do Havaí assinou um contrato de compra de energia de 20 anos com a empresa SolarCity referente ao fornecimento de energia proveniente de um sistema híbrido de geração fotovoltaica e baterias em horário de pico. Este sistema possui $17 \mathrm{MW}$ de potência e 52 MWh de capacidade. 
- No início de 2016, após um vazamento de gás que representou uma possível crise no abastecimento da região, a comissão pública de concessionárias da Califórnia pediu para que as concessionárias adquirissem armazenadores de energia de $100 \mathrm{MW}$ e capacidade de fornecimento de energia de 4 horas. Em poucos meses, sistemas que totalizavam 400 MWh de energia armazenada via baterias de íons de Lítio foram instalados.

- Em agosto de 2016, uma licitação aberta no Reino Unido fez com que SAEs fossem oferecidos com preços inferiores à metade do esperado, sugerindo que tais sistemas poderiam competir com fontes convencionais de energia.

Tabela 1 - Tecnologias de bateria: características e unidades comerciais utilizadas em concessionárias de energia.

Tipo da bateria

Características

$\eta=70-75 \%$

Chumbo ácido

(tipo inundado)

$50-150(€ / \mathrm{kWh})$

1000-2000 ciclos

$25 \mathrm{Wh} / \mathrm{kg}$

$\eta=80-85 \%$

Chumbo ácido

(tipo regulado por

válvula)

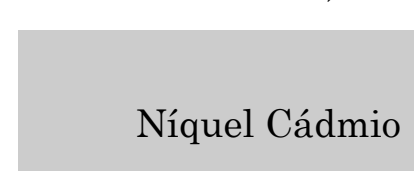

Níquel Cádmio

$50-150(€ / \mathrm{kWh})$

200-300 ciclos

$30-50 \mathrm{Wh} / \mathrm{kg}$

$\eta=70-75 \%$

200-600 (€/kWh)

3000 ciclos

$45-80 \mathrm{Wh} / \mathrm{kg}$

$\eta=89 \%\left(325^{\circ} \mathrm{C}\right)$

Sódio Enxofre

2500 ciclos
$100 \mathrm{Wh} / \mathrm{kg}$

$\eta=90-95 \%$

Íon Lítio

$700-1000(€ / \mathrm{kWh})$

3000 ciclos

90-190 Wh/kg

$\eta=85 \%$

Vanádio Redox

$$
\begin{gathered}
360-1000(€ / \mathrm{kWh}) \\
10.000 \text { ciclos } \\
30-50 \mathrm{Wh} / \mathrm{kg}
\end{gathered}
$$

$$
\eta=75 \%
$$

Zinco Bromo

$$
\begin{gathered}
360-1000(€ / \mathrm{kWh}) \\
70 \mathrm{Wh} / \mathrm{kg}
\end{gathered}
$$

$$
\text { Metal ar }
$$

$$
\eta=50 \%
$$

$50-200(€ / \mathrm{kWh})$

$450-650 \mathrm{Wh} / \mathrm{kg}$

\section{Exemplo de aplicação comercial}

\section{Capacidade Localização}

$\begin{array}{ll}10 \mathrm{MW} / & \text { Estados Unidos, } \\ 40 \mathrm{MWh} & \text { Califórnia - Chino }\end{array}$

$300 \mathrm{~kW} \mathrm{/} \quad$ Estados Unidos,

$580 \mathrm{kWh} \quad$ Wisconsin -

Milwaukee

$\begin{array}{cc}27 \mathrm{MW} / & \text { Estados Unidos, } \\ 6,75 \mathrm{MWh} & \text { Alaska }\end{array}$

Alaska

$9,6 \mathrm{MW} /$
$64 \mathrm{MWh}$

Aplicações apresentadas na seção Apêndice.

Fonte: (BUSINESS WIRE, 2017; DIVYA; ØSTERGAARD, 2009; EASE/EERA, 2013) 
O decaimento súbito no preço de baterias de íons de Lítio ocorreu devido às interações entre a indústria de baterias estacionárias e a de veículos elétricos (EPRI, 2017). Os esforços para o grande desenvolvimento deste mercado partiram de grandes fornecedores asiáticos de baterias, como a LG Chem, NES e Samsung SDI no início de 2008 e 2009. Estas empresas realizaram investimentos devido a contratos de longo prazo com fabricantes de automóveis. Nos anos subsequentes, a produção de baterias continuou avançando em produtividade e tecnologia.

O avanço do mercado de veículos elétricos impulsionou a produção de baterias em larga escala, maior até mesmo do que a demanda por baterias em um primeiro momento. Além disso, o desenvolvimento na área regulatória e legislativa também criou oportunidades de ganhos financeiros a partir da operação de armazenadores de energia. Estes fatores, em conjunto, contribuíram para um excesso na oferta de baterias e fez com que os preços decaíssem a níveis não imaginados dois ou três anos antes. Ainda segundo (EPRI, 2017), é possível que os preços da bateria de íons de Lítio continuem a cair. Sendo assim, vale destacar que a bateria de íons de Lítio possui vantagem significativa com relação às demais tecnologias de armazenamento de energia, uma vez que o uso em diversas aplicações contribuiu para um registro consolidado desta tecnologia e mostra um apreço pelas suas vantagens.

Já do ponto de vista de mercado, verifica-se que os fabricantes de baterias de íons de Lítio são empresas com maior reconhecimento e potencial de investimento, o que confere a estas uma maior confiabilidade no que diz respeito à garantia e à assistência técnica prestada após o fornecimento de baterias. O mesmo não ocorre com as demais tecnologias, visto que muitas destas são desenvolvidas por startups, de menor porte se comparadas às fabricantes de baterias de íons de Lítio, que se arriscam a entrar no mercado com um produto mais caro e sem maturidade comercial. Estes fatores são desafios que até mesmo tecnologias com melhor desempenho do que as baterias de íons de Lítio devem enfrentar para se consolidarem no mercado (EPRI, 2017).

Pelos motivos apresentados, pode-se concluir que aparentemente a tecnologia de íons de Lítio dominará as aplicações de armazenadores de energia por pelo menos os cinco próximos anos, e, talvez estender este domínio para a próxima década (EPRI, 2017). A predominância das baterias de íons de Lítio em aplicações localizadas nos Estados Unidos pode ser observada na Figura 6. 
Figura 6 - Implantação trimestral de SAEs por tecnologia

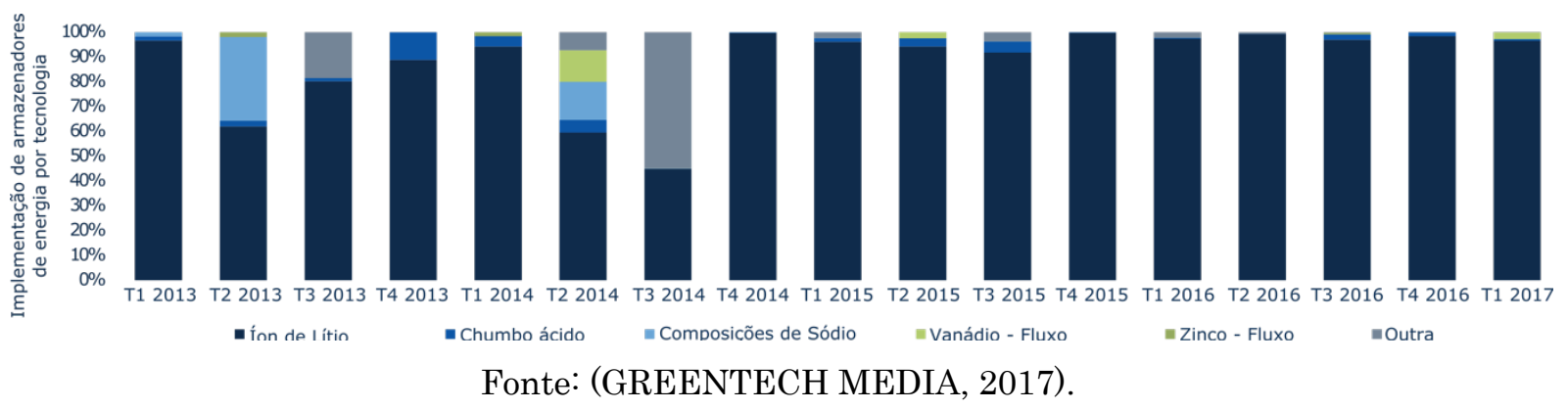

Ao analisar a Figura 6, constata-se que a partir do quarto trimestre de 2014 a tecnologia de íons de Lítio foi a que predominou em aproximadamente 90\% da capacidade total instalada, o que confirma o domínio deste tipo de tecnologia sobre as demais no que se refere à constituição química de baterias.

Com relação às aplicações de SAEs no sistema elétrico, pode-se dizer que a arbitragem e serviços de contingências são exemplos de funcionalidades que estes sistemas desenvolvem há décadas (HATZIARGYRIOU et al., 2016). Entretanto, arbitragem de energia pode não ser suficiente para garantir o retorno do investimento de um SAE. Sendo assim, os autores mencionados afirmam que as pesquisas em SAEs devem se preocupar com outros serviços a serem explorados para trazer mais benefícios e fazer com que o investimento em SAE seja mais atrativo financeiramente.

Ressalta-se que a inserção em massa da geração renovável de energia exige um número cada vez maior de SAEs para auxiliar a estabilidade e confiabilidade da rede elétrica (ABDELTAWAB; MOHAMED, 2017). Sendo assim, os sistemas de armazenamento de energia transportável (SAET) podem ser uma alternativa capaz de ampliar a variedade de serviços já prestados pelos SAEs estacionários. Isso se justifica devido à capacidade do primeiro ser transportado para qualquer ponto do sistema elétrico que comporte a sua conexão, característica que o torna capaz de mitigar problemas locais no sistema de distribuição (ABDELTAWAB; MOHAMED, 2017). Deste modo, um SAET pode providenciar suporte em casos de interrupção de fornecimento de energia, devido à emergência ou à manutenção programada, e em situações temporárias que exigem suporte de tensão.

Por fim, é importante mencionar que o sucesso da aplicação de um SAET está intimamente relacionado à sua alocação. Este é um dos fatores que contribui para que o armazenador de energia seja peça chave no sistema de distribuição, de modo a favorecer a redução de perdas e trazer benefícios econômicos para a distribuidora de energia (HATZIARGYRIOU et al., 2016). Sendo assim, a alocação de armazenadores de energia 
tem sido alvo de inúmeros estudos que utilizam diferentes ferramentas de otimização. Algumas delas são: algoritmo genético, algoritmo Grey Wolf e enxame de partículas em suas variações, como se vê em (BABACAN; TORRE; KLEISSL, 2016; KALKHAMBKAR; KUMAR; BHAKAR, 2016; KHALID MEHMOOD et al., 2017; MOEINI; KAMWA; DE MONTIGNY, 2015; ZHENG et al., 2014). Neste contexto, o intuito deste trabalho é contribuir no estudo de alocação de um SAET, visando estabelecer um índice ponderado como ferramenta a ser usada nesta tarefa e ainda aplicar um método de alocação baseado em uma única análise de sensibilidade de tensão do sistema elétrico, de modo semelhante ao que foi proposto por (AYRES et al., 2010; GIANNITRAPANI et al., 2017).

Neste trabalho o SAET é considerado como um sistema que é disponibilizado com uma capacidade de potência e de energia já predeterminada. Sendo assim, cabe a este estudo a determinação apenas da melhor alocação para a instalação do sistema referido, considerando suas operações de carga e descarga ao longo do período simulado.

\subsection{Objetivos}

O presente trabalho se propõe a desenvolver métodos práticos para a alocação mais favorável de um SAET via bateria de íons de Lítio em um sistema de distribuição de energia elétrica. A análise desenvolvida é focada no regime permanente do sistema. Além disso, compreende as operações de carga e descarga do SAET e avalia aspectos técnicos como:

- Perdas técnicas;

- Número de operações de chaveamento de taps de reguladores automáticos de tensão;

- Variações nas tensões das barras de carga;

- Carregamento dos alimentadores;

- Violações de tensão em regime permanente nas barras do sistema.

\subsection{Contribuições}

Com a finalidade de atingir o objetivo mencionado na subseção 1.1, o presente trabalho propõe duas ferramentas de fácil aplicação, uma vez que se baseiam em fluxos de carga. São elas: 
- Índice Médio Ponderado (IMP): índice baseado na resolução sucessiva de fluxos de potência e cujos resultados mensuram os impactos da atuação de um SAET. Será detalhado no capítulo 4;

- Método de Análise via Sensibilidades Estendido para Sistemas Trifásicos: método que utiliza a análise da matriz jacobiana do método de NewtonRaphson (NR) aplicado a um sistema elétrico trifásico para calcular suas tensões nodais e as máximas injeções de potências nodais que um SAET pode realizar, de modo a contribuir para a identificação da sua melhor alocação. Será detalhado no capítulo 5.

\subsection{Organização do documento}

Este documento está organizado da seguinte maneira: capítulo 2, contendo uma revisão bibliográfica sobre alocação de SAEs; capítulo 3, em que a metodologia utilizada neste estudo é apresentada; capítulo 4, em que os resultados obtidos serão expostos e, por fim, no capítulo 5 têm-se as conclusões deste trabalho.

\subsection{Publicações}

Até o momento, os seguintes trabalhos referentes ao tema deste estudo foram publicados:

- Congresso 2018 Simpósio Brasileiro de Sistemas Elétricos (SBSE), Niterói, RJ, Brasil, com o título "Mitigation of voltage variations during cloud transients by using energy storage systems." Disponível em: https://ieeexplore.ieee.org/document/8395538.

- Congresso 2019 Powertech, Milão, Itália, com o título "Impact Index for Allocating Transportable Energy Storage Systems in Power Distribution Networks.” Disponível em: https://ieeexplore.ieee.org/document/8810675. 


\section{Capítulo 2}

\section{Aplicações de sistemas de}

\section{armazenamento de energia em redes}

\section{elétricas}

Neste capítulo, uma revisão geral a respeito de dispositivos armazenadores de energia será apresentada. Dentre os aspectos a serem abordados estão incluídas as aplicações, métodos para dimensionamento e, principalmente, métodos de alocação de SAEs. Posteriormente, são tecidas as considerações finais sobre o seu conteúdo.

\subsection{Aplicações, dimensionamento e alocação}

Uma vez constatada a importância de se explorar serviços para que o investimento em SAE se torne financeiramente viável, é importante destacar que as aplicações de SAE estacionários são inúmeras, e incluem: peak shaving, nivelamento de carga, compensação de geração intermitente de energia, suporte de reativos, suporte da frequência, dentre outras (ABDELTAWAB; MOHAMED, 2017; HATZIARGYRIOU et al., 2016).

Como exemplo de aplicação de um sistema de armazenamento de energia via baterias (SAEB), é possível mencionar o trabalho (ATWA; EL-SAADANY, 2010). No contexto considerado, há perda financeira por parte do produtor de energia devido à restrição de exportação. Por este motivo, o estudo investiga o uso de baterias como meio de possibilitar uma maior exportação da energia gerada. Uma das ferramentas utilizadas nesta tarefa como responsável pela alocação da bateria foi um cálculo de fluxo de potência ótimo.

O procedimento proposto pelo trabalho, juntamente com a alocação da bateria, foi aplicado em um estudo de caso rural. A tecnologia de bateria utilizada foi a de Zinco/Bromo devido ao menor custo em relação às demais comparadas. Como resultado, houve 
benefícios financeiros tanto para o dono da geração distribuída (GD) quanto para a concessionária de energia, que juntos superaram os investimentos necessário para a solução. Entretanto, vale destacar que o referido estudo não considerou outras vantagens do uso do SAEB, como o deslocamento de pico de consumo, postergação de investimentos na rede elétrica, aumento da confiabilidade, dentre outros. Se considerados, tais benefícios podem conferir ao SAEB um retorno financeiro ainda melhor do que o constatado.

Um segundo trabalho, (ZHENG et al., 2014), mostra a aplicação de várias unidades de SAEBs visando à mitigação de riscos relacionados às operações financeiras das distribuidoras de energia associados à presença de geração renovável. De acordo como o trabalho mencionado, o uso de GDs por parte das concessionárias de energias pode representar fonte de lucro a estas uma vez que poderão diminuir a quantidade de energia comprada e também vender o excedente gerado. A intermitência das GDs de fontes renováveis resulta em prejuízos financeiros oriundos da diferença entre demanda prevista e demanda atual do sistema. Isto ocorre porque os preços de aquisição de energia para as concessionárias são variáveis.

Neste contexto, os autores propõem um modelo de aquisição de energia paras as concessionárias distribuidoras baseado em SAEB com a finalidade de diminuir os riscos das participações dessas empresas no mercado de energia. A estratégia visa dar suporte à curva de demanda prevista e diminuir a quantidade de energia trocada na subestação ao invés de tentar compensar localmente as intermitências das GDs. A alocação do SAEB é feita com o uso da otimização fuzzy por enxame de partículas (OEP). Nesta tarefa, a otimização fuzzy OEP foi superior em termos de iterações necessárias para a otimização em comparação com a otimização por OEP tradicional e à via algoritmos genéticos.

Por fim, pode-se afirmar que a metodologia proposta contribuiu para a mitigação dos riscos das distribuidoras referentes às suas participações no mercado de energia, uma vez que foi responsável pela diminuição das penalidades que estas pagariam devido à diferença entre as demandas prevista e real, por meio da alocação e atuação dos SAEBs. Apesar desta contribuição, nota-se que o trabalho mencionado não aborda os aspectos técnicos, como regulação de tensão, em que o SAEB pode atuar e, por isso, não consideram esses benefícios para o sistema e para a concessionária.

Já em (MOEINI; KAMWA; DE MONTIGNY, 2015) constata-se que os autores reconhecem o SAEB de íons de Lítio como uma ferramenta capaz de contribuir para a solução de problemas técnicos concernentes à operação de um sistema elétrico. Mais especificamente, (MOEINI; KAMWA; DE MONTIGNY, 2015) se propõem a estudar o uso de SAEBs para realização do deslocamento do pico de demanda, denominado peak shaving, 
e da redução de perdas. Nesta tarefa, os autores sugerem o uso de uma ferramenta denominada otimização íntegra por enxame de partículas multi-objetivo restrita por velocidade.

A ferramenta aplicada fornece um conjunto de soluções ótimas para dimensionamento e alocação de cada um dos três SAEBs considerados no estudo. Posteriormente, o deslocamento de pico de demanda é realizado com base em taxas de carga e descarga calculadas. A metodologia proposta foi simulada em um sistema de teste de confiabilidade do IEEE e resultou em redução de perdas de aproximadamente 1,5 GWh ao longo de um ano, além de mitigação de perdas em horário de pico para o pior dia do ano simulado e economia média de 4,2\% em perdas elétricas em horário de pico durante o período simulado. Entretanto, este resultado pode não ser replicado em situações em que não existam lugares para a conexão de vários armazenadores ao longo do sistema.

Fato é que a grande gama de aplicações e as especificidades de cada uma delas sugerem que não há solução única para o uso de um SAE no que diz respeito ao seu dimensionamento e alocação (HATZIARGYRIOU et al., 2016). Além disso, pode-se afirmar que o sucesso da aplicação de armazenadores de energia está fortemente relacionado com o seu planejamento, que envolve o dimensionamento, a alocação e a operação destes. Dependendo desses fatores, o armazenador de energia pode ser peça chave no sistema de distribuição, de modo a contribuir para a redução de perdas e trazer benefícios econômicos para a distribuidora de energia (HATZIARGYRIOU et al., 2016).

Destaca-se ainda que a quantidade de energia disponível em um SAEB é limitada, enquanto as cargas elétricas variam no tempo e podem se concentrar em pontos específicos do sistema elétrico. Esta situação requer que estudos sejam realizados com a finalidade de determinar o local para a instalação dos SAEBs, a estratégia de carga/descarga e como obter o máximo proveito deste dispositivo (MOEINI; KAMWA; DE MONTIGNY, 2015).

Desta forma, torna-se evidente a importância do estudo da alocação e dimensionamento de um SAEB. Neste sentido, (HATZIARGYRIOU et al., 2016) se dispõe a realizar uma revisão bibliográfica referente às diferentes aplicações de SAEs no sistema elétrico e às metodologias utilizadas para o dimensionamento e alocação destes, principalmente, no sistema elétrico de distribuição.

Embora o número de características técnicas de um SAE seja elevado, visto que capacidade de potência, capacidade de energia, tempo de resposta, taxa de carga/descarga, dentre outras podem ser cruciais para determinado fim, na literatura os SAEs são escolhidos geralmente com base nos seguintes critérios: capacidade de potência, 
capacidade de energia e local de aplicação na rede elétrica (HATZIARGYRIOU et al., 2016).

Os autores do artigo referido defendem, ainda, que as capacidades de potência e de energia sejam tratadas como características independentes uma da outra, dados os custos associados a cada uma destas. Caso estas características sejam consideradas como independentes, os métodos de busca exaustiva encontrados na literatura podem ser aplicados na busca de seus valores ótimos. Além disso, as potências de carga e descarga são importantes na definição do tipo de SAE a ser utilizado.

Ainda de acordo com (HATZIARGYRIOU et al., 2016), a determinação simultânea da localização e capacidade de um SAE é um problema de difícil resolução. Com a finalidade de se determinar a localização e capacidade de um SAE, diversos métodos são utilizados, de acordo com a literatura. Tais métodos podem ser agrupados em quatro grupos principais, segundo (HATZIARGYRIOU et al., 2016), de acordo com a metodologia utilizada. São eles: métodos analíticos (MA), programação matemática (PM), métodos heurísticos e busca exaustiva.

De acordo com essa classificação, os MA abordados são os que não utilizam ferramentas de otimização matemática. Além disso, esses métodos utilizam restrições operacionais e do sistema elétrico predefinidas, de modo a se basear em registros de curvas de demanda e na análise estatística de dados. Adicionalmente, esses não consideram dados específicos da rede elétrica. Ainda segundo os autores, os MA são atualmente utilizados apenas para a determinação da capacidade ótima do SAE para balancear a produção de energia proveniente de fontes renováveis.

Já os métodos baseados em PM compreendem diferentes métodos numéricos que localizam com eficiência uma solução ótima em modelos aproximados. Mais especificamente no contexto de alocação e dimensionamento de SAE, PM é utilizada para resolver problemas operacionais geralmente expressos como problemas de pré-despacho e de fluxo de potência ótimo (FPO). Dentre os métodos baseados em PM, pode-se afirmar que o mais eficiente é o método de programação linear (PL), o que significa que o método mencionado é sempre capaz de encontrar uma única solução ótima global. Para tanto, é necessário que a função objetivo e as restrições do modelo sejam mantidas lineares. Um exemplo do uso de PL na determinação do dimensionamento e alocação de SAE se encontra no trabalho (ATWA; EL-SAADANY, 2010), mencionado no início desta subseção, visto que este utiliza PL inteira-mista para a solução de fluxos de potências ótimos e formulou o problema de dimensionamento e alocação de SAEs de forma a buscar o menor preço anual da energia. 
Adicionalmente, os métodos heurísticos incluem os métodos em que a experiência e conhecimento referentes a um devido problema são incorporados no algoritmo. Recentemente, os métodos heurísticos passaram a se referir também aos métodos computacionais que emulam de modo inteligente algum comportamento ou processo encontrado na natureza para solucionar problemas (HATZIARGYRIOU et al., 2016). É importante ressaltar que embora estes métodos sejam considerados robustos, eles não garantem que a solução ótima global seja encontrada e ainda exigem um alto esforço computacional. Destaca-se ainda que em inúmeras vezes estes métodos são empregados na tentativa de se determinar simultaneamente o melhor dimensionamento e alocação de um SAE. Os métodos heurísticos são responsáveis pela resolução da parte combinatorial de um problema de otimização, enquanto outros métodos são usados para avaliar as soluções geradas por esses. Como exemplos de trabalhos que aplicam métodos heurísticos, pode-se mencionar (ABDELTAWAB; MOHAMED, 2017; GIANNITRAPANI et al., 2017; KARANKI; XU, 2016).

Em (KARANKI; XU, 2016), ressalta-se que os SAEBs surgem como um meio eficaz para a diminuição do pico de demanda, além de poderem ser utilizados em funções como regulação de tensão e controle de frequência. Ainda segundo os autores mencionados, a alocação e dimensionamento de um SAEB podem causar sub ou sobretensões na rede de distribuição, bem como afetar as perdas de energia. Desta forma, a correta alocação de um SAEB é necessária para a obtenção de um efeito ótimo de sua aplicação. Neste cenário, o trabalho em análise propõe um método baseado em um índice de sensibilidade de perdas para determinar a alocação ótima de um SAEB em um sistema de distribuição. $O$ dimensionamento deste é realizado com o uso de uma função de custo. Já a estratégia de atuação do SAEB foi determinada a partir da aplicação de uma OEP.

O procedimento proposto é testado com dados reais, com o uso do método iterativo de NR. No estudo mencionado, o dimensionamento do SAEB é avaliado considerando três condições distintas, sendo que a de melhor desempenho considerou a quantidade de energia trocada entre a rede e a geração eólica como variável a ser otimizada. Já a quantidade de potência a ser injetada/absorvida pelo SAEB é obtida via OEP. Em um caso, houve a minimização de perdas no sistema e em outro, a minimização de perdas e do número de fases violando os limites de tensão. No primeiro caso, as perdas foram reduzidas em 10,33\%. Já quando as violações de tensão foram também minimizadas, houve uma diminuição de $24,76 \%$ destas.

Sendo assim, o trabalho de (KARANKI; XU, 2016) permite afirmar que os SAEBs alocados e dimensionados de forma ótima e operados propriamente podem reduzir as 
perdas de um sistema e as violações de tensão. A operação abordada no trabalho, no entanto, considera a potência trocada com a rede como fixa ou ainda alvo de otimização. Sendo assim, o SAEB não conta com a rede para realizar recarga quando o limite estipulado de energia já foi trocado. Como consequência, a capacidade do armazenador de recarregar no período de baixa demanda e aliviar a demanda nos horários de pico todos os dias pode ser limitada. Isso restringiria os possíveis ganhos da concessionária, caso esta pudesse vender energia nos horários de pico.

Outro trabalho que emprega método heurístico juntamente com programação matemática na alocação de dispositivos armazenadores de energia é (GIANNITRAPANI et al., 2017). Segundo este trabalho, a manutenção da tensão entre os limites estabelecidos por normas de fornecimento é um dos principais desafios que os operadores de sistemas de distribuição enfrentam. Isto se deve, também, em razão do aumento da geração distribuída, visto que os seus picos de geração dificilmente coincidem com os picos de demanda do sistema. Como resultado, há o surgimento de sub e sobretensões.

$\mathrm{Na}$ tentativa de se resolver problemas como este, há quem proponha o controle de potência ativa e reativa das gerações distribuídas e o controle de reguladores de tensão. Entretanto, tais soluções podem não ser viáveis caso as concessionárias distribuidoras de energia não tenham controle sobre os geradores distribuídos e caso os reguladores de tensão não sejam automatizados, respectivamente. Recentemente, o uso de dispositivos armazenadores de energia tem sido investigado como forma de mitigar sub e sobretensões (GIANNITRAPANI et al., 2017). Tais dispositivos têm a capacidade de atuarem como cargas em caso de sobretensões e como geradores em caso de subtensões. Desta forma, os problemas de tensão podem ser solucionados localmente, sem limitar a GD e ainda sem transmitir distúrbios para a rede de média tensão (GIANNITRAPANI et al., 2017).

O trabalho mencionado tem o objetivo encontrar a alocação e dimensionamento ótimos de dispositivos armazenadores de energia aplicados com a finalidade de prevenir sub e sobretensões em uma rede de baixa tensão radial. Para tanto, os autores propõem uma metodologia heurística que determina a alocação e o dimensionamento de um dado número de dispositivos armazenadores na rede. O procedimento de alocação de SAEs proposto por (GIANNITRAPANI et al., 2017) considera a configuração da rede e os parâmetros de suas linhas. Nesta tarefa, uma matriz de sensibilidade é construída uma única vez de forma que seus valores representem o quanto a tensão de uma barra é influenciada pela injeção de potência ativa em outra barra. Em seguida, a escolha da barra para a conexão do SAE é realizada com o objetivo de maximizar a controlabilidade de tensão no subsistema. 
O método proposto foi aplicado a um sistema real de BT, bem como a uma versão modificada do sistema IEEE 34 barras e a 200 redes radiais geradas aleatoriamente. Como resultado para este último teste, verificou-se que para a alocação de 2 SAEs as soluções propostas pelo algoritmo foram ótimas em $45 \%$ dos casos, enquanto em apenas $9 \%$ dos casos a degradação da solução foi pior do que $5 \%$. Levando-se em consideração a qualidade das soluções fornecidas e ao menor esforço computacional requerido por este, cerca de 5456 vezes menor em comparação ao método de busca exaustiva no teste considera o sistema IEEE mencionado, pode-se concluir que o método mencionado apresentou bom desempenho.

O estudo, porém, limita a taxa de carga e descarga deste equipamento em $25 \mathrm{~kW}$, o que pode restringir a capacidade de resposta deste a eventos que requerem uma resposta mais rápida. Por fim, é interessante mencionar que no estudo mencionado foi constatado que as melhores alocações para os SAEs geralmente variam dependendo da condição de operação do sistema. Isto significa que para um número fixo de SAEs, não houve uma alocação única que garanta o custo ótimo para todas as condições analisadas.

Como último exemplo de trabalho que emprega método heurístico, destaca-se (ABDELTAWAB; MOHAMED, 2017). Este considera o uso de SAEs estacionários como uma forma de compensar a intermitência de fontes renováveis de energia elétrica, além de ser lucrativo. Neste cenário, o sistema de armazenamento de energia transportável é apontado como alternativa capaz de ampliar a variedade de serviços já prestados pelos SAEs estacionários.

Devido à sua capacidade de locomoção, um SAET pode prestar suporte à regulação de tensão, fornecer potência reativa localmente, contribuir para a redução de perdas de energia, auxiliar a integração com fontes renováveis e consequentemente postergar investimentos em melhorias nas redes de transmissão e distribuição de energia. Especificamente, um SAET consiste em um único dispositivo móvel de armazenamento de energia composto por um conjunto de baterias e equipamentos de conexão transportados por um ou mais caminhões, como ilustra a Figura 7. 
Figura 7 - Estrutura de locomoção de um SAET

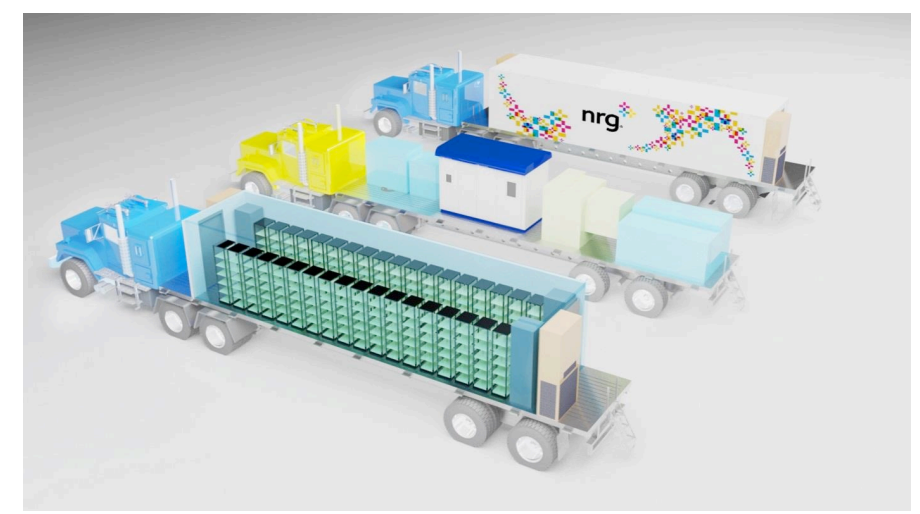

Fonte: (CON EDISON, 2017a).

Neste cenário, os autores consideram o uso de um SAET por parte da concessionária de energia com a finalidade de minimizar o custo da compra com um dia de antecedência da energia da rede elétrica e de prover suporte de reativos como forma de auxiliar a regulação da tensão da rede elétrica. Como forma de contribuir para estas tarefas, (ABDELTAWAB; MOHAMED, 2017) desenvolveram um sistema de gerenciamento de energia (EMS) de previsão de um dia à frente para um SAET sob posse de uma concessionária distribuidora de energia.

O EMS desenvolvido é capaz de indicar a potência ativa e reativa que o SAET deve fornecer em um dado instante e, além disso, definir a estação em que este deve estar conectado e o intervalo de tempo que o trânsito irá consumir até que o SAET chegue à estação desejada. Isto só é possível uma vez que o modelo usado para desenvolver o EMS contempla aspectos técnicos, como modelo de atraso de trânsito, fluxo de potência e dinâmica da bateria, e aspectos econômicos, que incluem custos operacionais. Vale destacar que uma otimização via OEP foi utilizada para que o lucro da concessionária de energia fosse maximizado.

Em dada etapa, o EMS desenvolvido foi aplicado em um sistema real. Nesta aplicação, as estações de carga e descarga do SAET foram alocadas ao final de cada alimentador do sistema. Estes são os locais de maior queda de tensão e que, por isso, são indicados para o suporte de reativo. Já as operações de cargas e descargas do SAET foram orientadas pelo preço da energia. Entretanto, as localidades destas operações foram relacionadas a aspectos técnicos. Como exemplo, ressalta-se que a carga inicial do SAET no trabalho referido foi localizada próximo às unidades de geração eólica de energia, que ocasionavam sobretensões no final do alimentador. No período da tarde, em que a geração eólica decaiu, a carga do SAET foi realizada próxima à subestação de energia, com a 
finalidade de resultar em menores perdas em comparação às que ocorreriam caso a carga fosse feita no fim do alimentador.

Como resultado do EMS proposto em (ABDELTAWAB; MOHAMED, 2017), o SAET foi responsável por eliminar as violações nos limites de tensão, reduzir as perdas em 5,5\% e aumentar o lucro geral em 3,1\%, em comparação à situação em que os serviços prestados pelo SAET não foram considerados. Contudo, (ABDELTAWAB; MOHAMED, 2017) não fez comparação do método proposto com outras possibilidades de alocação do SAET, tampouco com algum tipo de busca exaustiva. Sendo assim, não é possível se certificar que esta é a melhor estratégia de atuação para este dispositivo. Além disso, vale destacar que a solução apresentada se faz adequada para condições específicas de preço de energia, cargas e perfis de geração renováveis (ABDELTAWAB; MOHAMED, 2017) e, por este motivo, tem sua generalidade reduzida.

É importante notar, ainda, que além de considerar os custos com recursos humanos envolvidos na locomoção e operação de um SAET, o trabalho em questão considera a infraestrutura adequada para a sua conexão. Este fator é um desafio quando se consideram sistemas reais, uma vez que além do custo dos equipamentos de conexão há também a limitação de espaço físico para o deslocamento e posicionamento de um SAET. Desta forma, pode-se afirmar que o uso deste deve ser planejado de acordo com a realidade de sua aplicação para que seja capaz de compensar essas potenciais limitações.

Por fim, outro método utilizado com a finalidade de se determinar a localização e capacidade de um SAE é o método da busca exaustiva. Este é capaz de encontrar a solução ótima em um espaço de busca discreto limitado, ao custo de um esforço computacional elevado até mesmo para problemas de complexidade moderada. Embora geralmente aplicados na busca da capacidade ótima de potência e de energia de um SAE, o método em questão pode ser utilizado também na obtenção da alocação ótima desse sistema, como verificado em (AKHAVAN-HEJAZI; MOHSENIAN-RAD, 2014). Vale destacar que, quando se utiliza a busca exaustiva, a alocação deve ser obtida de forma separada das capacidades do sistema de armazenamento, uma vez que uma resolução simultânea do problema referido é praticamente inviável devido à sua natureza combinatorial.

Por fim, destaca-se que embora o dimensionamento e a alocação de SAEB seja um assunto amplamente estudado na literatura, há necessidade de ferramenta para determinar tanto o dimensionamento, quanto a alocação e estratégia de operação de um SAEB com a finalidade de redução de perdas elétricas em linhas de transmissão (MOEINI; KAMWA; DE MONTIGNY, 2015). 


\subsection{Aspectos econômicos}

Sabe-se que um SAE pode prestar inúmeros serviços à rede elétrica e que estes podem beneficiar consumidores, distribuidoras de energia e operadores do sistema independentes/organizações de transmissão regional. Entretanto, para que um SAE preste o maior número de serviços possíveis, é preciso que este seja alocado nas instalações do cliente final, isto é, atrás do medidor. Neste cenário, os autores de (FITZGERALD et al., 2015) constataram que a maioria dos SAEBs alocados dessa forma é subutilizada ao prestar apenas um tipo de serviço, enquanto poderia resultar em maior benefício econômico caso realizasse diversos serviços combinados.

Embora um estudo de custos para um SAE dependa de características singulares de contexto, pode-se afirmar que sob a presente estrutura de custos geralmente um SAE não consegue produzir um balanço financeiro positivo considerando apenas uma aplicação. Sendo assim, prover múltiplos serviços favorece economicamente o investimento em um SAEB. Ao analisar o uso de um SAEB alocado atrás do medidor com serviço principal de postergar investimentos no sistema de distribuição, foi constatado que este foi um caso cujos custos do sistema não foram superados por suas receitas. Esta situação provavelmente seria revertida caso o sistema fosse utilizado também para aplicações voltadas ao consumidor final, tais como redução de demanda ou suprimento de energia. Sendo assim, os SAEBs devem ser planejados para atuarem em diversos modos visando maior retorno financeiro, na medida em que haja necessidade, a possibilidade técnica e de monetização do serviço prestado (FITZGERALD et al., 2015).

Já os SAETs são um conceito que vem sendo estudado e já se encontram em etapa experimental (FITZGERALD et al., 2015), como é possível se verificar também no Apêndice. Há, entretanto, a necessidade de um planejamento mais elaborado com relação a este tipo de sistema em comparação aos sistemas estacionários devido à sua locomoção. Além de ter de respeitar possíveis legislações sobre transporte de baterias, esta etapa demanda esforço logístico e também gastos com o transporte e com a mão de obra que este requer. Sendo assim, os serviços a serem prestados por um SAET devem justificar financeiramente os gastos de transporte e instalação do equipamento cada vez que este for utilizado. Neste cenário, destaca-se que a postergação de investimentos de sistemas de distribuição é apontada em (FITZGERALD et al., 2015) como o serviço de maior valor estimado dentre os que um SAEB pode prestar. Isto indica que este serviço tem a maior probabilidade de justificar a atuação de um SAET. 
Ao se comparar SAEs estacionários e SAETs, é importante notar também a potência e quantidade de energia armazenada que a aplicação desejada requer. Isto porque algumas aplicações podem requerer grandes sistemas de armazenamento. Estes, por sua vez, apresentam estimativas de preço por kWh inferiores às de armazenadores de menor porte. Considerando a aplicação de suporte às redes de distribuição e transmissão, enquanto um $\mathrm{kWh}$ possui preço estimado de 340 US $\$-600$ US $\$$ para SAEBs de íons de Lítio de 10$20 \mathrm{MW}, 4$ horas de duração, este preço sobe para 500 US\$-1000 US\$ considerando unidades de 1-5 MW, 2 horas de duração (EPRI, 2018). Desta forma, constata-se que a aplicação de um SAE pode influenciar a escolha entre um equipamento estacionário ou transportável. Por fim, dada a complexidade do cálculo de custos e retorno de investimento conclui-se que cada aplicação de um SAE deve ser planejada cuidadosamente para que a decisão por um SAET ou SAEB estacionário seja feita de modo adequado.

\subsection{Considerações Finais do Capítulo}

Por meio do exposto nesta seção, percebe-se que na literatura os SAEs são escolhidos geralmente com base na sua capacidade de potência, capacidade de energia e local de aplicação na rede elétrica. Já o tipo de SAE é fortemente influenciado pela taxa de carga e descarga necessária em cada aplicação. Considerando que os SAEBs são o tipo de SAE que tem predominado em aplicações nos sistemas de distribuição, fica evidente que o sucesso da aplicação desses depende de seus dimensionamentos, alocações e a estratégias de operação. Este fato torna-se evidente quando se considera que a quantidade de energia disponível em um SAEB é limitada, enquanto as cargas elétricas de um sistema podem se concentrar em locais específicos e ainda variar no tempo. Sendo assim, conclui-se que não há solução única no que diz respeito ao dimensionamento e alocação de um SAEB. Desta forma, estes aspectos devem ser objetos de estudo.

Ademais, constata-se que os SAEBs podem ser aplicados com várias finalidades, dentre elas: possibilitar uma maior exportação da energia gerada por GDs, mitigar riscos relacionados às operações financeiras e minimizar o custo da compra da energia da rede elétrica por parte da concessionaria distribuidoras de energia, realizar peak shaving, reduzir perdas e violações de tensão e prover suporte de reativos. Para tanto, várias técnicas são empregadas: cálculo de fluxo de potência ótimo, otimização OEP e fuzzy OEP, PL inteira-mista, índice de sensibilidade de perdas e metodologias heurísticas, por exemplo. Neste contexto, percebe-se que a natureza combinatorial existente na 
determinação da alocação e dimensionamento favorece o uso de métodos heurísticos na obtenção de respostas a ambos os problemas. Isto ocorre porque a determinação simultânea da localização e capacidade de um SAE é um problema de difícil resolução. Porém, ressalta-se que estas técnicas não garantem que a solução ótima global seja encontrada e ainda exigem um alto esforço computacional. Dada a complexidade do problema e também das soluções geralmente propostas, percebe-se que uma ferramenta de bom desempenho e de fácil aplicação se faz de grande valia.

É interessante destacar que em (GIANNITRAPANI et al., 2017), as melhores alocações para os SAEs geralmente variam dependendo da condição de operação do sistema. Este problema poderia ser solucionado caso o SAEB pudesse ser transportado. Funcionalidade que torna o SAET atrativo, visto que suas alocações podem ser direcionadas de modo a atender os aspectos técnicos prioritários em dado período. Além disso, devido à grande variedade de funções que os SAEBs podem desempenhar e à singularidade das características de cada sistema de distribuição, é possível afirmar que dificilmente um trabalho poderá abranger todas as variáveis para o uso desses equipamentos. Nota-se que os aspectos econômicos são geralmente mais difíceis de serem encontrados nos trabalhos. Estudos que considerem um armazenador operando com mais de duas funcionalidades também são raros de serem encontrados.

Percebe-se, ainda, que a maioria dos trabalhos revisados consideram o uso de SAEBs estacionários, isto é, que são instalados e operam em determinado local e ali permanecem. Entretanto, o presente estudo faz parte de um projeto de Pesquisa e Desenvolvimento (P\&D) de responsabilidade da Copel Distribuição S. A. que considera o uso de um SAET. Por se tratar de um caso real cujo dimensionamento é definido, este trabalho tem como objetivo o estudo da melhor alocação para o equipamento mencionado, bem como o desenvolvimento de ferramentas para tanto.

Neste intuito, alguns conceitos e métodos aplicados em (GALLARDO, 2005) e em (AYRES et al., 2010; AYRES, 2010) foram usados neste estudo. O primeiro trabalho aborda os impactos de geradores síncronos em sistemas de distribuição e propõe índices como meio de quantizar o impacto que uma GD tem sobre o regime permanente destes. No decorrer do trabalho, o autor elabora um índice global que unifica os índices até então definidos. Este conceito foi aproveitado na elaboração do IMP.

Já o segundo e terceiro trabalhos forneceram a base teórica para o Método de Sensibilidades. Os seus autores utilizaram sensibilidades obtidas a partir da matriz Jacobiana de um único fluxo de carga convergido na determinação da máxima penetração de geração distribuída em uma rede de distribuição monofásica. Nesta dissertação, a ideia 
foi estender as formulações apresentadas nesses dois trabalhos para sistemas trifásicos e aplicá-las na avaliação das possíveis alocações para um SAET considerando as violações de tensões nodais como fator limitante. 


\section{Capítulo 3}

\section{Componentes dos Sistemas Elétricos}

No decorrer deste capítulo, os sistemas elétricos considerados nesta dissertação são apresentados, bem como o programa utilizado para as simulações. Os modelos dos principais elementos simulados também serão detalhados. Dentre estes se encontram o sistema de armazenamento de energia e os reguladores automáticos de tensão.

\subsection{Sistema IEEE 34 barras}

Neste estudo, um dos sistemas utilizados é o sistema de testes IEEE 34 barras, à mostra na Figura 8. Este é um sistema real localizado no estado de Arizona, EUA, com tensão nominal de 24,9 kV. Pode-se destacar que este é um sistema muito longo e levemente carregado, o que é crítico para a operação de um SAET. A potência ativa e reativa desse sistema são de aproximadamente $2.042 \mathrm{~kW}$ e $290 \mathrm{kvar}$, o que resulta em uma potência aparente de $2.062 \mathrm{kVA}$. Além disso, o sistema contém dois reguladores de tensão, um transformador abaixador para uma pequena seção com tensão nominal de 4,16 $\mathrm{kV}$, cargas desbalanceadas tanto pontuais quanto distribuídas, que são conectadas no centro de cada segmento de linha de distribuição, e capacitores shunt (KERSTING, 2001). Destaca-se que a modelagem desse sistema neste trabalho leva em consideração sua configuração trifásica. 
Figura 8 - Sistema IEEE 34 barras, com barras de carga destacadas em ver

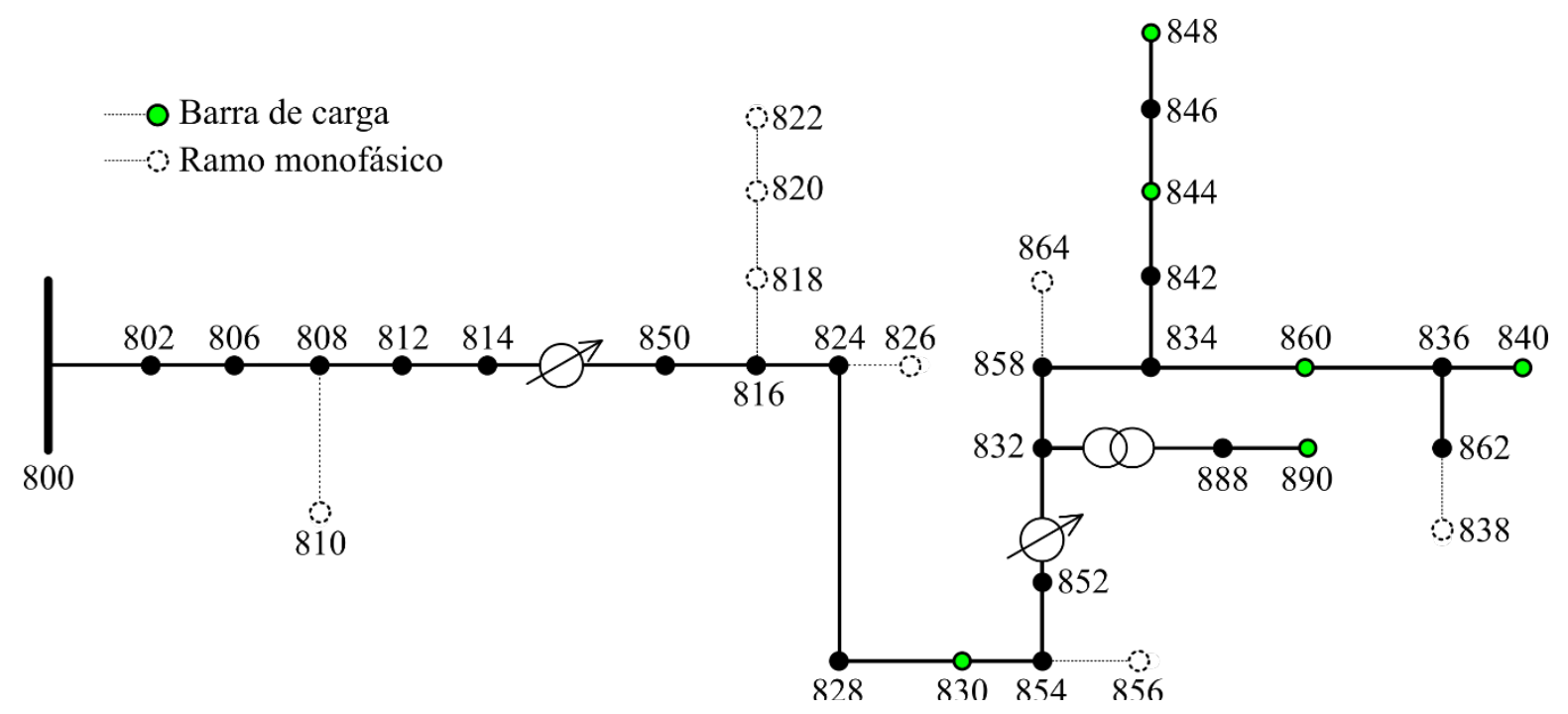

Fonte: Adaptado de (IEEE POWER ENGINEERING SOCIETY, 1992).

Para o desenvolvimento desta pesquisa, foi considerado que todas as cargas do referido sistema seguem o perfil diário de potência ativa e reativa apresentado na Figura 9. Este perfil é característico de uma carga residencial, visto que apresenta seu maior pico no período noturno. Vale destacar que o perfil de carga influencia os resultados dos métodos propostos neste trabalho, mas não anula a capacidade de generalização destes para cenários em que diferentes perfis de demanda estão presentes.

Figura 9 - Perfil de demanda diária

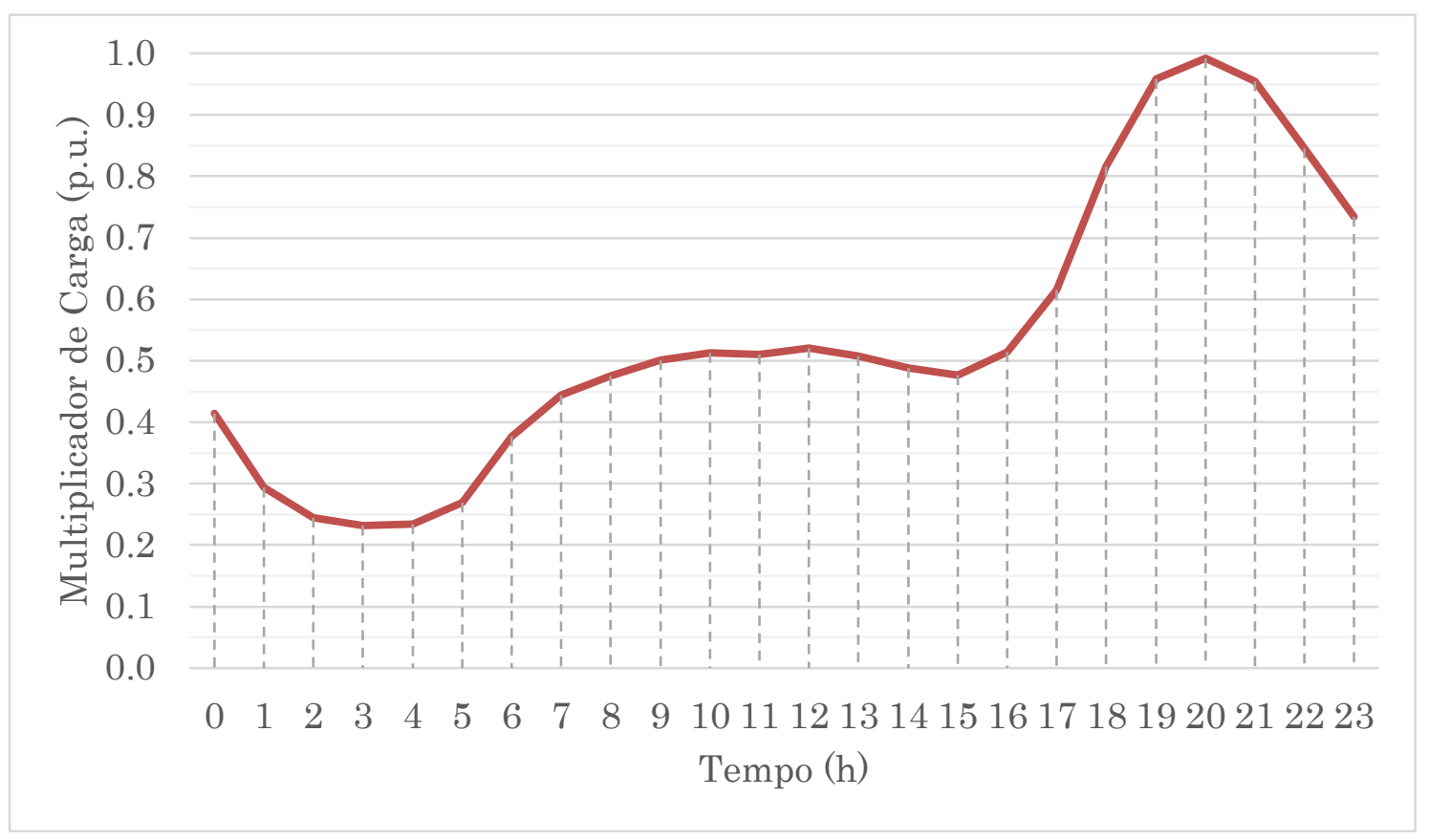

Fonte: Autor. 


\subsection{Sistema IEEE 123 barras}

Em determinada etapa de estudo, o sistema de testes IEEE 123 barras é analisado. Trata-se de um sistema cuja tensão nominal é $4,16 \mathrm{kV}$, caracterizado por reguladores de tensão e capacitores, além de várias chaves. Além disso, o sistema é composto de várias fases e cargas desbalanceadas de diferentes tipos (KERSTING, 2001). Sendo assim, tratase de um sistema de maior complexidade do que o IEEE 34 barras e, por isso, representa um desafio adicional à tarefa de alocação de um SAET. O sistema em questão na configuração usada neste trabalho se encontra na Figura 10. Destaca-se que a modelagem desse sistema neste trabalho levou em consideração sua configuração trifásica.

Figura 10 - Sistema IEEE 123 barras, com barras de carga destacadas em verde

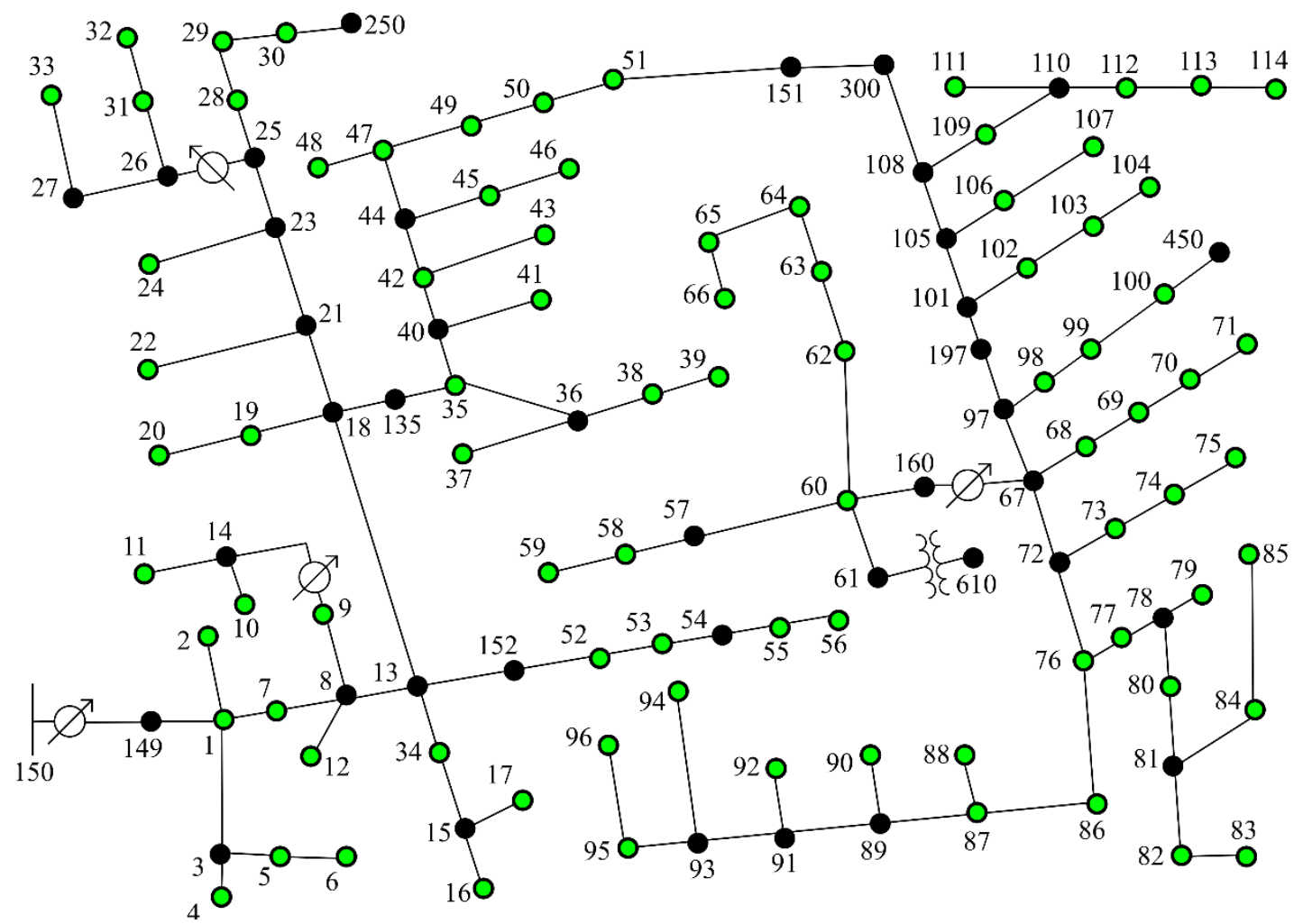

Fonte: Autor.

Por fim, destaca-se que todas as cargas usadas no estudo deste sistema seguem à curva apresentada na Figura 9, porém existem diferentes modelos de carga (potência constante, impedância constante e corrente constante). 


\subsection{OpenDSS}

O programa de simulação utilizado para simulação foi o OpenDSS. De acordo com (DUGAN et al., 2018), este programa é uma ferramenta de simulação de sistemas elétricos desenvolvida para sistemas de distribuição de concessionárias de energia. Sua versão executável tem uma interface gráfica de usuário baseada em textos, para auxiliar a criação de scripts e a observação dos resultados. Tal interface pode ser vista na Figura 11.

Figura 11 - Interface gráfica OpenDSS

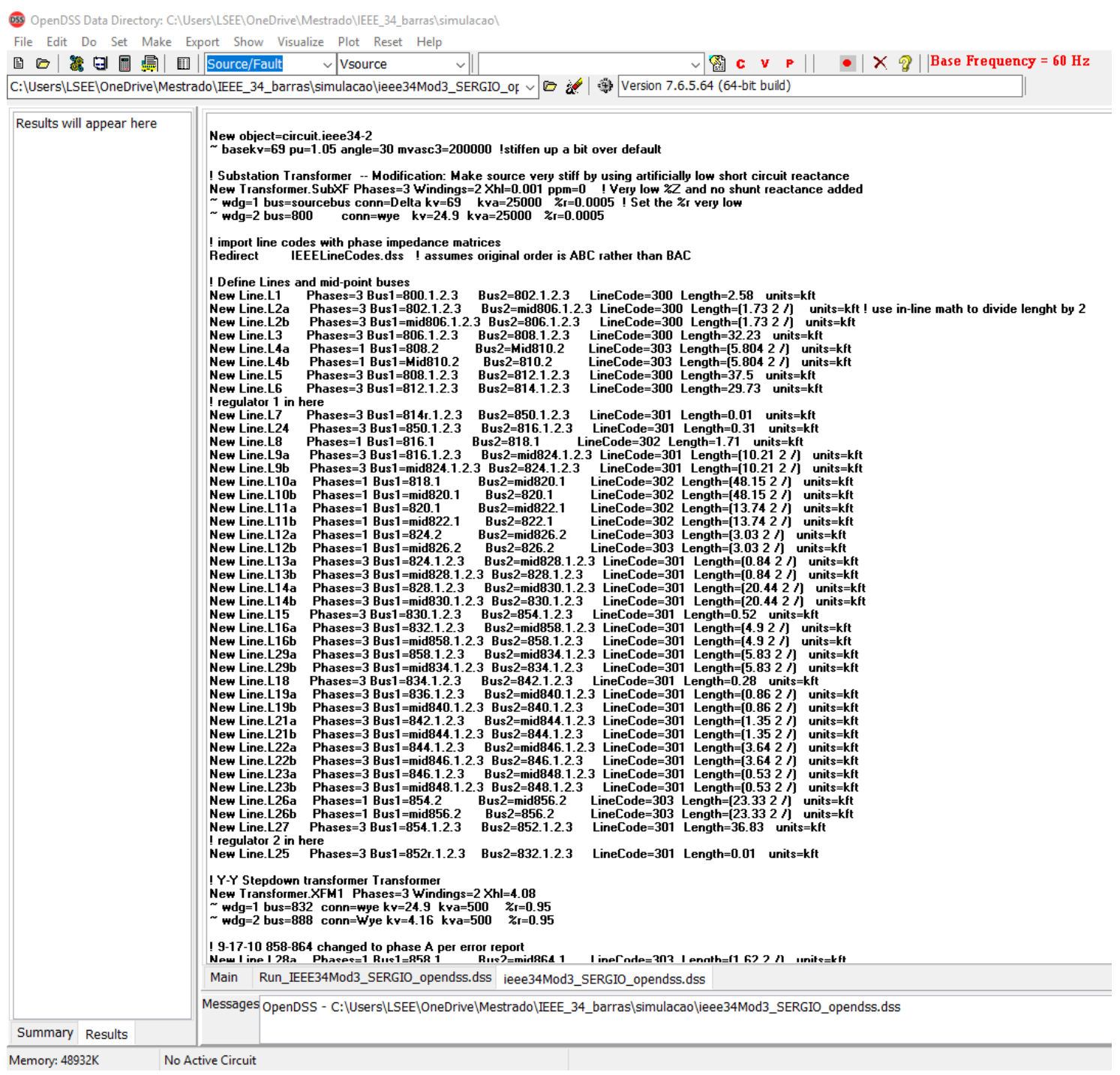

Fonte: Autor.

O OpenDSS é capaz de realizar praticamente todas as análises em regime permanente comumente executadas para o planejamento e análise de sistemas de concessionárias de distribuição (DUGAN et al., 2018). Além disso, o programa referido 
suporta novos tipos de análises, desenvolvidos com vista às necessidades futuras, impulsionadas por um contexto marcado pela desregulação das concessionárias e pelo advento das smart grids. Destaca-se que o OpenDSS foi criado para ser expansível, de modo a ser facilmente modificável para atender as necessidades que surgirem.

O OpenDSS pode ser utilizado em várias tarefas (DUGAN et al., 2018). Dentre elas destacam-se:

- Análise e planejamento de sistemas de distribuição;

- Análise geral de circuitos CA multi-fases;

- Análise de interconexões de Geração Distribuída;

- Simulações anuais de carga e geração;

- Simulação de sistemas de proteção;

- Modelagem de dispositivos armazenadores de energia;

- Simulações de impactos de veículos elétricos;

- Desenvolvimento de casos relacionados aos alimentadores de teste IEEE.

Adicionalmente, alguns dos modos de solução do programa mencionado são (DUGAN et al., 2018; SEXAUER; EPRI, 2012):

- Fluxo de potência instantâneo (SnapShot);

- Fluxo de potência diário;

- Fluxo de potência anual;

- Fluxo de potência por ciclo de trabalho;

- Análise harmônica;

- Análise dinâmica;

- Estudo de faltas;

- Estudo de faltas com Monte Carlo.

Além disso, o OpenDSS pode ser programado para usos mais específicos através da interface COM, por meio da qual o usuário final pode programar funções em outros programas, como MATLAB, e linguagens, como Python, C\#, R e outras (DUGAN et al., 2018), e fazer com que o OpenDSS seja executado da forma que mais lhe for conveniente. Sendo assim, funções podem ser desempenhadas de forma sequencial e automatizada e seus resultados podem ser exportados no formato Comma-Separated Value (CSV), que facilitam o pós-processamento por meio de ferramentas como o Microsoft Excel ou mesmo o MATLAB. Por fim, o usuário do OpenDSS também pode optar por desenvolver Bibliotecas de Vínculo Dinâmico (DLL), para uso mais específico (NAKASHIMA, 2018). Sendo assim, pode-se afirmar que o OpenDSS é uma ferramenta capaz de ser usada no planejamento das smart grids (SAMPER et al., 2017). 
O fato de ser gratuito e possuir as funcionalidades necessárias para este estudo embasa a escolha do OpenDSS como programa de simulação. Outro fator que contribui para esta escolha é o fato de ele ter sido adotado pela Agência Nacional de Energia Elétrica (ANEEL), conforme a nota técnica $n^{0}$ 057/2014-SRD/ANEEL, como ferramenta para o cálculo de fluxo de potência nas distribuidoras, realizado para o cálculo de perdas técnicas. Sendo assim, deduz-se que a utilização do programa mencionado no Brasil tem se intensificado, visto que em 2017 o país foi o segundo em número de downloads do software em questão de acordo com (SOURCEFORGE, 2018).

Em seguida, alguns dos principais elementos de circuitos utilizados para a construção de um sistema de distribuição via OpenDSS serão explicados resumidamente.

\subsubsection{Equivalente de Thévenin}

O equivalente de Thévenin é responsável por representar toda a rede de transmissão à qual o sistema de distribuição está conectado. Tal função é realizada no OpenDSS através do elemento Circuit. Este elemento é o responsável pela criação da barra de referência do sistema de distribuição em estudo e, desta forma, é necessário para todo circuito criado no OpenDSS (RADATZ, 2015).

Os principais parâmetros do elemento mencionado são expostos na Tabela 2.

Tabela 2 - Principais parâmetros do elemento Circuit

\begin{tabular}{cc} 
Parâmetro & Descrição \\
\hline basekv & Tensão de linha nominal [kV] \\
r1 & Resistência de sequência positiva da fonte $[\Omega]$ \\
x1 & Reatância de sequência positiva da fonte $[\Omega]$ \\
mvasc3 & Potência de curto-circuito trifásico [MVA] \\
mvasc1 & Potência de curto-circuito monofásico [MVA] \\
phases & Número de fases \\
pu & Valor por unidade da tensão na barra
\end{tabular}

Fonte: (NAKASHIMA, 2018; RADATZ, 2015)

\subsubsection{Linha}

O modelo matemático utilizado pelo OpenDSS para a modelagem de linhas de distribuição é o modelo $\pi$ com capacitores em derivação. Representadas pelo elemento Line, as linhas podem ser caracterizadas por meio de sua matriz de admitâncias nodais, matrizes de resistências e de reatâncias ou através do elemento LineCode. Este, por sua 
vez, é um elemento responsável por armazenar informações referentes aos parâmetros de linhas. Sendo assim, um determinado grupo de linhas pode ser caracterizado pelo mesmo LineCode, o que facilita a programação visto que na maioria dos casos, o sistema é composto por grupos de linhas que possuem características iguais (RADATZ, 2015).

Os principais parâmetros dos elementos Line e LineCode estão expostos na Tabela 3 e na Tabela 4, respectivamente.

Tabela 3 - Principais parâmetros do elemento Line

\begin{tabular}{cc} 
Parâmetro & Descrição \\
\hline phases & Número de fases (o default é 3) \\
bus1 & Nome da barra a qual o terminal 1 é conectado \\
bus2 & Nome da barra a qual o terminal 2 é conectado \\
length & Comprimento da linha \\
units & Unidade de comprimento utilizada \\
linecode & Contém as informações da linha \\
& Fonte: (RADATZ, 2015)
\end{tabular}

Tabela 4 - Principais parâmetros do elemento LineCode

\begin{tabular}{cc} 
Parâmetro & Descrição \\
\hline nphases & Número de fases \\
basefreq & Frequência base para as reatâncias \\
r1 & Resistência de sequência positiva $[\Omega /$ unidade de comprimento] \\
r0 & Resistência de sequência zero $[\Omega /$ unidade de comprimento] \\
x1 & Reatância de sequência positiva $[\Omega /$ unidade de comprimento] \\
x0 & Reatância de sequência zero $[\Omega /$ unidade de comprimento] \\
c1 & Capacitância de sequência positiva [nF/unidade de comprimento] \\
c0 & Capacitância de sequência zero [nF/unidade de comprimento] \\
rmatriz & Matriz triangular inferior de resistências $[\Omega /$ unidade de comprimento] \\
xmatriz & Matriz triangular inferior de reatâncias $[\Omega /$ unidade de comprimento] \\
cmatriz & Matriz triangular inferior de capacitâncias nodais [nF/unidade de \\
units & comprimento] \\
normamps & Unidade de comprimento \\
\hline
\end{tabular}

Fonte: (NAKASHIMA, 2018) 


\subsubsection{Carga}

No OpenDSS, as cargas são elementos de conversão de energia com apenas um terminal (RADATZ, 2015). O elemento Load é o responsável pela representação das cargas no OpenDSS. Para caracterizá-las é necessário que os valores de um dos seguintes pares sejam informados (RADATZ, 2015):

- Potência ativa nominal em $\mathrm{kW}$ e fator de potência;

- Potência ativa nominal em kW e potência reativa em kvar;

- Potência aparente nominal em kVA e fator de potência.

Além disso, os principais modelos utilizados na modelagem das cargas (RADATZ, 2015) são:

- Potência ativa e reativa constantes;

- Impedância constante;

- Potência ativa constante e potência reativa quadrática;

- Potência ativa nominal linear e potência reativa quadrática;

- Magnitude de corrente constante;

- Especial ZIPV.

Desta forma, os principais parâmetros do elemento Load no OpenDSS são apresentados na Tabela 5 .

Tabela 5 - Principais parâmetros do elemento Load

\begin{tabular}{cc} 
Parâmetro & Descrição \\
\hline bus1 & Nome da barra a qual a carga é conectada \\
phases & Número de fases \\
\hline conn & Tipo de conexão da carga (estrela ou delta) \\
model & Modelo da carga \\
kv & Tensão nominal \\
kva & Potência aparente nominal \\
kw & Potência ativa nominal \\
kvar & Potência reativa nominal \\
fp & Fator de potência \\
daily & Nome da curva (Loadshape) associada, para análise diária \\
& Fonte: (NAKASHIMA, 2018; RADATZ, 2015)
\end{tabular}

Destaca-se ainda, o elemento Loadshape, citado na Tabela 5. Este representa a curva de carga que é utilizada nos modos de simulação de fluxo de potência diário ou anual. Os seus principais parâmetros estão à mostra na Tabela 6. 
Tabela 6 - Principais parâmetros do elemento Loadshape

\begin{tabular}{cc} 
Parâmetros & Descrição \\
\hline mult & Vetor com os multiplicadores dos valores da carga [p.u.] \\
npts & Número de pontos da curva de carga \\
interval & Intervalo entre os pontos da curva de carga [h]
\end{tabular}

Fonte: (NAKASHIMA, 2018; RADATZ, 2015)

Neste trabalho, o elemento Loadshape foi utilizado para a caracterização da curva apresentada na Figura 9. Vale ressaltar que o intervalo de tempo entre as amostras utilizadas na construção desta curva foi de 5 minutos, resultando em um vetor com 288 pontos.

\subsubsection{Transformador}

O transformador é representado pelo elemento denominado Transformer e pode apresentar diversos enrolamentos, de acordo com a configuração que se deseja representar. Este elemento pode ser ainda, monofásico ou multifásico (RADATZ, 2015). Dentre os seus principais parâmetros, portanto, podem-se mencionar: número de fases, número de enrolamentos, tipo de conexão, perdas em vazio e perdas a plena carga.

Alguns dos principais parâmetros utilizados na implementação do referido elemento no OpenDSS são apresentados na Tabela 7.

Tabela 7 - Principais parâmetros do elemento Transformer

\begin{tabular}{cc} 
Parâmetro & Descrição \\
\hline phases & Número de fases (o default é 3) \\
\hline windings & Número de enrolamentos (o default é 2) \\
xlh & Reatância série entre os enrolamentos [p.u.] \\
\hline \%noloadloss & Perda em vazio com base na carga nominal [\%] \\
\hline wdg & Enrolamento que receberá os parâmetros a seguir \\
\hline bus & Nome da barra a qual o terminal do elemento é conectado \\
\hline conn & Tipo de ligação do enrolamento (estrela ou triângulo) \\
\hline kv & Tensão de linha nominal do enrolamento [kV] \\
kva & Potência aparente nominal do transformador [kVA] \\
\hline$\% r$ & Resistência de cada enrolamento [\%] \\
\hline \%imag & Corrente de magnetização [\%]
\end{tabular}

Fonte: (DUGAN; EPRI, 2013; NAKASHIMA, 2018; RADATZ, 2015) 


\subsubsection{Regulador automático de tensão}

O regulador automático de tensão é responsável pelo controle da tensão no local em que atua. Este controle ocorre com base na compensação de queda de tensão. Desta forma, o elemento denominado RegControl é munido dos parâmetros referentes ao controle da tensão e caso a tensão do ponto em que está monitorando ultrapassa os limites estabelecidos, realiza a mudança de tap do transformador ao qual está acoplado (RADATZ, 2015). Vale mencionar que o regulador possui também o parâmetro de tempo atraso, que permite a atuação coordenada de mais de um equipamento.

Alguns dos principais parâmetros utilizados na implementação do elemento mencionado no OpenDSS são apresentados na Tabela 8.

Tabela 8 - Principais parâmetros do elemento RegControl

\begin{tabular}{cc} 
Parâmetro & Descrição \\
\hline transformer & Transformador ao qual está acoplado \\
winding & Enrolamento em que está acoplado \\
vreg & Tensão de referência para o regulador \\
pratio & Relação de transformação do transformador de potencial \\
band & Faixa de regulagem para a tensão de referência \\
& Fonte: (RADATZ, 2015).
\end{tabular}

\subsubsection{Sistema de armazenamento de energia}

O modelo de um SAE utilizado pelo OpenDSS é genérico e feito para ser utilizado em estudos de planejamento (DUGAN; TAYLOR; MONTENEGRO, 2017). Desta forma, o modelo, representado pelo elemento do OpenDSS denominado Storage, não traz consigo características de determinada tecnologia de armazenamento de energia, mas a caracterização de uma dada tecnologia pode ser feita através dos ajustes de seus parâmetros. Estes estão expostos na Figura 12. 
Figura 12 - Modelo de SAE do OpenDSS

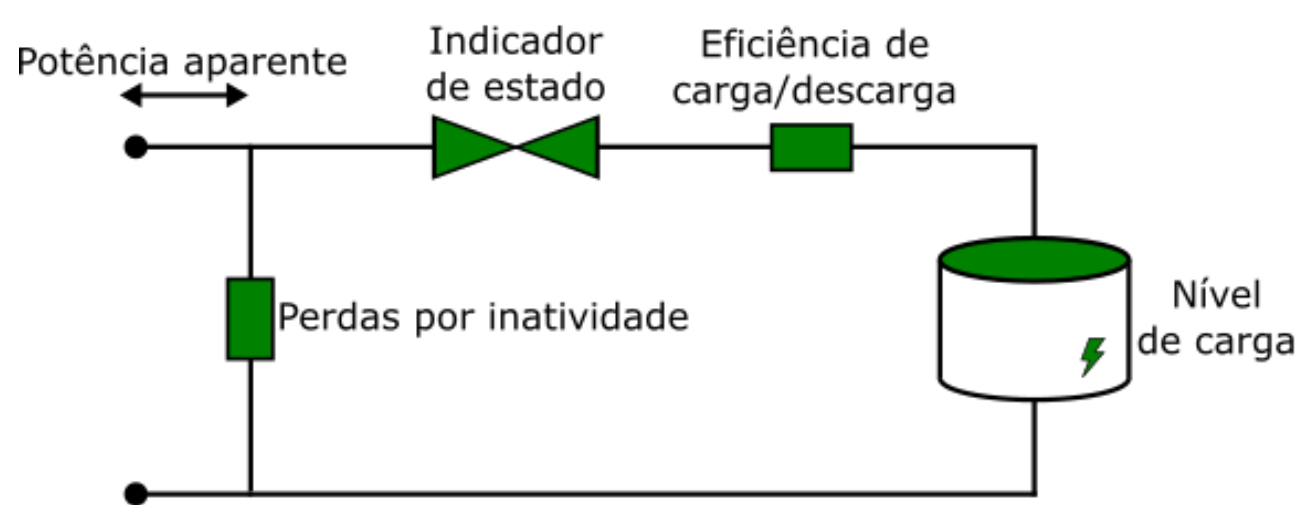

Fonte: (DE MORAIS FILHO; DIAS; DE MELO VIEIRA, 2018).

A seguir, tem-se uma explicação detalhada a respeito de cada um dos parâmetros à mostra na Figura 12 (EPRI, 2011).

- Potência aparente: potência aparente nominal do SAE, em kVA.

- Perdas por inatividade: perdas que representam a energia necessária para manter os controles internos e sistemas de refrigeração em funcionamento.

- Indicador de estado: indica o estado de operação do SAE, seja ele carga, descarga ou inatividade.

- Eficiência de carga/descarga: representa as eficiências, especificadas de forma separada e em \%, na conversão de energia durante as operações de carga e descarga do sistema considerado, uma vez que as perdas estão sempre presentes nestes processos.

- Nível de carga: indica a quantidade de energia armazenada no SAE, em kWh.

Além disso, o OpenDSS permite a simulação do armazenador de energia em três modos de variação de potência de saída com relação à tensão. São eles: potência ativa e reativa constante, admitância constante e injeção de potência conforme especificado pelo usuário através um uma DLL (EPRI, 2011).

Ainda de acordo com (EPRI, 2011), o elemento armazenador é essencialmente um gerador de energia que pode ser acionado para produzir ou consumir energia com certos valores de potência e capacidade nominais. O elemento pode ser usado no modo Snapshot, em que um fluxo de carga é computado considerando apenas um estado do armazenador, e no modo em que a simulação é feita com variação do tempo. Este segundo modo é o adequado para estudos de fenômenos que ocorrem no decorrer de um período. Além disso, ressalta-se que o elemento armazenador também pode produzir ou absorver potência reativa dentro da capacidade nominal do inversor, até mesmo enquanto em inatividade. 
Com relação ao modo de despacho, isto é, controle de carga e descarga, o SAE pode atuar nas seguintes configurações (EPRI, 2011).

- Modo padrão (Default mode): neste modo, o sistema de armazenamento irá descarregar a uma taxa especifica e fixa sempre que o objeto Loadshape exceder o valor de disparo de descarga. Em seguida, ele irá permanecer neste estado até que o valor do Loadshape caia abaixo do valor de disparo mencionado ou até que a carga do SAE atinja o seu nível de reserva. De modo semelhante, quando o Loadshape cai abaixo do valor de disparo de carga, o SAE irá carregar a uma taxa específica e fixa até que atinja o seu limite máximo de carga ou que outra descarga seja necessária.

- Modo Seguidor (Follow mode): neste modo, a injeção de potência ativa e reativa do SAE segue os multiplicadores indicados pelo Loadshape até que o SAE atinja seus limites de carga superior ou inferior. Desta forma, pode-se afirmar que as operações de carga e descarga são proporcionais a potência nominal do sistema de armazenamento. Ressalta-se, ainda, que o sistema mencionado carrega para valores negativos e descarrega para valores positivos.

- Modo Valor Global (Loadlevel ou price mode): neste modo de operação, o armazenador de energia orienta suas operações de carga e descarga a partir de um valor de preço ou de nível de carga definido, ao invés de seguir um Loadshape. Desta maneira, curvas de preço ou de carga são inseridas no OpenDSS, bem como o valor que se deseja definir como referência.

- Modo Externo (External mode): Assume-se, neste modo, que um elemento externo seja o responsável pelo controle das operações de carga e descarga do SAE. Sendo assim, este é um modo de controle apto a ser utilizado em simulações em tempo real ou mesmo simulações em que não se sabe o padrão de carga e descarga do armazenador de energia.

Adicionalmente, os principais parâmetros do elemento Storage estão expostos na Tabela 9 . 
Tabela 9 - Principais parâmetros do elemento Storage

Parâmetro

\begin{tabular}{|c|c|}
\hline phases & Número de fases \\
\hline conn & Tipo de conexão \\
\hline bus 1 & Barra em que o elemento está conectado \\
\hline $\mathrm{kv}$ & Tensão de linha nominal [kV] \\
\hline pf & Fator de potência \\
\hline basefreq & Frequência nominal $[\mathrm{Hz}]$ \\
\hline kwrated & $\begin{array}{l}\text { Potência nominal de saída [kW]. Utilizada como base para os } \\
\text { seguintes parâmetros: \%charge, \%discharge, \%idlingkw }\end{array}$ \\
\hline kwhrated & Capacidade de armazenamento de energia nominal [kWh] \\
\hline$\%$ reserve & $\begin{array}{c}\text { Percentagem da capacidade nominal que deve ser mantida } \\
\text { para a operação normal da bateria [\%] }\end{array}$ \\
\hline kwhstored & $\begin{array}{l}\text { Quantidade presente de energia armazenada na bateria } \\
\qquad[\mathrm{kWh}]\end{array}$ \\
\hline ChargeTrigger & Abaixo desse valor, a bateria começa a carregar [p.u.] \\
\hline DischargeTrigger & Acima desse valor, a bateria começa a descarregar [p.u.] \\
\hline$\underset{\mathrm{r}}{\text { TimeChargeTrigge }}$ & $\begin{array}{l}\text { A partir desse instante, a bateria começa a carregar } \\
\text { independentemente do parâmetro ChargeTrigger. }\end{array}$ \\
\hline \%charge & Taxa de carregamento [\%] \\
\hline \%discharge & Taxa de descarregamento [\%] \\
\hline \%effcharge & Eficiência da taxa de carregamento [\%] \\
\hline \%effdischarge & Eficiência da taxa de descarregamento [\%] \\
\hline$\% \mathrm{r}$ & Resistência interna [\%] \\
\hline \%idlingkw & $\begin{array}{l}\text { Potência consumida necessária para manter o elemento } \\
\text { (controles internos e sistemas de refrigeração) [\%] }\end{array}$ \\
\hline dispmode & Modo de operação \\
\hline daily & Curva de controle de carga e descarga \\
\hline
\end{tabular}

Fonte: (EPRI, 2011; RADATZ, 2015)

Uma vez que o presente trabalho foi desenvolvido como contribuição ao projeto de Pesquisa e Desenvolvimento (P\&D) intitulado Sistema de Armazenamento Transportável para Suporte a Contingências Programadas em SES (2866-0454/2016), o 
dimensionamento do SAET foi realizado considerando o projeto mencionado. Desta forma, o SAET foi simulado com 1 MW / 1 MWh, parâmetros que fazem com que este seja de uma potência de aproximadamente metade da carga total do sistema descrito na subseção 3.1 e tenha capacidade suficiente para fornecer energia por 1 hora considerando sua carga completa.

Adicionalmente, o controle de carga e descarga do SAET foi simulado no modo seguidor. Já a curva de referência mais utilizada para este controle se encontra à mostra na Figura 13. Nesta, os valores -1 e 1 indicam a operação de carga e descarga, respectivamente. Observa-se que, de acordo com esta estratégia, o SAET carrega durante um período de uma hora, das 3:00 às 4:00. Este período de carga foi considerado visto que é um período de baixa demanda de energia em um típico sistema elétrico de distribuição. Sendo assim, o preço da energia neste período tende a ser dos mais baixos no decorrer do dia, o que torna o carregamento do SAET mais economicamente viável. Já a descarga do SAET acontece durante o horário que compreende o maior consumo de energia de acordo com a Figura 9, isto é, das 20:00 às 21:00. Neste período, denominado período de pico, o preço da energia tende a ser maior, o que torna a operação de descarga, ou venda da energia do SAET, mais economicamente vantajosa. Esta estratégia de operação é denominada peak shaving.

Figura 13 - Curva de controle aplicada ao SAET com taxa de descarga $1 \mathrm{C}$

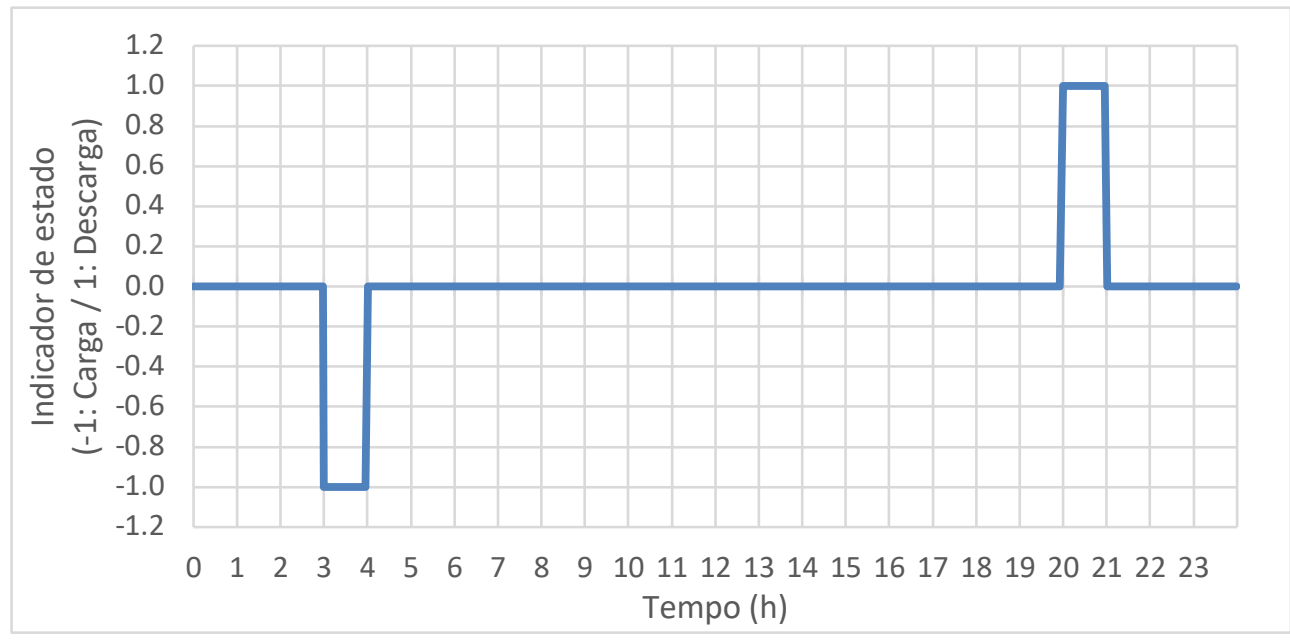

Fonte: Autor.

Como forma de ampliar o estudo, outras curvas de controle do SAET foram utilizadas. Estas curvas se encontram ilustradas nas Figura 14 até a Figura 16 e se caracterizam por possuírem taxas de descargas de 0,5 C, 0,33 C e 0,2 C, respectivamente. 
Figura 14 - Curva de controle aplicada ao SAET com taxa de descarga 0,5 C

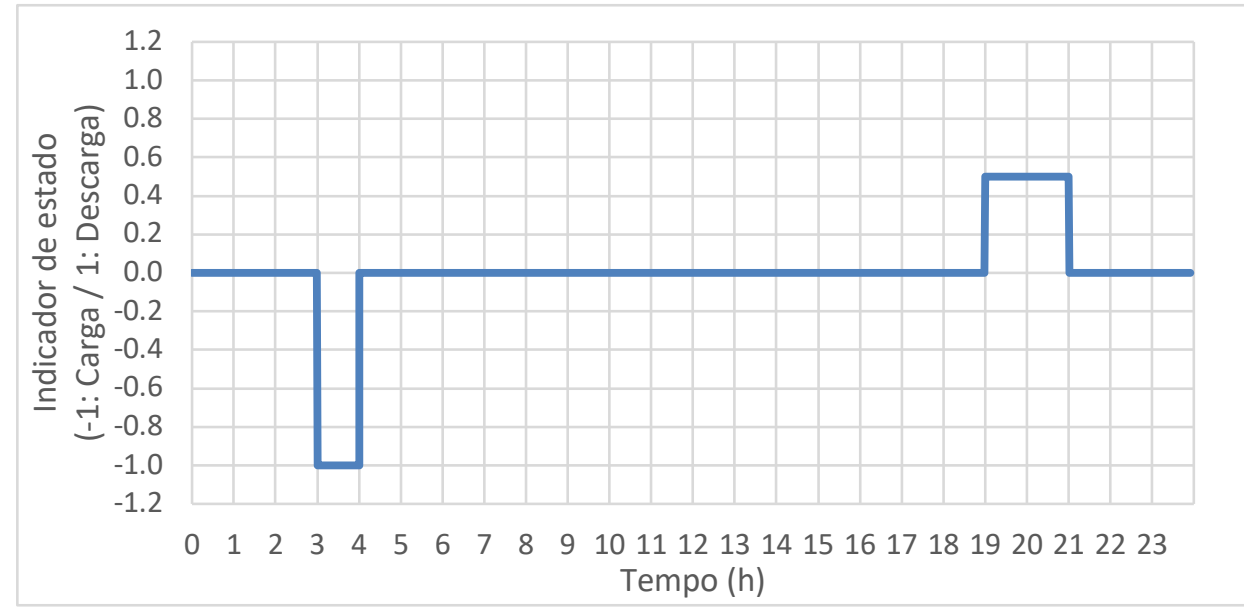

Fonte: Autor.

Figura 15 - Curva de controle aplicada ao SAET com taxa de descarga 0,33 C

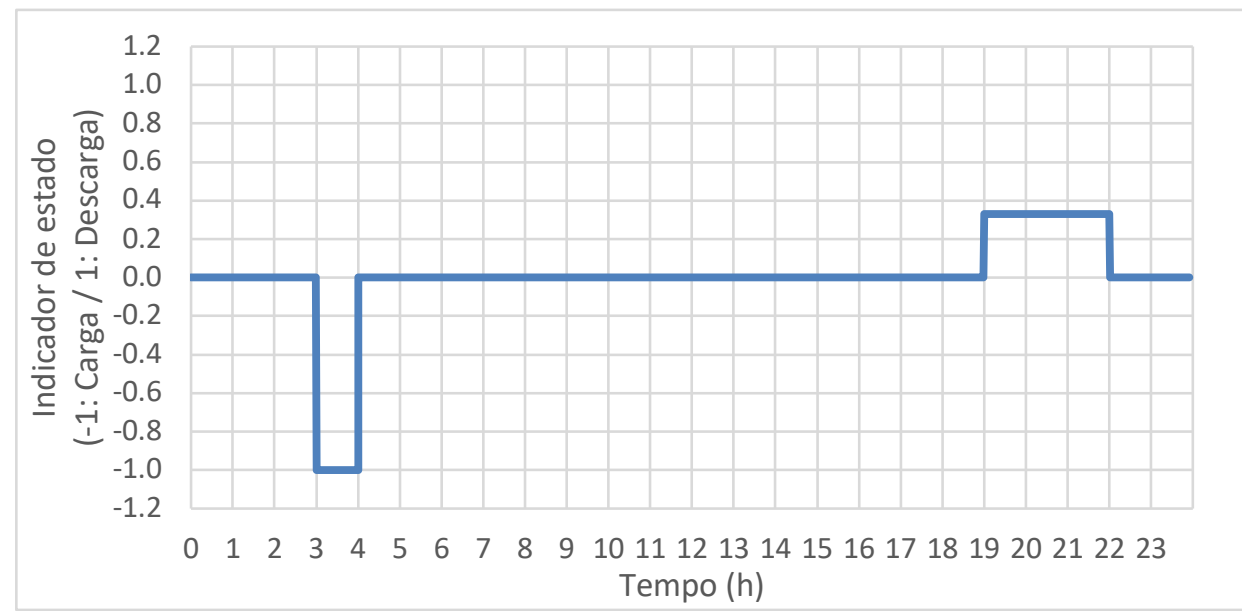

Fonte: Autor.

Figura 16 - Curva de controle aplicada ao SAET com taxa de descarga 0,2 C

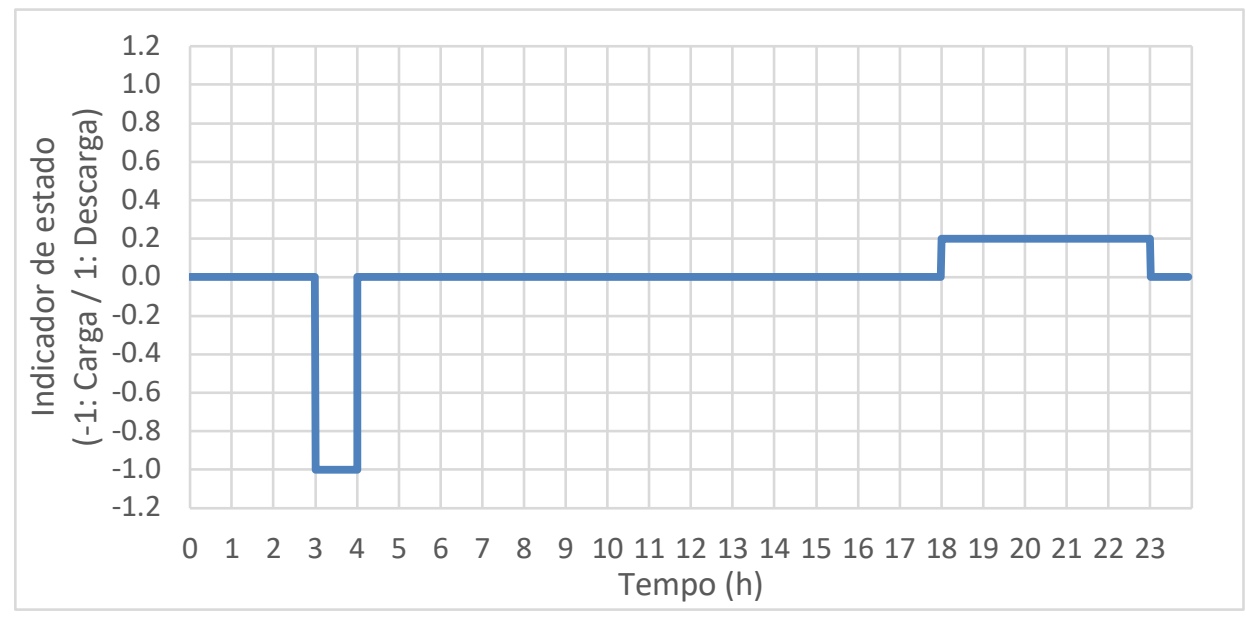

Fonte: Autor. 
Neste estudo, devido à predominância da tecnologia de íons de Lítio sobre as demais tecnologias aplicadas a armazenamento de energia via baterias (GREENTECH MEDIA, 2017), o SAE simulado foi caracterizado de acordo com características pertinentes a tecnologia mencionada. Sendo assim, os parâmetros adotados podem ser vistos na Tabela 10.

Tabela 10 - Parâmetros utilizados para o SAET.

\begin{tabular}{cc} 
Parâmetro & Valor \\
\hline \%effcharge & $92,5 \%$ \\
\%effdischarge & $92,5 \%$ \\
\%idlingkw & $3 \%$ da potência nominal \\
\%charge & $100 \%$ da potência nominal \\
\%discharge & $100 \%$ da potência nominal \\
\%reserve & $20 \%$ da capacidade nominal $(\mathrm{kWh})$ \\
fp & 1
\end{tabular}

Fonte: (CHEVRON ENERGY SOLUTIONS COMPANY, 2014), (DIVYA; ØSTERGAARD, 2009), (AKHIL et al., 2015). 


\section{Capítulo 4}

\section{Método do Índice Médio Ponderado}

Neste capítulo, foi proposto um conjunto de índices para indicar as melhores alocações para o SAET, considerando os impactos do mesmo sobre o sistema elétrico segundo diferentes aspectos técnicos. Estes índices foram agrupados de forma a obter um índice médio ponderado, cujo objetivo é agregar informações sobre o melhor local para instalar o SAET.

\subsection{Análise de impacto em regime permanente}

Inicialmente, o método denominado "busca exaustiva" foi utilizado para o estudo dos impactos da operação do SAET ao longo do sistema IEEE 34 barras. Ressalta-se que o uso desse método é importante uma vez que possibilitará a comparação futura entre os seus resultados e os obtidos com o Método de Análise via Sensibilidades Estendido para Sistemas Trifásicos, de modo a contribuir para a análise de desempenho deste.

Para esta parte do estudo, a execução sequencial do OpenDSS foi programada em linguagem Python, tendo em vista a elevada quantidade de execução de cálculos de fluxo de carga necessária. A escolha da linguagem de programação mencionada se deu devido a esta ser de licença gratuita, o que permite a sua utilização até mesmo para fins comerciais, e possuir suporte da comunidade.

O processo de busca exaustiva demanda a resolução de um fluxo de carga utilizando o método de NR para cada instante de tempo que se deseja analisar. A cada resolução, os valores instantâneos de carga do sistema e da injeção de potência do SAET são considerados. Ao término de cada fluxo de carga, os valores pontuais de tensão e corrente de cada uma das barras do sistema são armazenados para análise posterior. O procedimento descrito é ilustrado na Figura 17, em que a parte simulada via OpenDSS é destacada em verde e a realizada via Python, em azul. 
Figura 17 - Metodologia de busca exaustiva

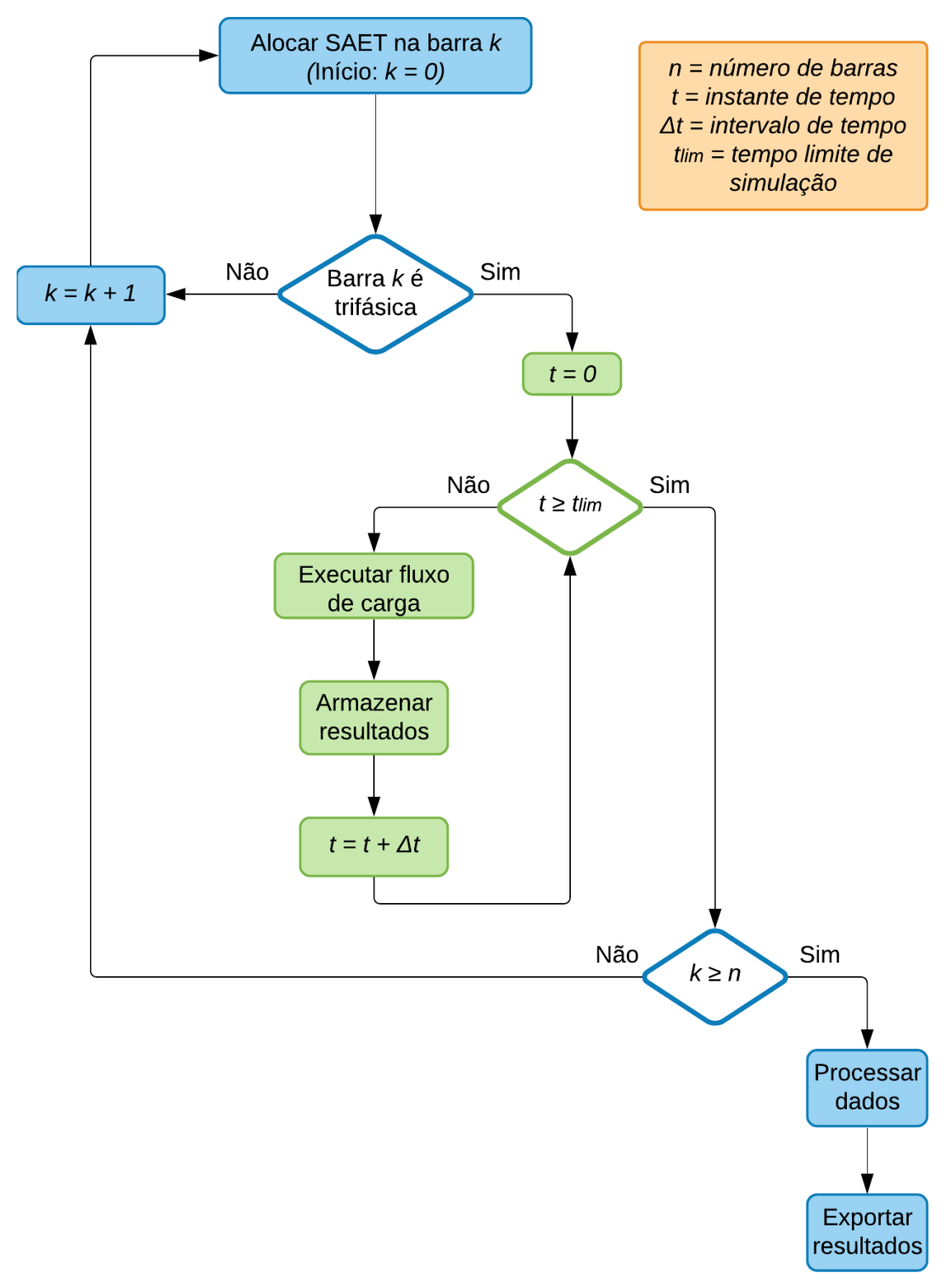

Fonte: Autor.

Como primeiro passo do procedimento de simulação adotado, o sistema é simulado sem a operação do armazenador de energia, essa configuração é mencionada na Figura 17 como "Início: $k=0$ ". Em seguida, o SAET passa a ser alocado sempre em uma única barra do sistema por vez. A partir de então, a sua operação é simulada de acordo com o descrito no parágrafo anterior. Ao término de cada simulação, o armazenador de energia é desconectado da barra em que estava alocado e conectado à uma próxima barra. $\mathrm{O}$ mesmo processo é executado considerando a nova alocação do equipamento mencionado. Ressaltase aqui que apenas as barras trifásicas foram consideradas como aptas a receberem a alocação do SAET neste estudo, uma vez que este é trifásico. 
Caso apenas as violações de tensões nodais fossem alvo de análise, o estudo da alocação de um SAET poderia ser realizado considerando dois instantes: um correspondente ao período de carga e outro ao período de descarga. Desta forma, a dinâmica temporal do armazenador, que inclui suas perdas internas e eficiência de carga/descarga, não seria considerada. Entretanto, como esta etapa compreende a dinâmica mencionada e aspectos técnicos que ocorrem ao longo do tempo, como perdas de energia e chaveamento de taps de reguladores de tensão, o estudo da alocação de um SAET contemplou sua operação em um horizonte de vinte e quatro horas, discretizado em intervalos de tempo de 30 segundos. Estes parâmetros são inseridos na simulação por meio das variáveis tlim e $\Delta t$, respectivamente, apresentadas na Figura 17.

Ao fim da simulação de operação do SAET em uma determinada barra, além das grandezas elétricas registradas nas barras do sistema IEEE 34 barras, os valores de magnitude de corrente em cada uma de suas linhas, os valores de perdas técnicas bem como os valores amostrados na saída de cada um dos reguladores de tensão são armazenados. Destaca-se que os dois reguladores de tensão são constituídos, cada um, por três reguladores monofásicos de atuação independente e automática.

Assim que a simulação é realizada para todas as barras do sistema, os dados de interesse são fornecidos pelo OpenDSS em arquivos do tipo cSV. Em seguida, esses dados são lidos e processados com o uso de um programa desenvolvido em linguagem Python. Esta etapa corresponde ao bloco "Processar dados" da Figura 17. Uma vez processados, os dados dão origem aos índices de impactos do SAET no sistema elétrico. Estes, por sua vez, são exportados também em formato csV, o que está ilustrado no bloco "Exportar resultados" da Figura 17.

Desta forma, é possível que o estado de funcionamento do sistema considerando uma determinada alocação do SAET seja conhecido para cada instante de tempo simulado. Como consequência, os índices gerados, descritos na próxima subseção, possibilitam uma análise detalhada do impacto do SAET no sistema elétrico para cada alocação considerada.

\section{2 Índices de impacto em regime permanente}

Nesta subseção, índices capazes de mensurar os impactos da alocação do SAET em um sistema elétrico são apresentados como forma de tornar mais prática a comparação entre diferentes alocações. Tais índices dizem respeito aos efeitos da operação do SAET em regime permanente e consideram os seguintes fatores: carregamento dos 
alimentadores, número de operações de chaveamento de taps de reguladores automáticos de tensão, perdas técnicas e valores máximo e mínimo de tensão nas barras de carga.

\subsection{1 Índice de Máxima Tensão (IMAT)}

Com a finalidade de analisar a contribuição da operação do SAET para o aumento da tensão nas barras de carga do sistema em estudo, definiu-se o Índice de Máxima Tensão. Este índice consiste no quociente entre a máxima tensão registrada entre as barras de carga $\left(V_{M A X(p . u .)}\right)$ e o limite superior de tensão crítica definido em (ANEEL, 2018), conforme apresentado na Eq. (1). Sendo assim, cada alocação pode ser analisada com relação ao impacto que a operação do SAET possui sobre as tensões nas barras de carga. Ressalta-se que este índice é importante durante o período de descarga do SAET e em situações em que o perfil de tensão é elevado.

$$
I M A T=\frac{V_{M A X(p . u .)}}{1,05}
$$

\subsection{2 Índice de Mínima Tensão (IMIT)}

De modo análogo ao que o IMAT se propõe, o Índice de Mínima Tensão tem como finalidade auxiliar a análise da operação do SAET com relação à diminuição de tensão nas barras de carga do sistema em estudo. Desta forma, o índice consiste em subtrair de $1 \mathrm{o}$ menor valor de tensão registrado dentre as barras de carga $\left(V_{M I N(p . u .)}\right)$. Posteriormente, o valor obtido é dividido pelo limite inferior de tensão crítica definido em (ANEEL, 2018), conforme apresentado na Eq. (2). Este índice é mais importante durante o período de carga do SAET e em situações em que o perfil de tensão é baixo.

$$
I M I T=\frac{1-V_{M I N(p . u .)}}{0,9}
$$

\subsection{3 Índice de Chaveamento (ICH)}

O Índice de Chaveamento é definido com o propósito de permitir a comparação entre as alocações do SAET com relação ao número de atuações dos taps nos reguladores de tensão ao longo do período simulado. Desta forma, o índice referido consiste no quociente 
entre a quantidade de atuação dos taps dos reguladores de tensão para uma dada alocação $\left(I C H_{A L O C}\right)$ e o valor máximo da mesma quantidade dentre todas as alocações $\left(I C H_{M A X}\right)$, conforme se observa na Eq. (3).

$$
I C H=\frac{I C H_{A L O C}}{I C H_{M A X}}
$$

\subsection{4 Índice de Perdas de Energia (IPE)}

Uma vez que as perdas técnicas de energia são de grande importância na análise do sistema elétrico, o Índice de Perdas de Energia foi definido. Deste modo, as alocações do SAET podem ser comparadas com relação ao montante de perdas de energia registradas para cada caso. Para tanto, o índice mencionado foi definido como o quociente entre a quantidade de perda de energia em $\mathrm{kWh}$ para uma dada alocação $\left(P E_{A L O C}\right)$ e a quantidade de perdas de energia em $\mathrm{kWh}$ registrada para o caso base $\left(P E_{B A S E}\right)$, isto é, para o caso em que não há a operação do SAET. O referido índice é apresentado na Eq. (4).

$$
I P E=\frac{P E_{A L O C}}{P E_{B A S E}}
$$

\subsection{5 Índice Médio Ponderado (IMP)}

De posse dos índices previamente apresentados, define-se o Índice Médio Ponderado. Este tem o objetivo de unir os demais índices em um único indicador que representa o quão benéfica uma determinada alocação de SAET é para o sistema elétrico em estudo. Para tanto, os índices IMAT, IMIT, ICH e IPE são, primeiramente, normalizados com relação aos seus respectivos maiores valores. Em seguida, tais índices são ponderados por pesos individuais. Deste modo, tem-se um indicador que é capaz de privilegiar o índice a que se deseja atribuir maior relevância. O IMP é apresentado na Eq. (5).

$$
I M P=\frac{P_{1} \cdot I P E+P_{2} \cdot I C H+P_{3} \cdot I M A T+P_{4} \cdot I M I T}{\sum_{i=1}^{4} P_{i}}
$$

Destaca-se que a soma dos pesos deve respeitar o limite máximo unitário. Sendo assim, os pesos individuais devem ser escolhidos dentro do intervalo [0,1] em qualquer combinação cuja soma destes seja igual a 1. Por exemplo, é possível estabelecer que $P_{1}=$ 0,$2 ; P_{2}=0,25 ; P_{3}=0,3 ; P_{4}=0,25$ caso o objetivo seja dar maior importância ao índice 
IMAT, ou ainda $P_{1}=0,5 ; P_{2}=0,25 ; P_{3}=0,15 ; P_{4}=0,10$, caso o IPE seja o índice de maior relevância em determinada aplicação. Por fim, é necessário ressaltar que os índices mencionados foram desenvolvidos de modo que quanto mais benéfica é a operação do SAET em uma dada alocação, menores são os índices associados à esta. $\mathrm{O}$ mesmo é verdadeiro com relação ao IMP, uma vez que este é composto dos índices referidos.

\subsection{Resultados}

No decorrer desta subseção, os resultados obtidos para os estudos mencionados neste capítulo serão apresentados e discutidos.

\subsubsection{Análise de impacto em regime permanente}

Como parte dos estudos realizados, a inserção de um SAET nas barras trifásicas do sistema IEEE 34 barras foi simulada no OpenDSS, controlado via Python. Inicialmente, o sistema em estudo foi simulado considerando um período de 24 horas de operação sem a presença do SAET, caso denominado caso base (CB). Posteriormente, o SAET foi conectado a cada uma das barras trifásicas do sistema em estudo, apresentado na Figura 8, de modo que em cada simulação esse foi conectado a apenas uma barra.

Além disso, a operação do SAET foi simulada considerando uma série temporal de 24 horas, discretizada em intervalos de 30 segundos. Vale destacar que as cargas do sistema foram simuladas de modo a considerar a curva de carga apresentada na Figura 9. Esta curva de carga foi adotada para todas as cargas do sistema. O controle da operação do SAET, por sua vez, foi realizado de acordo com a Figura 13, conforme apresentado na subseção 3.3.6.

Nesta etapa, os seguintes aspectos foram analisados: violações nos limites de tensão das barras e nos limites de ampacidade das linhas, atuação dos reguladores de tensão, perdas técnicas e valores máximo e mínimo de tensão.

\subsubsection{Violações dos limites de tensão nas barras}

Ressalta-se que, neste estudo, as violações de tensão são indicadas cada vez que o valor de tensão de uma barra do sistema em estudo ultrapassa os limites determinados em (ANEEL, 2018). Segundo o documento citado, os valores de tensão devem permanecer entre 0,93 p.u. e 1,05 p.u. para que a operação adequada seja caracterizada. 
Os resultados obtidos após a simulação da operação do SAET conforme descrito na subseção 4.1 mostraram que no CB de simulação não houve violação alguma nos limites de tensão. Nos demais casos simulados, a alocação do SAET na barra 890 foi a única que resultou em violações de tensão nos períodos de carga e descarga deste. Estas violações ocorreram nos limites inferior e superior de tensão justamente nas tensões das fases A, B e C da barra 890. Acontece que a operação do SAET representa em períodos distintos uma carga adicional, que contribui para a queda de tensão, e uma injeção de potência que resulta em uma elevação de tensão.

Por outro lado, constatou-se que a alocação do SAET não ocasionou violações de tensão quando realizada nas demais barras do sistema, além da barra 890. O fato de não ter ocorrido violações de tensão durante a operação de carga do SAET e nem mesmo durante a descarga deste sistema, torna as barras, com exceção da barra 890, candidatas à alocação do sistema de armazenamento em estudo, em uma análise preliminar.

Para as barras em que a alocação do SAET não resultou em violações de tensão, aspectos como ampacidade das linhas, chaveamento de taps nos reguladores de tensão, perdas técnicas e variações de tensão em barras de carga podem ser considerados para a identificação da melhor alocação possível do SAET, isto é, alocação que resulte em maior benefício para o sistema elétrico.

\subsubsection{Violações dos limites de ampacidade nas linhas}

Com a finalidade de tornar a análise mais próxima à realidade, a ampacidade das linhas de distribuição também foi considerada neste estudo.

Ressalta-se que, neste estudo, as violações dos limites de ampacidade são indicadas cada vez que o valor de magnitude da corrente de uma linha ultrapassa os limites determinados em (IEEE POWER ENGINEERING SOCIETY, 1992). Segundo o documento citado, os valores de magnitude da corrente das linhas devem permanecer entre os limites apresentados na Tabela 11 para que a operação adequada seja caracterizada.

Como resultado da simulação, constatou-se que não houve violações nos limites de ampacidade das linhas do sistema em estudo para qualquer que seja a alocação do SAET. Isto significa que a operação do SAET em quaisquer das alocações analisadas não foi capaz de causar elevação de corrente nos condutores além dos limites estabelecidos. Por este motivo, todas as barras podem ser candidatas à alocação do sistema de armazenamento em estudo considerando apenas este critério técnico. 
Tabela 11 - Limites de ampacidade das linhas do sistema IEEE 34 barras

\begin{tabular}{|c|c|c|}
\hline Barra inicial & Barra final & Limite de ampacidade @ $50^{\circ} \mathrm{C}(\mathrm{A})$ \\
\hline 800 & 802 & 230 \\
\hline 802 & 806 & 230 \\
\hline 806 & 808 & 230 \\
\hline 808 & 810 & 140 \\
\hline 808 & 812 & 230 \\
\hline 812 & 814 & 230 \\
\hline 814 & 850 & 180 \\
\hline 816 & 818 & 140 \\
\hline 816 & 824 & 180 \\
\hline 818 & 820 & 140 \\
\hline 820 & 822 & 140 \\
\hline 824 & 826 & 140 \\
\hline 824 & 828 & 180 \\
\hline 828 & 830 & 180 \\
\hline 830 & 854 & 180 \\
\hline 832 & 858 & 180 \\
\hline 834 & 860 & 180 \\
\hline 834 & 842 & 180 \\
\hline 836 & 840 & 180 \\
\hline 836 & 862 & 180 \\
\hline 842 & 844 & 180 \\
\hline 844 & 846 & 180 \\
\hline 846 & 848 & 180 \\
\hline 850 & 816 & 180 \\
\hline 852 & 832 & 180 \\
\hline 854 & 856 & 140 \\
\hline 854 & 852 & 180 \\
\hline 858 & 864 & 140 \\
\hline 858 & 834 & 180 \\
\hline 860 & 836 & 180 \\
\hline 862 & 838 & 180 \\
\hline 888 & 890 & 230 \\
\hline
\end{tabular}

Fonte: (IEEE POWER ENGINEERING SOCIETY, 1992).

\subsubsection{Número de chaveamento de taps dos reguladores de tensão}

A atuação dos reguladores de tensão foi analisada com base no número total de operações de chaveamento de taps dos dois reguladores de tensão presentes no sistema em estudo. Como mencionado na subseção 4.1, os reguladores de tensão são constituídos, cada um, por três reguladores monofásicos de atuação independente e automática.

Os valores amostrados na saída de cada um dos seis reguladores monofásicos de tensão são armazenados. Posteriormente, estes valores são analisados de forma que cada operação de chaveamento de tap seja contabilizada. Desta forma, a cada diferença entre dois valores amostrados e armazenados em sequência contabiliza-se uma operação de chaveamento de tap no regulador em análise. 
Sendo assim, a Figura 18 apresenta a soma total de operações de chaveamento de taps dos dois reguladores de tensão presentes no sistema em estudo. Nesta figura, o CB representa o total de atuações dos reguladores de tensão quando o sistema opera sem a presença do SAET. Esta situação serve de parâmetro para avaliar como a operação deste afetou a quantidade de chaveamento de taps nos reguladores de tensão.

Figura 18 - Total de atuação dos reguladores de tensão por alocação do SAET

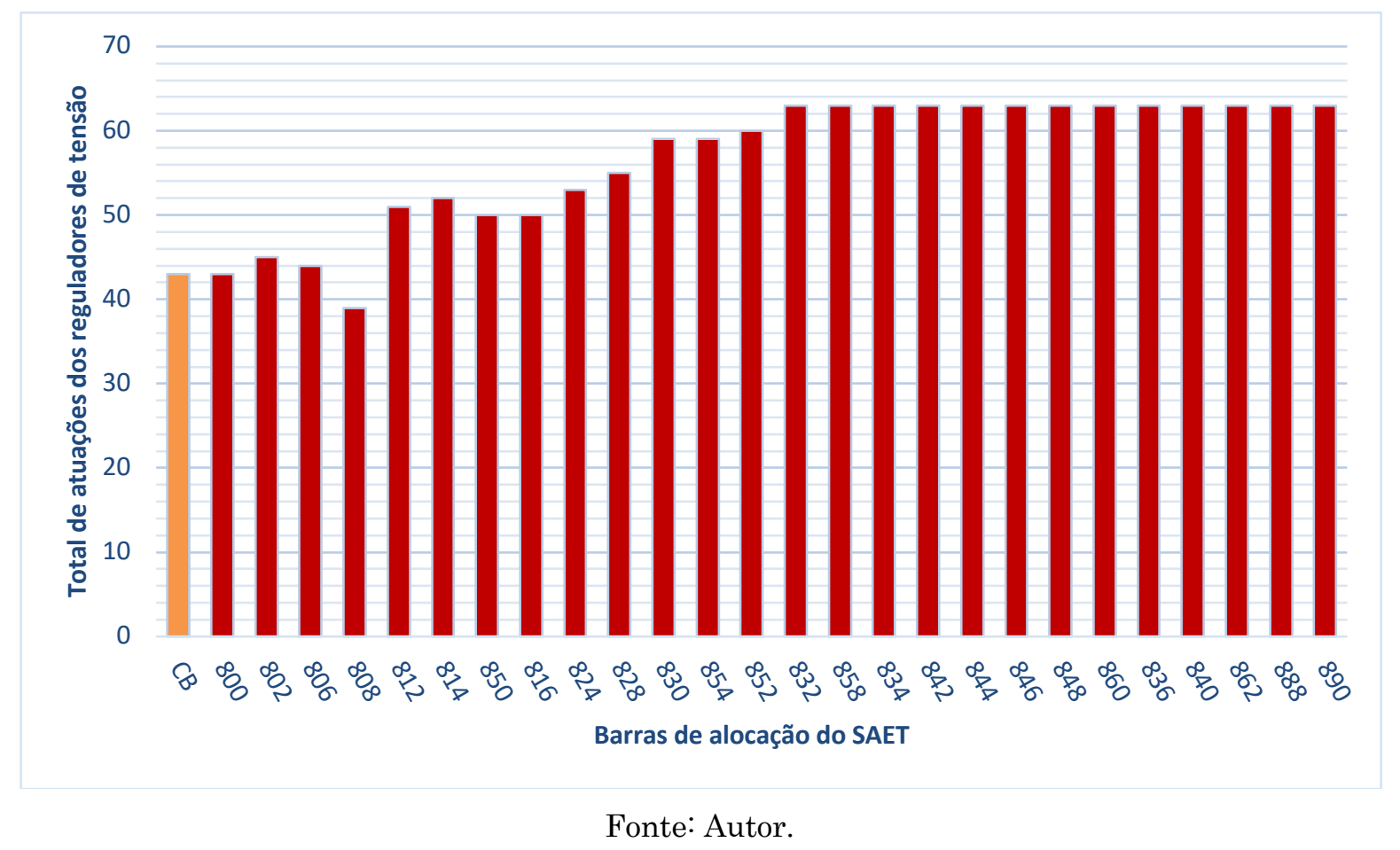

A partir dos resultados apresentados na Figura 18, observa-se que, de modo geral, quanto mais distante da subestação, maior é a quantidade de operações de chaveamento de taps dos reguladores de tensão demandada para cada alocação do SAET. Já as alocações que demandaram menor quantidade de operações de chaveamento de taps dos reguladores de tensão ocorreram nas barras mais próximas à subestação, como as barras 806 e 808 . Observa-se que as alocações em barras mais distantes da subestação, como é o caso das barras 858, 846 e 862, por exemplo, demandaram geralmente 63 atuações dos reguladores de tensão, ao longo de $24 \mathrm{~h}$ de operação. Este comportamento ocorre visto que estas barras estão distantes da subestação, o que resulta em uma maior sensibilidade de tensão. Portanto, resulta em maior variação de taps nos reguladores de tensão.

\subsubsection{Perdas técnicas}

Outro aspecto analisado nesta etapa de estudo foram as perdas técnicas. Para tanto, os valores de perdas técnicas referentes à operação diária do SAET em cada alocação foram 
obtidos a partir do OpenDSS. Este permite o registro da energia ativa que foi perdida no sistema elétrico ao longo do período considerado em simulação. Desta forma, os valores de perdas técnicas do sistema em estudo referentes à cada alocação do SAET estão apresentados na Figura 19.

Figura 19 - Perdas de energia (kWh) por alocação do SAET em um dia de operação

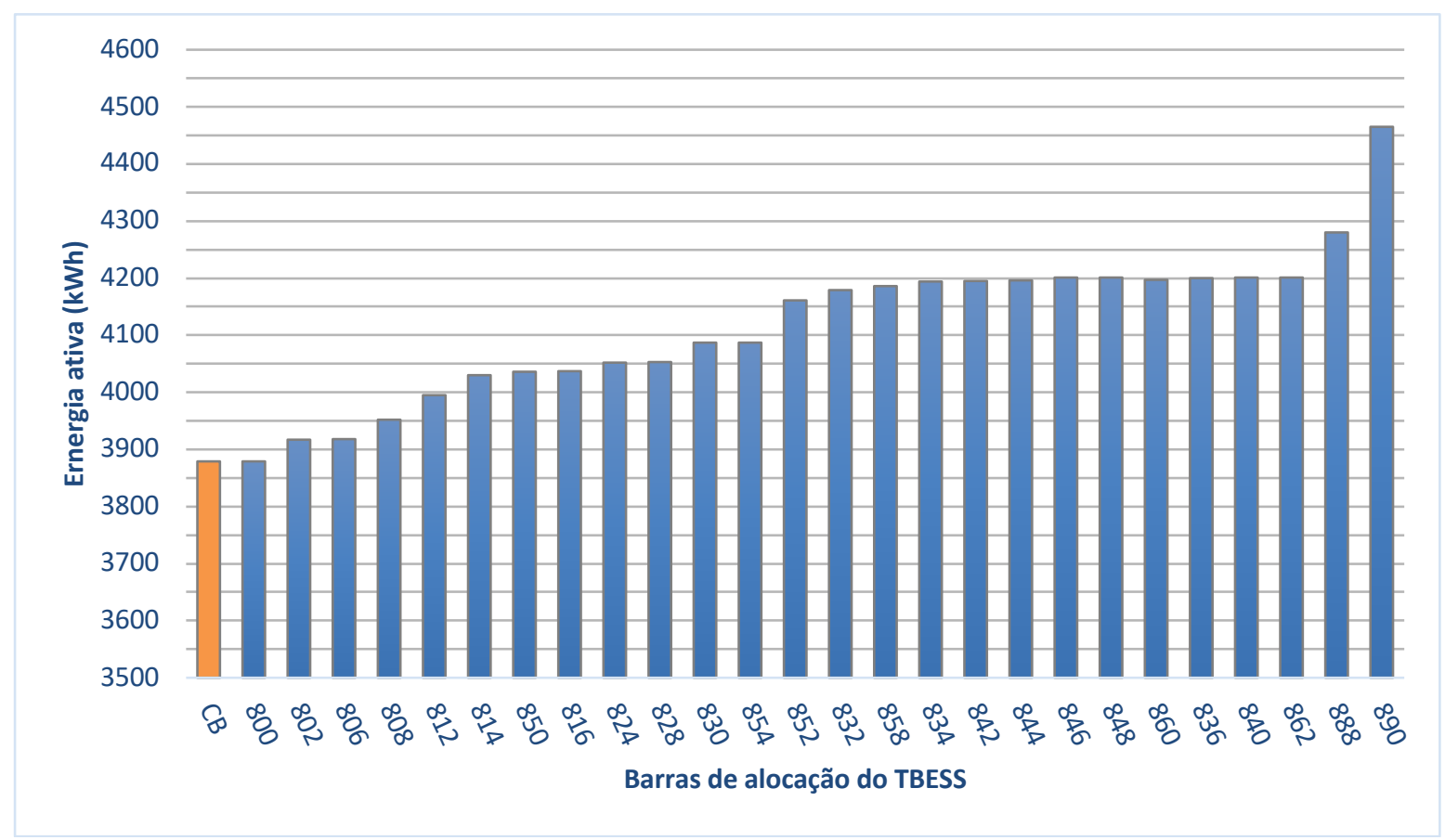

Fonte: Autor.

De acordo com os resultados apresentados na Figura 19, verifica-se que a alocação do SAET simulado resulta em uma menor quantidade de perdas ativas quanto mais próxima à subestação de energia. Em contrapartida, as maiores quantidades de perdas ativas se verificam em casos de alocações distantes da subestação, como no caso das barras 848, 840 e 862, por exemplo. As maiores perdas nas barras 888 e 890 se justificam pela grande resistência entre estas e a subestação. Sendo assim, de acordo com a tendência também constatada na subseção 4.3.1.3, as melhores barras para alocação do SAET considerando a perda de energia ativa como critério são as barras 802 e 806.

\subsubsection{Valores máximo e mínimo de tensão}

Com a finalidade de desenvolver uma maior familiaridade com o sistema em estudo, os valores máximos e mínimos de tensão das barras de carga do sistema foram analisados. A preocupação seletiva com estas barras se deu visto que violações dos limites de tensão estabelecidos em (ANEEL, 2018) nestas barras podem resultar em multas para a concessionária de distribuição e eventual ressarcimento em caso de danos aos 
equipamentos de seus clientes. A finalidade desta análise é de verificar quais as barras cujas tensões mais se aproximam dos limites mencionados com o objetivo de evitar que a alocação do SAET seja realizada nestas. Além disso, a partir da observação desses valores, é possível saber o quão uniforme se encontra o perfil de tensão das barras de carga. Quanto menor a diferença entre esses valores, mais uniforme este perfil de tensão está. Os resultados obtidos via simulação são apresentados na Tabela 12.

Com base nos resultados obtidos, é possível constatar que a barra de carga que apresenta o menor valor de tensão para todas as alocações simuladas é a 830. Trata-se da barra de carga mais próxima a um regulador de tensão. Percebe-se que esta barra está alocada próxima a uma localidade que precisa de um dispositivo para corrigir a tensão o que pode indicar que esta região do sistema é passível de maiores desvios nos valores desta grandeza elétrica. Nota-se que os valores mínimos de tensão são registrados no horário de carga do SAET, que vai das 3:00 às 4:00.

Já os maiores valores de tensão são verificados na fase $\mathrm{C}$ da barra 848. Tal resultado se justifica pelo fato de esta ser uma barra de carga em que há a presença de um capacitor em derivação. Este dispositivo contribui para o aumento de tensão nesta barra. Ademais, deve-se considerar a localização da barra 848 no sistema IEEE 34 barras. Acontece que nesta parte do sistema, a tensão deve ser regulada em valores altos para que o limite inferior de tensão na barra 844 não seja atingido devido à grande carga presente nesta. Ao mesmo tempo, a carga na barra 848 é demasiadamente leve para causar uma queda significativa no valor de tensão. Como resultado tem-se na barra 848 um valor de tensão alto, devido a sua carga relativamente pequena para a parte do sistema em que está localizada. Por fim, observa-se que os valores máximos de tensão são registrados no período em que o SAET está realizando a descarga, que ocorre das 20:00 às 21:00.

Portanto, constata-se que as barras 830 e 848 são alocações cujos valores de tensão mais se aproximam dos limites estabelecidos em (ANEEL, 2018) e, por este motivo, devem ser evitadas. 
Tabela 12 - Valores mínimo e máximo de tensão para cada alocação do SAET

Valor mínimo de tensão

Valor máximo de tensão

\begin{tabular}{|c|c|c|c|c|c|c|c|c|}
\hline Alocação & $\begin{array}{c}\text { Tensão } \\
\text { (p.u.) }\end{array}$ & $\begin{array}{l}\text { Horário } \\
\text { (h) }\end{array}$ & Barra & Fase & $\begin{array}{c}\text { Tensão } \\
\text { (p.u.) }\end{array}$ & $\begin{array}{l}\text { Horário } \\
\text { (h) }\end{array}$ & Barra & Fase \\
\hline $\mathrm{CB}$ & 0,9897 & 4 & 830 & $\mathrm{~A}$ & 1,0475 & 21 & 848 & $\mathrm{C}$ \\
\hline 800 & 0,9897 & 4 & 830 & A & 1,0475 & 21 & 848 & $\mathrm{C}$ \\
\hline 802 & 0,9897 & 4 & 830 & $\mathrm{~A}$ & 1,0475 & 21 & 848 & $\mathrm{C}$ \\
\hline 806 & 0,9897 & 4 & 830 & A & 1,0475 & 21 & 848 & $\mathrm{C}$ \\
\hline 808 & 0,9897 & 4 & 830 & $\mathrm{~A}$ & 1,0475 & 21 & 848 & $\mathrm{C}$ \\
\hline 812 & 0,9897 & 4 & 830 & A & 1,0475 & 21 & 848 & $\mathrm{C}$ \\
\hline 814 & 0,9897 & 4 & 830 & $\mathrm{~A}$ & 1,0475 & 21 & 848 & $\mathrm{C}$ \\
\hline 850 & 0,9897 & 4 & 830 & A & 1,0475 & 21 & 848 & $\mathrm{C}$ \\
\hline 816 & 0,9897 & 4 & 830 & $\mathrm{~A}$ & 1,0475 & 21 & 848 & $\mathrm{C}$ \\
\hline 824 & 0,9897 & 4 & 830 & A & 1,0475 & 21 & 848 & $\mathrm{C}$ \\
\hline 828 & 0,9897 & 4 & 830 & $\mathrm{~A}$ & 1,0475 & 21 & 848 & $\mathrm{C}$ \\
\hline 830 & 0,9897 & 4 & 830 & A & 1,0475 & 21 & 848 & $\mathrm{C}$ \\
\hline 854 & 0,9897 & 4 & 830 & $\mathrm{~A}$ & 1,0475 & 21 & 848 & $\mathrm{C}$ \\
\hline 852 & 0,9897 & 4 & 830 & A & 1,0475 & 21 & 848 & $\mathrm{C}$ \\
\hline 832 & 0,9897 & 4 & 830 & $\mathrm{~A}$ & 1,0475 & 21 & 848 & $\mathrm{C}$ \\
\hline 858 & 0,9897 & 4 & 830 & A & 1,0475 & 21 & 848 & $\mathrm{C}$ \\
\hline 834 & 0,9897 & 4 & 830 & $\mathrm{~A}$ & 1,0475 & 21 & 848 & $\mathrm{C}$ \\
\hline 842 & 0,9897 & 4 & 830 & A & 1,0473 & 21 & 848 & $\mathrm{C}$ \\
\hline 844 & 0,9900 & 4 & 830 & $\mathrm{~A}$ & 1,0455 & 21 & 848 & $\mathrm{C}$ \\
\hline 846 & 0,9897 & 4 & 830 & $\mathrm{~A}$ & 1,0473 & 21 & 848 & $\mathrm{C}$ \\
\hline 848 & 0,9897 & 4 & 830 & $\mathrm{~A}$ & 1,0475 & 21 & 848 & $\mathrm{C}$ \\
\hline 860 & 0,9897 & 4 & 830 & A & 1,0475 & 21 & 848 & $\mathrm{C}$ \\
\hline 836 & 0,9897 & 4 & 830 & $\mathrm{~A}$ & 1,0475 & 21 & 848 & $\mathrm{C}$ \\
\hline 840 & 0,9897 & 4 & 830 & $\mathrm{~A}$ & 1,0473 & 21 & 848 & $\mathrm{C}$ \\
\hline 862 & 0,9897 & 4 & 830 & $\mathrm{~A}$ & 1,0475 & 21 & 848 & $\mathrm{C}$ \\
\hline 888 & 0,9897 & 4 & 830 & $\mathrm{~A}$ & 1,0475 & 21 & 848 & $\mathrm{C}$ \\
\hline 890 & 0,9897 & 4 & 830 & $\mathrm{~A}$ & 1,0475 & 21 & 848 & $\mathrm{C}$ \\
\hline
\end{tabular}

Fonte: Autor.

\subsubsection{Aplicação dos índices de impacto em regime permanente}

Como parte do estudo da alocação do SAET ao longo do sistema IEEE 34 barras, o índice IMP apresentado na subseção 4.2.5 foi aplicado. Em um primeiro momento, este índice foi aplicado considerando uma curva de operação do SAET que possui taxas de carga e descarga de 1 C. Em seguida, o resultado desta aplicação é apresentado e analisado. Posteriormente, com o objetivo de investigar a capacidade de generalização deste e a sua sensibilidade aos pesos do IMP, estudos são realizados considerando diversos cenários, 
cada um constituído de uma combinação de pesos usados no cálculo do índice em questão. Ademais, estudos com relação à alocação do SAET considerando taxas de descarga de 0,5 C, 0,33 C e 0,2 C também são realizados por meio da aplicação do IMP. Seus resultados são expostos e, em seguida, faz-se uma comparação entre o desempenho da operação do SAET e de suas alocações para cada uma das taxas de descargas simuladas.

\subsubsection{Taxa de descarga $1 \mathrm{C}$}

Inicialmente, a taxa de descarga de $1 \mathrm{C}$ será aplicada no estudo de dois sistemas distintos. São eles o sistema de testes IEEE 34 barras e o sistema de testes IEEE 123 barras.

\section{a. Sistema IEEE 34 barras}

Neste primeiro caso, a alocação do SAET é estudada no sistema IEEE 34 barras considerando uma taxa de descarga de 1 C. Além disso, os pesos incluídos na formulação do IMP foram considerados todos iguais a 0,25 . Os resultados estão apresentados na Tabela 13, em que as barras do sistema estão organizadas por ordem crescente de IMP.

A partir da análise da Tabela 13, pode-se verificar que a alocação que resultou em melhores benefícios para o sistema foi a barra 800. Esta alocação se destaca com relação às demais principalmente no que diz respeito aos índices IPE e ICH, referentes a perdas técnicas e a chaveamento de taps dos reguladores de tensão, respectivamente.

Primeiramente, nota-se que a pouca distância entre o SAET e a subestação contribui para que não haja uma grande alteração nas perdas ao longo dos alimentadores em comparação ao CB, justificando o bom desempenho da barra 800 quanto ao IPE. Além disso, o fato de esta barra ser a própria subestação do sistema faz com que não haja uma grande variação de tensão quando o SAET entra em operação. Deste modo, são necessárias poucas atuações dos reguladores de tensão, o que se reflete em um bom ICH.

Como tendência geral, percebe-se que as alocações do SAET que tiveram melhores valores de IMP foram as que estão mais próximas à subestação de energia. Esta tendência pode ser observada com mais facilidade na Figura 20. 
Tabela 13 - Índice IMP para taxa de descarga 1 C, sistema IEEE 34 barras

\begin{tabular}{|c|c|c|c|c|c|}
\hline Barra & IPE & ICH & IMAT & IMIT & IMP \\
\hline 800 & 0,211 & 0,199 & 0,240 & 0,075 & 0,725 \\
\hline 802 & 0,214 & 0,197 & 0,240 & 0,075 & 0,726 \\
\hline 806 & 0,214 & 0,197 & 0,240 & 0,075 & 0,726 \\
\hline 808 & 0,216 & 0,219 & 0,240 & 0,076 & 0,751 \\
\hline 812 & 0,218 & 0,219 & 0,240 & 0,076 & 0,753 \\
\hline 814 & 0,220 & 0,223 & 0,240 & 0,077 & 0,759 \\
\hline 850 & 0,220 & 0,226 & 0,240 & 0,075 & 0,761 \\
\hline 816 & 0,220 & 0,226 & 0,240 & 0,075 & 0,761 \\
\hline 824 & 0,221 & 0,226 & 0,240 & 0,075 & 0,762 \\
\hline 828 & 0,221 & 0,226 & 0,240 & 0,076 & 0,762 \\
\hline 830 & 0,223 & 0,240 & 0,240 & 0,076 & 0,778 \\
\hline 854 & 0,223 & 0,240 & 0,240 & 0,076 & 0,778 \\
\hline 852 & 0,226 & 0,247 & 0,240 & 0,072 & 0,784 \\
\hline 862 & 0,228 & 0,245 & 0,240 & 0,072 & 0,785 \\
\hline 836 & 0,228 & 0,245 & 0,240 & 0,072 & 0,785 \\
\hline 840 & 0,228 & 0,245 & 0,240 & 0,072 & 0,785 \\
\hline 846 & 0,228 & 0,245 & 0,240 & 0,072 & 0,785 \\
\hline 848 & 0,228 & 0,245 & 0,240 & 0,072 & 0,785 \\
\hline 834 & 0,228 & 0,247 & 0,240 & 0,072 & 0,786 \\
\hline 842 & 0,228 & 0,247 & 0,240 & 0,072 & 0,786 \\
\hline 860 & 0,228 & 0,247 & 0,240 & 0,072 & 0,786 \\
\hline 844 & 0,228 & 0,247 & 0,240 & 0,072 & 0,786 \\
\hline 858 & 0,227 & 0,248 & 0,240 & 0,072 & 0,787 \\
\hline 888 & 0,229 & 0,247 & 0,240 & 0,072 & 0,788 \\
\hline 832 & 0,227 & 0,250 & 0,240 & 0,072 & 0,788 \\
\hline 890 & 0,250 & 0,250 & 0,250 & 0,250 & 1,000 \\
\hline
\end{tabular}

Fonte: Autor.

Figura 20 - Sistema IEEE 34 barras, com barras agrupadas de acordo com os valores de IMP

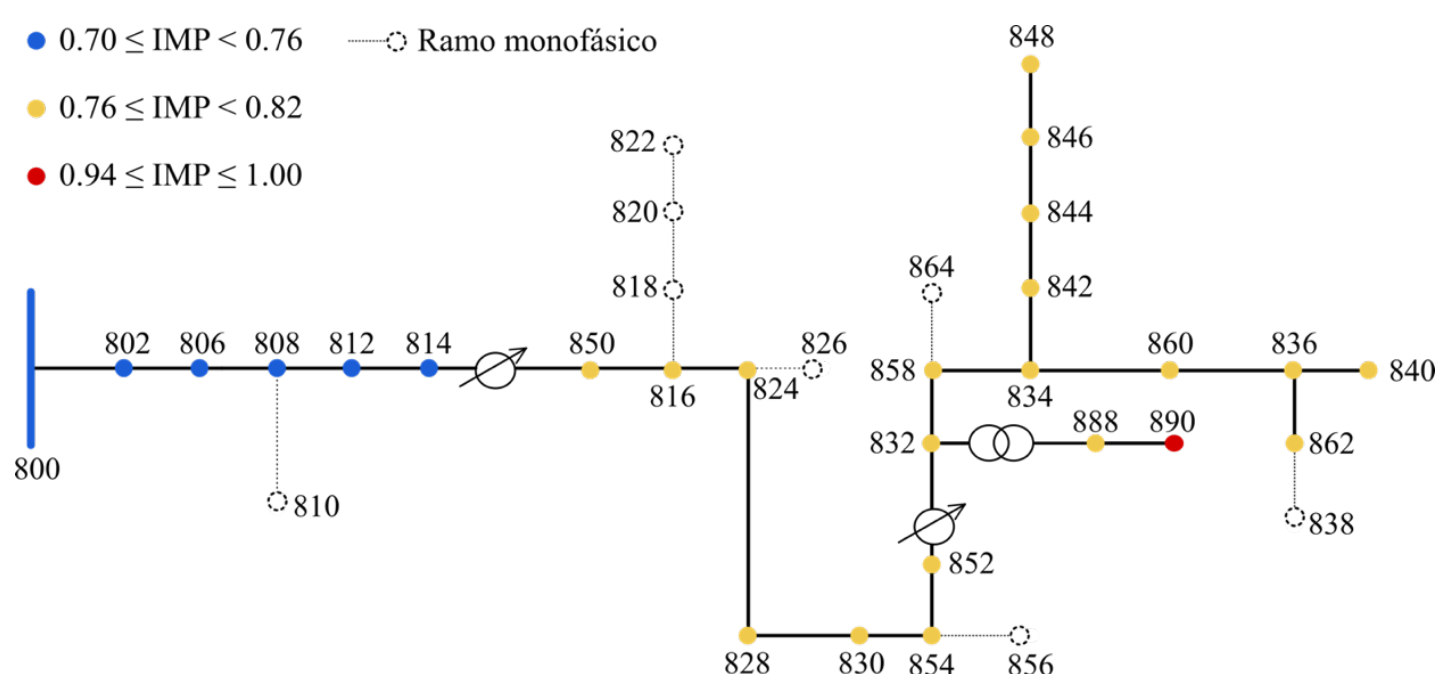

Fonte: Autor. 
Com a finalidade de se estudar a sensibilidade das alocações do SAET com relação aos pesos do índice IMP, vários cenários foram analisados. Cada um destes é caracterizado por diferentes combinações entre os pesos que compõem o IMP, cuja formulação pode ser vista na Eq. (5). Os cenários considerados são apresentados na Tabela 14.

Tabela 14 - Cenários de pesos para cálculo do IMP

\begin{tabular}{cccccccc} 
Pesos & Cenário & Cenário & Cenário & Cenário & Cenário & Cenário & Cenário \\
& $\mathbf{1}$ & $\mathbf{2}$ & $\mathbf{3}$ & $\mathbf{4}$ & $\mathbf{5}$ & $\mathbf{6}$ & $\mathbf{7}$ \\
\hline P1 & 0,25 & 0,1 & 0,4 & 0,25 & 0,25 & 0,5 & 0,2 \\
P2 & 0,25 & 0,4 & 0,1 & 0,25 & 0,25 & 0,2 & 0,5 \\
P3 & 0,25 & 0,25 & 0,25 & 0,1 & 0,4 & 0,15 & 0,15 \\
P4 & 0,25 & 0,25 & 0,25 & 0,4 & 0,1 & 0,15 & 0,15 \\
& \multicolumn{7}{c}{ Fonte: Autor. }
\end{tabular}

As alocações do SAET apresentam diferentes valores de IMP para cada cenário. Os desempenhos dessas para cada um desses cenários são expostos na Figura 21. Nesta, as alocações são ordenadas por ordem de desempenho, em que a primeira posição corresponde à alocação mais benéfica ao sistema e a última, à mais prejudicial a operação deste.

Figura 21 - Classificação de alocações do SAET por IMP para diferentes cenários no Sistema IEEE 34 barras

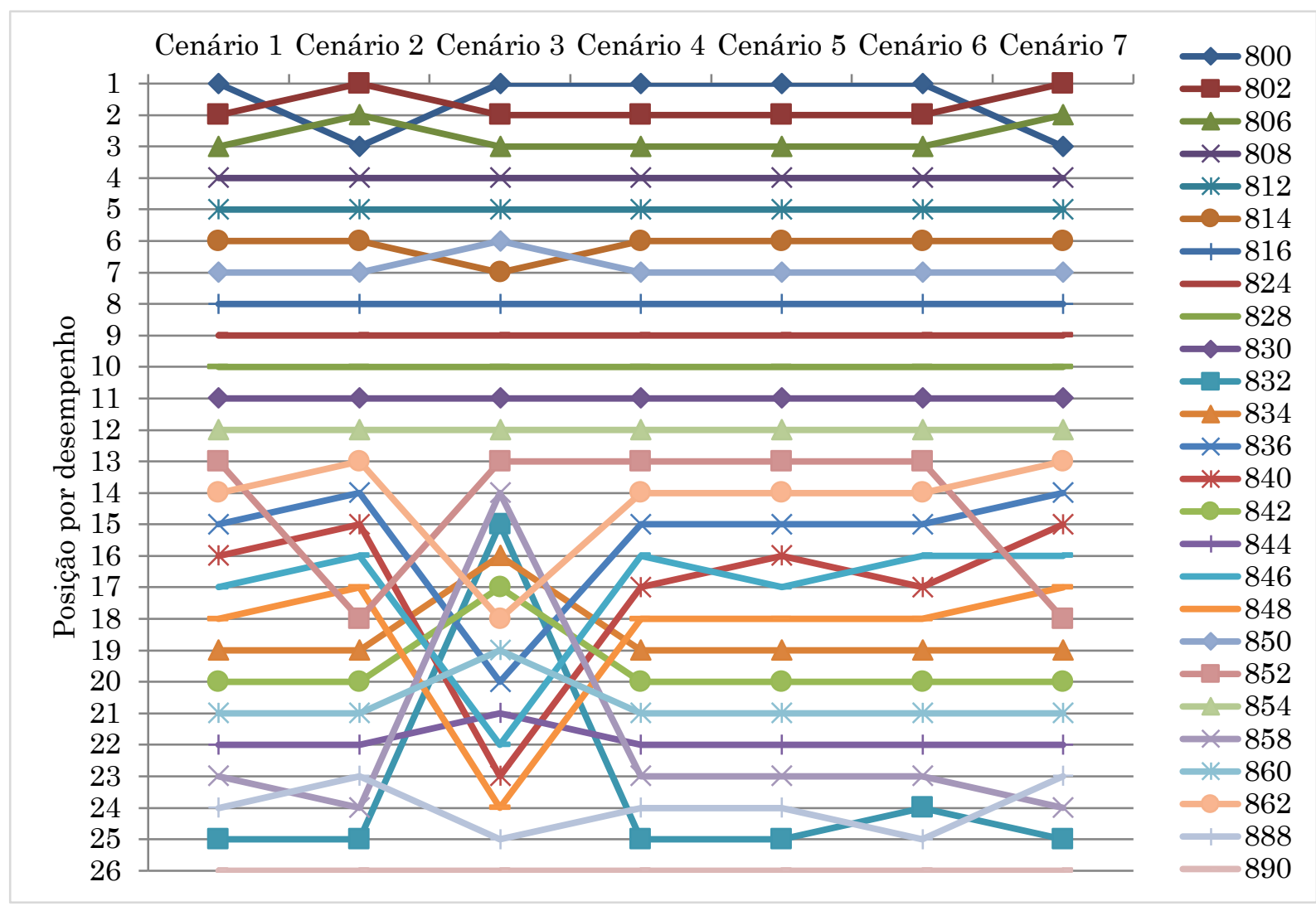

Fonte: Autor. 
A partir da análise da Figura 21, pode-se observar que as barras 800, 802, 806, 808 e 812 são as que sempre figuraram como as cinco melhores alocações para o SAET, independentemente do cenário considerado. Sendo assim, estas alocações se mostraram as mais vantajosas mesmo que importâncias distintas sejam dadas ao IPE, ICH, IMAT e IMIT. Isto demonstra um bom desempenho destas alocações com relação a todos esses índices. O mesmo não se verifica, por exemplo, nas barras 832 e 858. Estas alocações se destacam com relação ao IPE, porém este bom desempenho é comprometido quando se considera o mau desempenho destas mesmas alocações com relação aos demais índices que compõem o IMP.

\section{b. Sistema IEEE 123 barras}

No caso do sistema IEEE 123 barras, constatou-se que também não houve violação de ampacidade em nenhuma alocação. Houve violações de tensão somente nas barras 82, 83 e 610. É importante mencionar apenas as barras 82 e 83 são barras de carga, dentre essas. Além disso, tais violações já estavam presentes desde o CB e foram as mesmas para todas as alocações analisadas. Já as menores e maiores tensões ocorreram nas barras 65 e 83, respectivamente e, por isso, sugere-se que estas sejam evitadas como alocações de um SAET. Adicionalmente, as menores perdas e os menores números de chaveamentos de taps ocorreram para as alocações 149, 150, 1, 7 e 8. Por fim, a alocação de um SAET é estudada no sistema IEEE 123 barras mediante a aplicação do índice IMP. Os pesos deste índice foram considerados iguais a 0,25. A Tabela 15 contém os resultados obtidos.

Observa-se que a tendência constatada no sistema IEEE 34 barras também está presente quando o sistema analisado é o IEEE 123 barras. De acordo com os resultados obtidos, as melhores alocações estão localizadas próximas à subestação (barra 150). Devido principalmente aos bons desempenhos nos índices IPE e ICH, as barras 149, 1, 7, 8, 13 e 152 foram as que se destacaram como melhores alocações, juntamente com a barra 150 . Já as barras mais distantes eletricamente foram as que figuraram entre as alocações com maiores índices e, por isso estão nas últimas posições da Tabela 15 . O resultado da aplicação do IMP para o sistema em questão está à mostra na Figura 22.

Por fim, a sensibilidade das alocações do SAET foi analisada para o sistema IEEE 123 barras. Os cenários utilizados nesta análise foram os mesmos ilustrados na Tabela 14. As dez melhores alocações para cada cenário são apresentadas na Figura 23. A partir da análise desta figura, verifica-se que as alocações nas barras 149, 150, 1, 7 e 8 figuraram entre as cinco melhores alocações em todos os cenários considerados. Isto significa que o desempenho das alocações mencionadas é satisfatório ao se considerar os índices IPE, ICH, 
IMAT e IMIT mesmo com prioridades distintas entre eles, o que torna estas alocações as mais robustas para o sistema em estudo.

Tabela 15 - Índice IMP para taxa de descarga 1 C, sistema IEEE 123 barras

\begin{tabular}{|c|c|c|c|c|c|}
\hline Barra & IPE & ICH & IMAT & IMIT & IMP \\
\hline 149 & 0,216 & 0,217 & 0,249 & 0,246 & 0,928 \\
\hline 150 & 0,216 & 0,217 & 0,249 & 0,246 & 0,928 \\
\hline 1 & 0,222 & 0,220 & 0,249 & 0,246 & 0,938 \\
\hline 7 & 0,223 & 0,227 & 0,249 & 0,246 & 0,945 \\
\hline 8 & 0,223 & 0,234 & 0,249 & 0,247 & 0,952 \\
\hline 13 & 0,223 & 0,240 & 0,249 & 0,247 & 0,959 \\
\hline 152 & 0,223 & 0,240 & 0,249 & 0,247 & 0,959 \\
\hline 52 & 0,224 & 0,240 & 0,249 & 0,247 & 0,960 \\
\hline 57 & 0,223 & 0,240 & 0,249 & 0,247 & 0,960 \\
\hline 53 & 0,224 & 0,240 & 0,249 & 0,247 & 0,960 \\
\hline 44 & 0,224 & 0,240 & 0,249 & 0,247 & 0,960 \\
\hline 54 & 0,224 & 0,240 & 0,249 & 0,247 & 0,960 \\
\hline 47 & 0,224 & 0,240 & 0,249 & 0,247 & 0,961 \\
\hline 55 & 0,224 & 0,240 & 0,249 & 0,247 & 0,961 \\
\hline 48 & 0,224 & 0,240 & 0,249 & 0,247 & 0,961 \\
\hline 56 & 0,224 & 0,240 & 0,249 & 0,247 & 0,961 \\
\hline 49 & 0,225 & 0,240 & 0,249 & 0,247 & 0,961 \\
\hline 101 & 0,227 & 0,237 & 0,249 & 0,248 & 0,961 \\
\hline 50 & 0,225 & 0,240 & 0,249 & 0,247 & 0,961 \\
\hline 60 & 0,225 & 0,240 & 0,249 & 0,248 & 0,962 \\
\hline 160 & 0,225 & 0,240 & 0,249 & 0,248 & 0,962 \\
\hline 51 & 0,225 & 0,240 & 0,249 & 0,247 & 0,962 \\
\hline 61 & 0,225 & 0,240 & 0,249 & 0,248 & 0,962 \\
\hline 151 & 0,226 & 0,240 & 0,249 & 0,248 & 0,963 \\
\hline 300 & 0,226 & 0,240 & 0,249 & 0,248 & 0,963 \\
\hline 108 & 0,226 & 0,240 & 0,249 & 0,248 & 0,963 \\
\hline 105 & 0,226 & 0,240 & 0,249 & 0,248 & 0,963 \\
\hline 62 & 0,225 & 0,240 & 0,249 & 0,248 & 0,963 \\
\hline 63 & 0,226 & 0,240 & 0,249 & 0,249 & 0,964 \\
\hline 97 & 0,227 & 0,240 & 0,249 & 0,248 & 0,964 \\
\hline 197 & 0,227 & 0,240 & 0,249 & 0,248 & 0,964 \\
\hline 98 & 0,227 & 0,240 & 0,249 & 0,248 & 0,965 \\
\hline 99 & 0,228 & 0,240 & 0,249 & 0,248 & 0,965 \\
\hline
\end{tabular}

\begin{tabular}{|c|c|c|c|c|c|}
\hline Barra & IPE & ICH & IMAT & IMIT & IMP \\
\hline 64 & 0,228 & 0,240 & 0,249 & 0,249 & 0,966 \\
\hline 18 & 0,224 & 0,247 & 0,249 & 0,247 & 0,967 \\
\hline 135 & 0,224 & 0,247 & 0,249 & 0,247 & 0,967 \\
\hline 21 & 0,224 & 0,247 & 0,249 & 0,247 & 0,967 \\
\hline 35 & 0,224 & 0,247 & 0,249 & 0,247 & 0,967 \\
\hline 40 & 0,224 & 0,247 & 0,249 & 0,247 & 0,967 \\
\hline 23 & 0,224 & 0,247 & 0,249 & 0,247 & 0,967 \\
\hline 42 & 0,224 & 0,247 & 0,249 & 0,247 & 0,967 \\
\hline 65 & 0,229 & 0,240 & 0,249 & 0,250 & 0,969 \\
\hline 66 & 0,230 & 0,240 & 0,249 & 0,250 & 0,970 \\
\hline 450 & 0,229 & 0,243 & 0,249 & 0,248 & 0,970 \\
\hline 25 & 0,225 & 0,250 & 0,249 & 0,247 & 0,971 \\
\hline 28 & 0,225 & 0,250 & 0,249 & 0,247 & 0,971 \\
\hline 67 & 0,227 & 0,247 & 0,249 & 0,248 & 0,971 \\
\hline 29 & 0,225 & 0,250 & 0,249 & 0,247 & 0,971 \\
\hline 72 & 0,227 & 0,247 & 0,249 & 0,248 & 0,971 \\
\hline 76 & 0,228 & 0,247 & 0,249 & 0,248 & 0,971 \\
\hline 30 & 0,225 & 0,250 & 0,249 & 0,247 & 0,972 \\
\hline 250 & 0,226 & 0,250 & 0,249 & 0,247 & 0,972 \\
\hline 77 & 0,228 & 0,247 & 0,249 & 0,248 & 0,972 \\
\hline 86 & 0,228 & 0,247 & 0,249 & 0,248 & 0,972 \\
\hline 100 & 0,228 & 0,247 & 0,249 & 0,248 & 0,972 \\
\hline 78 & 0,225 & 0,250 & 0,249 & 0,248 & 0,973 \\
\hline 79 & 0,225 & 0,250 & 0,249 & 0,248 & 0,973 \\
\hline 87 & 0,226 & 0,250 & 0,249 & 0,248 & 0,973 \\
\hline 80 & 0,226 & 0,250 & 0,250 & 0,248 & 0,973 \\
\hline 89 & 0,226 & 0,250 & 0,249 & 0,248 & 0,973 \\
\hline 81 & 0,226 & 0,250 & 0,250 & 0,248 & 0,974 \\
\hline 91 & 0,226 & 0,250 & 0,249 & 0,248 & 0,974 \\
\hline 93 & 0,227 & 0,250 & 0,249 & 0,248 & 0,974 \\
\hline 82 & 0,226 & 0,250 & 0,250 & 0,248 & 0,974 \\
\hline 95 & 0,227 & 0,250 & 0,249 & 0,248 & 0,974 \\
\hline 83 & 0,226 & 0,250 & 0,250 & 0,248 & 0,974 \\
\hline 610 & 0,250 & 0,250 & 0,249 & 0,248 & 0,997 \\
\hline
\end{tabular}

Fonte: Autor. 
Figura 22 - Sistema IEEE 123 barras, com barras agrupadas de acordo com os valores de IMP $0.925 \leq \mathrm{IMP}<0.950 \bigcirc 0.950 \leq \mathrm{IMP}<0.975 \bigcirc 0.975 \leq \mathrm{IMP} \leq 1 \quad$ Ramo não trifásico

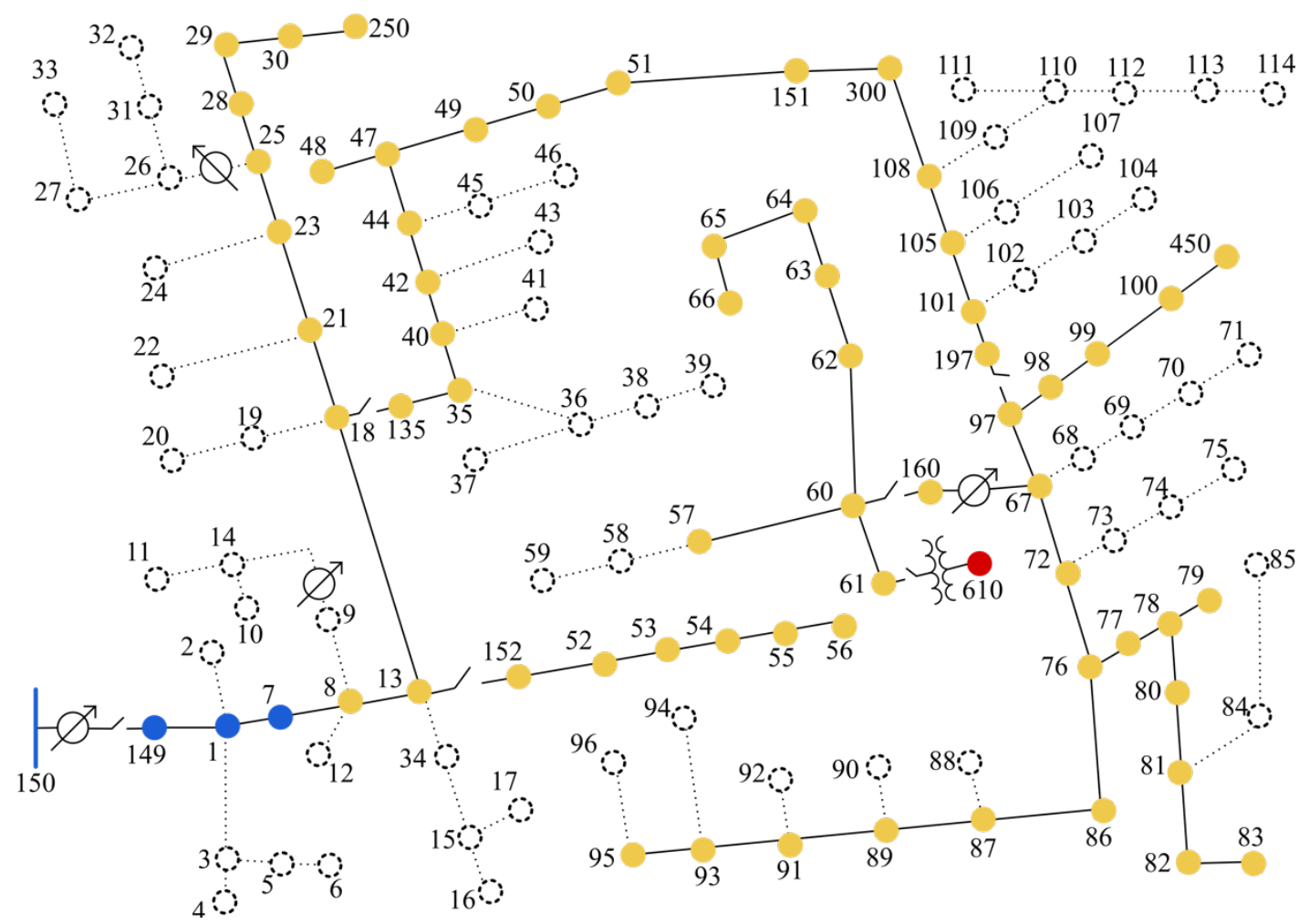

Fonte: Autor.

Figura 23 - Classificação de alocações do SAET por IMP para diferentes cenários no Sistema IEEE 123 barras (10 melhores alocações para cada cenário)

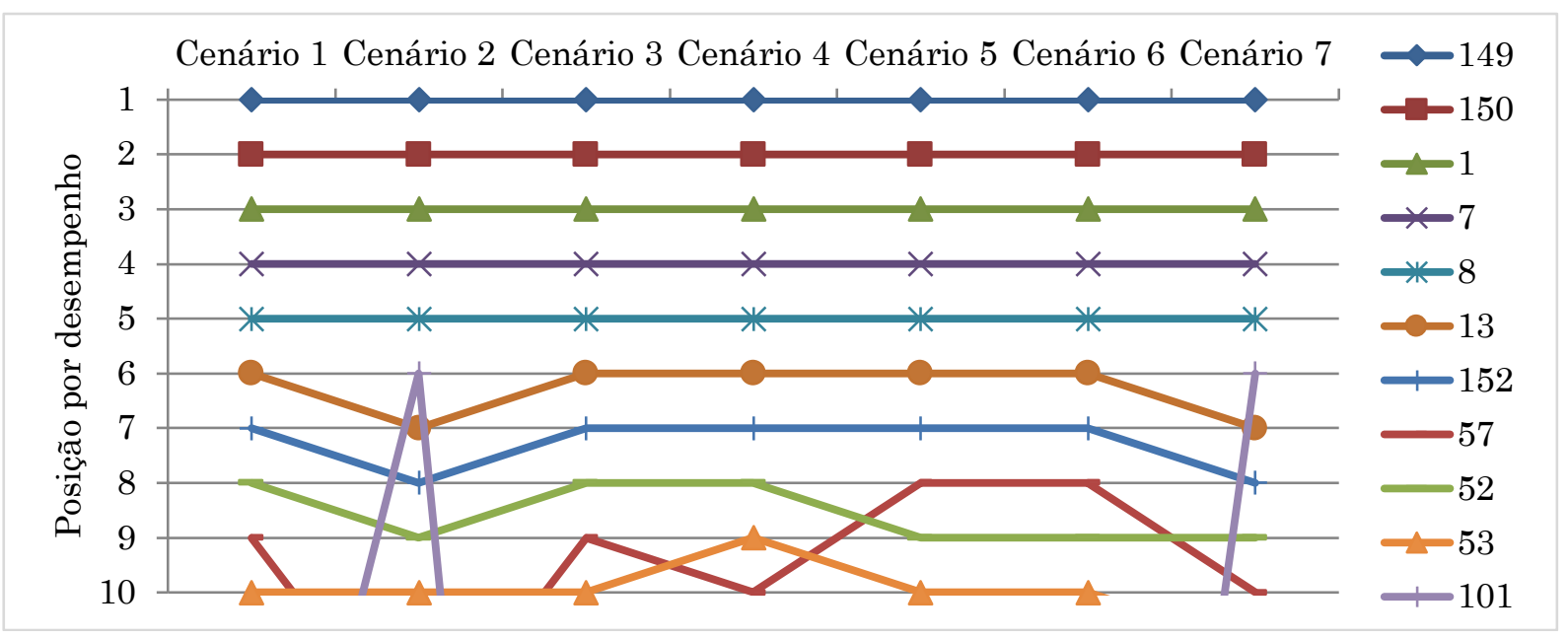

Fonte: Autor. 


\subsubsection{Operação do SAET considerando diferentes taxas de descarga}

Com o intuito de analisar o desempenho do SAET simulado via OpenDSS, as curvas de controle com diferentes taxas de descarga (ilustradas na Figura 13 até a Figura 16) foram implementadas em simulações. O sistema em estudo foi o IEEE 34 barras, descrito na subseção 3.1, com a tensão da subestação ajustada em 1,035 p.u. com a finalidade de evitar violações de tensão para o CB.

Desta forma, o efeito do SAET sob o sistema elétrico bem como seu estado de carga ao longo de 24 horas são ilustrados na Figura 24 até a Figura 27. Vale ressaltar que em um primeiro momento o SAET foi considerado ideal, isto é, possui eficiência de carga e descarga de 100\%, não apresenta perdas por inatividade e, além disso, não opera com reserva de energia.

Inicialmente, a Figura 24 apresenta a potência do sistema em estudo vista pela subestação, isto é, medida na barra 800. Verifica-se que quanto menor a taxa de descarga do SAET, maior o tempo desta operação e menor é a corrente de descarga. Este fenômeno pode ser observado também na Figura 25, em que quanto menor a taxa de descarga, maior o tempo necessário para que o estado de carga do SAET diminua até que a carga deste se esgote.

Figura 24 - Potência na subestação do sistema ao longo do dia, desconsiderando perdas no SAET

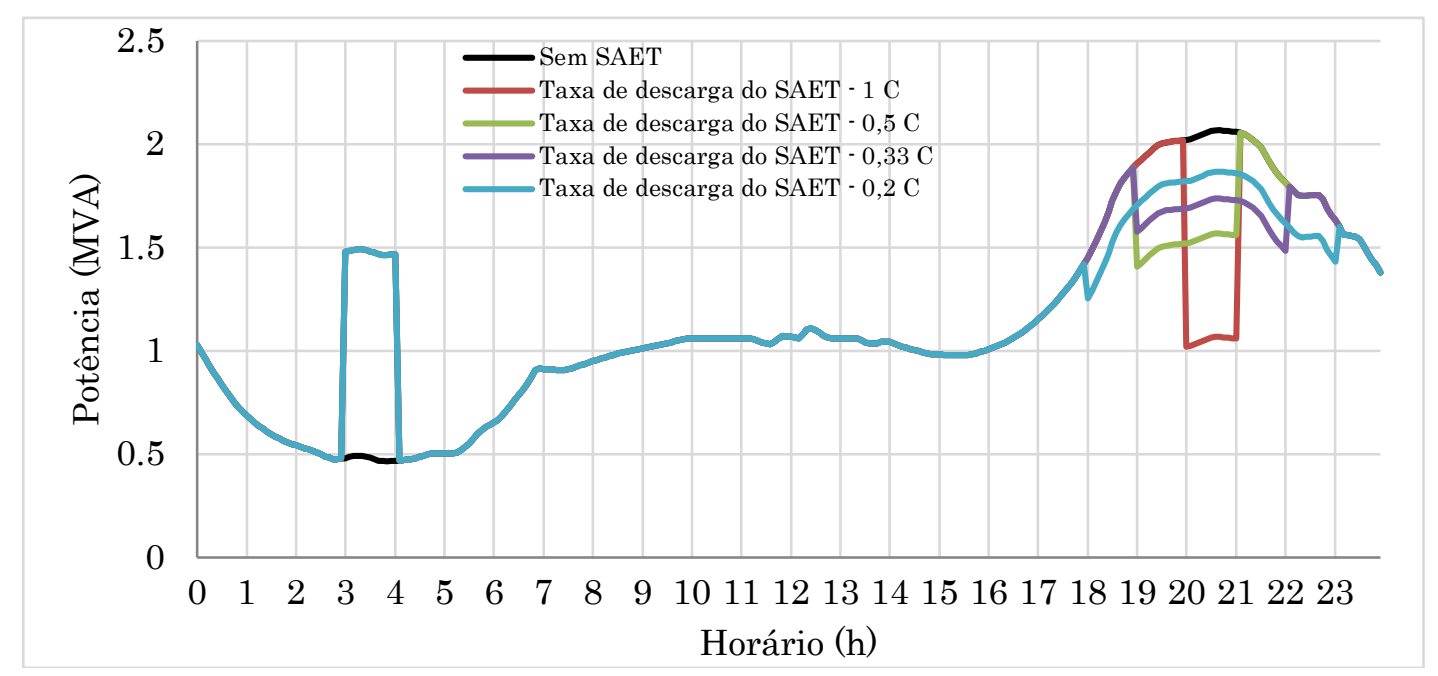

Fonte: Autor. 
Figura 25 - Estado de carga do SAET operando com diferentes taxas de descarga, desconsiderando perdas no SAET

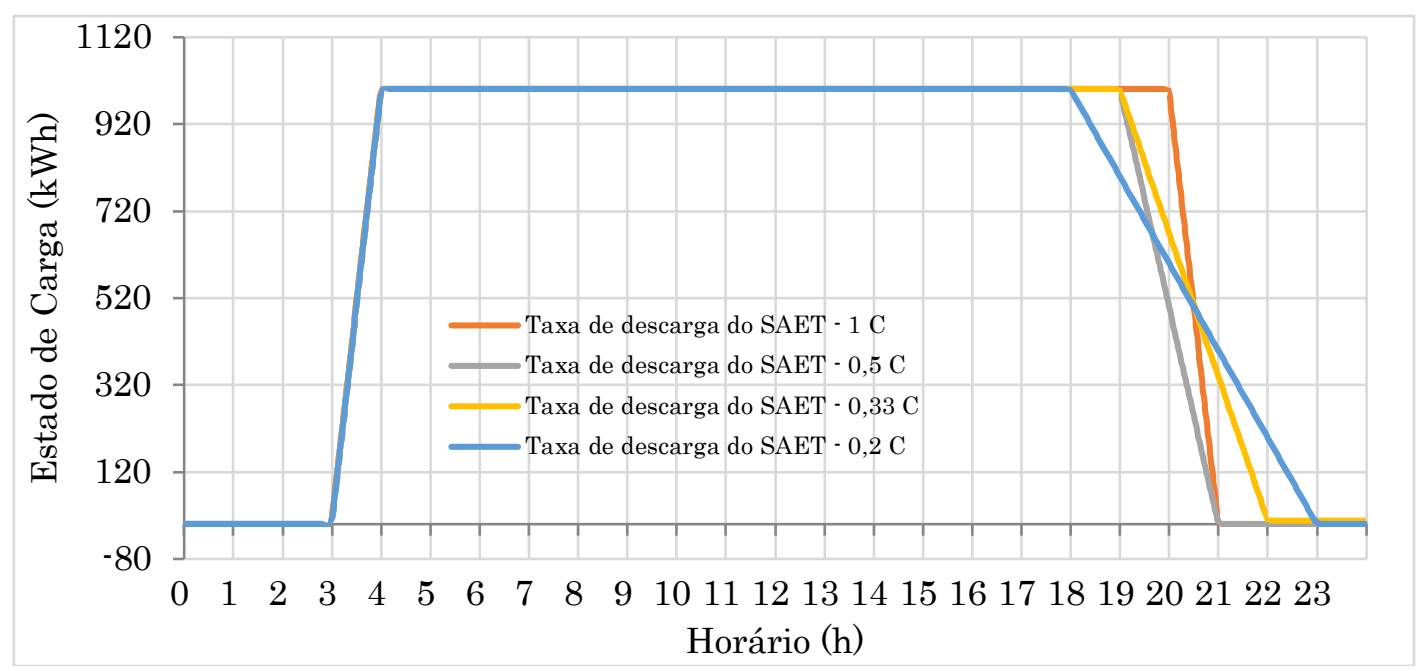

Fonte: Autor.

Em seguida, uma situação que se assemelha mais às condições reais de operação de um SAET é simulada considerando eficiência de carga e descarga de $92,5 \%$, perdas por inatividade de 3\% e reserva de energia de 20\%. A Figura 26 e Figura 27 apresentam os resultados desta operação com relação à potência do sistema vista pela subestação e ao estado de carga do SAET, respectivamente.

Figura 26 - Potência na subestação do sistema ao longo do dia, considerando perdas no SAET

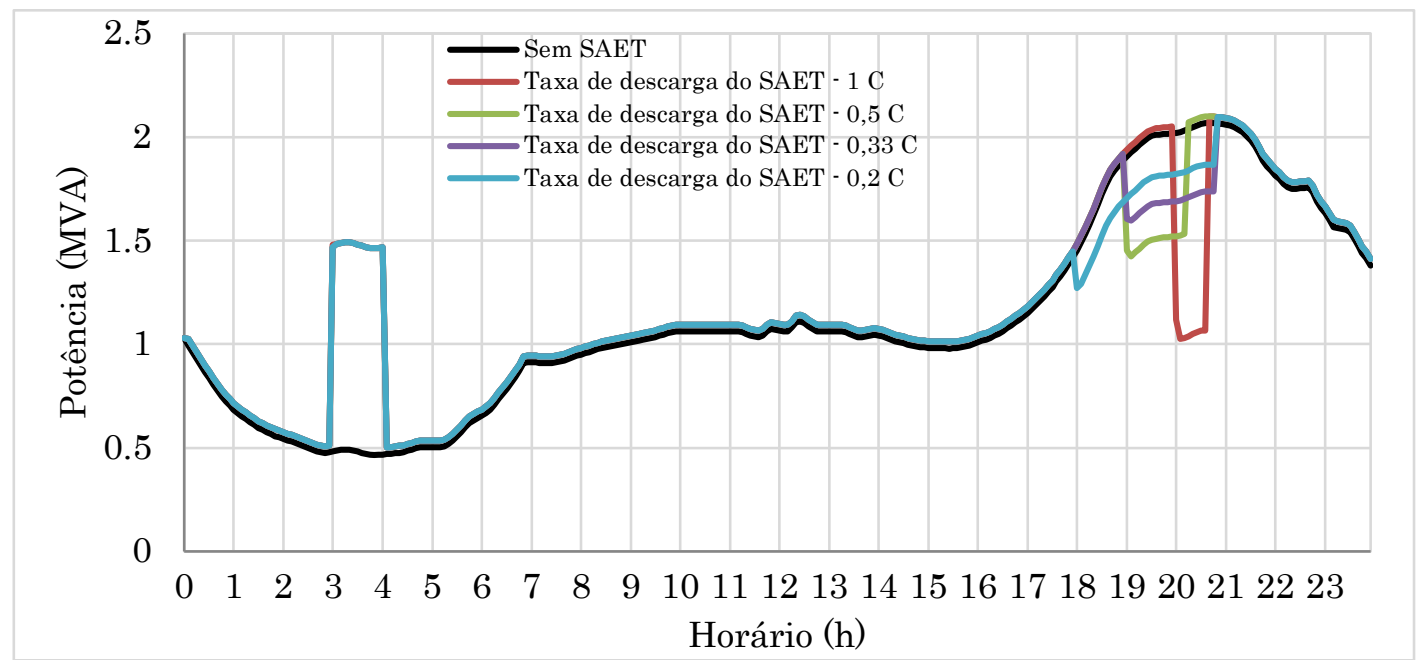

Fonte: Autor. 
Figura 27 - Estado de carga do SAET operando com diferentes taxas de descarga, considerando perdas no SAET

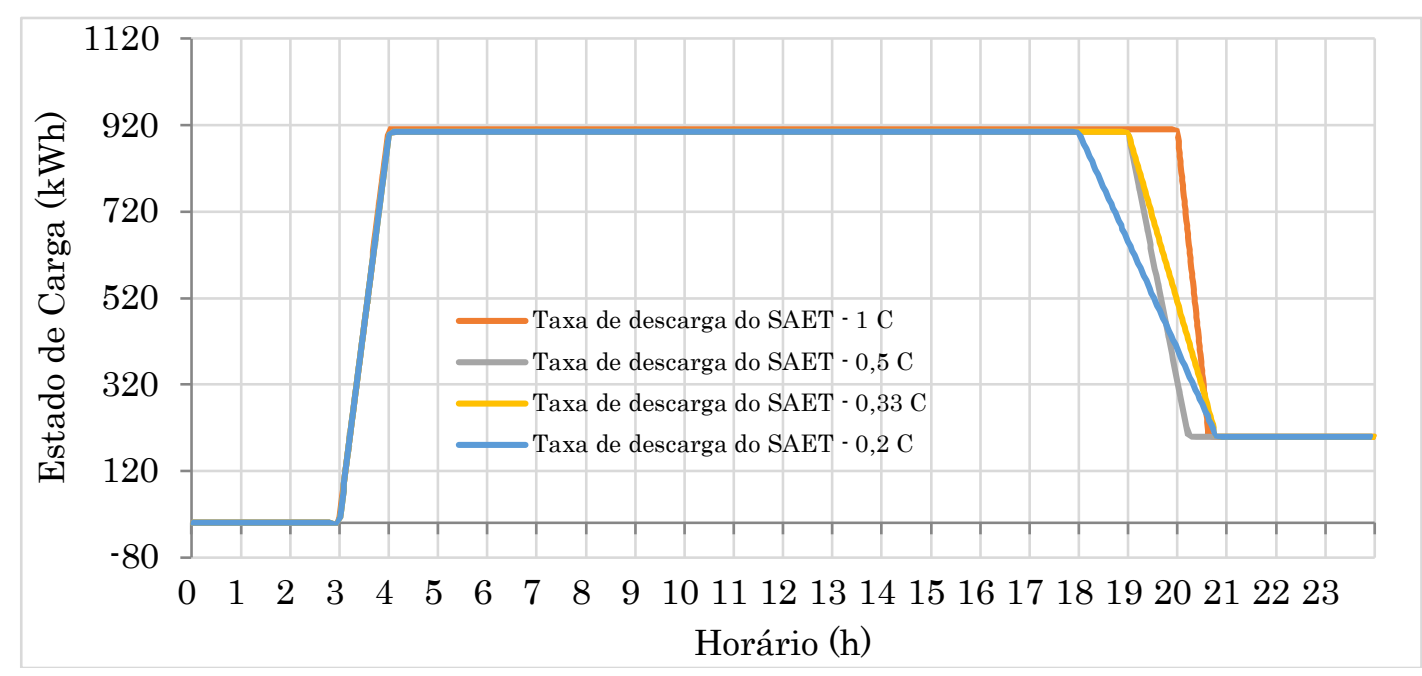

Fonte: Autor.

Observa-se, na Figura 26, que as estratégias com taxas de descargas de 0,5 C, 0,33 $\mathrm{C}$ e 0,2 C não garantem um fornecimento de energia até o instante em que se esperava considerando um cenário ideal (ver Figura 24). Este fenômeno pode ser compreendido a partir da análise da Figura 27, em que é possível observar que devido à perda por inatividade e à eficiência de carga, o maior valor que o estado de carga do SAET atinge é de aproximadamente $920 \mathrm{kWh}$. Desta forma, há uma menor quantidade de energia armazenada no SAET em comparação ao cenário ideal. Isto significa que o SAET atingirá seu valor de reserva mais rapidamente em sua operação de descarga.

Como consequência das perdas intrínsecas à operação do SAET constata-se que a taxa de descarga de 0,2 $\mathrm{C}$ foi a que mais apresentou diferença com relação ao tempo de descarga ideal (Figura 25) e ao tempo de descarga real (Figura 27). De modo geral, quanto menor a taxa de descarga, maior é esta diferença. Sendo assim, pode-se afirmar que a taxa de descarga de $1 \mathrm{C}$ é a que apresenta a menor diferença mencionada, ou seja, é a taxa de descarga em que a operação do SAET é menos afetada pelas suas perdas intrínsecas. Isto se verifica visto que, com esta taxa, a descarga do SAET termina cerca de 12 minutos antes do que o verificado no cenário ideal, diferença esta que é a menor em comparação ao que ocorre considerando as outras taxas analisadas.

Em seguida, as demais taxas de descargas serão implementadas apenas no sistema de testes IEEE 34 barras. 
a. Taxa de descarga $0,5 C$

Considera-se, nesta subseção, que a curva de controle do SAET apresenta taxa de descarga de 0,5 C e os resultados da aplicação dos índices estão apresentados na Tabela 16. Assim como na subseção 4.3.2.1b, os pesos incluídos na formulação do IMP foram considerados todos iguais a 0,25. Os resultados estão apresentados na Tabela 16.

Tabela 16 - Índice IMP para taxa de descarga 0,5 C, sistema IEEE 34 barras

\begin{tabular}{|c|c|c|c|c|c|}
\hline Barra & IPE & ICH & IMAT & IMIT & IMP \\
\hline 800 & 0,217 & 0,196 & 0,243 & 0,075 & 0,732 \\
\hline 802 & 0,220 & 0,195 & 0,243 & 0,075 & 0,733 \\
\hline 806 & 0,220 & 0,195 & 0,243 & 0,075 & 0,733 \\
\hline 808 & 0,221 & 0,205 & 0,243 & 0,076 & 0,745 \\
\hline 812 & 0,223 & 0,215 & 0,243 & 0,077 & 0,758 \\
\hline 816 & 0,225 & 0,220 & 0,243 & 0,077 & 0,764 \\
\hline 850 & 0,225 & 0,220 & 0,243 & 0,077 & 0,764 \\
\hline 814 & 0,224 & 0,220 & 0,243 & 0,077 & 0,764 \\
\hline 824 & 0,225 & 0,220 & 0,243 & 0,076 & 0,765 \\
\hline 828 & 0,225 & 0,220 & 0,243 & 0,076 & 0,765 \\
\hline 830 & 0,227 & 0,233 & 0,243 & 0,076 & 0,780 \\
\hline 854 & 0,227 & 0,233 & 0,243 & 0,076 & 0,780 \\
\hline 852 & 0,230 & 0,243 & 0,243 & 0,076 & 0,793 \\
\hline 836 & 0,231 & 0,245 & 0,243 & 0,078 & 0,798 \\
\hline 846 & 0,231 & 0,245 & 0,244 & 0,078 & 0,798 \\
\hline 862 & 0,232 & 0,245 & 0,243 & 0,078 & 0,798 \\
\hline 840 & 0,232 & 0,245 & 0,243 & 0,078 & 0,798 \\
\hline 848 & 0,232 & 0,245 & 0,244 & 0,078 & 0,798 \\
\hline 888 & 0,232 & 0,247 & 0,243 & 0,076 & 0,799 \\
\hline 842 & 0,231 & 0,247 & 0,243 & 0,078 & 0,800 \\
\hline 834 & 0,231 & 0,247 & 0,243 & 0,078 & 0,800 \\
\hline 844 & 0,231 & 0,247 & 0,243 & 0,078 & 0,800 \\
\hline 860 & 0,231 & 0,247 & 0,243 & 0,078 & 0,800 \\
\hline 858 & 0,231 & 0,248 & 0,243 & 0,078 & 0,801 \\
\hline 832 & 0,230 & 0,250 & 0,243 & 0,079 & 0,803 \\
\hline 890 & 0,250 & 0,243 & 0,250 & 0,250 & 0,993 \\
\hline
\end{tabular}

Observa-se na Tabela 16 que a maior mudança de desempenho de alocação do SAET ocorreu na barra 888, em comparação à sua posição na Tabela 13. Entretanto esta mudança se deve à piora do desempenho de outras alocações quando se trata desta nova taxa de descarga. Acontece que as alocações das barras 842, 834, 844, 860, 858 e 832 se mostraram piores do que a alocação na barra 888 principalmente no que diz respeito ao índice IMIT. Com a taxa de descarga de 0,5 C, as barras mencionadas passaram a 
acarretar maiores quedas de tensão dentre as barras de carga do que a alocação na barra 888. Comparada à barra 888, as barras 858 e 832 também obtiveram um pior ICH, relacionado à atuação de reguladores de tensão.

Já a barra 816 foi uma alocação que apresentou melhora no índice referente ao chaveamento de reguladores de tensão, ICH, com relação à melhor alocação do sistema. Esta foi uma das razões que contribuiu para que esta alocação passasse a ser a sexta melhor do sistema. Vale enfatizar que as cinco melhores alocações considerando o índice IMP permanecem as mesmas observadas para a taxa de descarga de $1 \mathrm{C}$, apresentadas na subseção 4.3.2.1a.

b. Taxa de descarga $0,33 \mathrm{C}$

Do mesmo modo como foi feito na subseção anterior, os pesos do IMP são considerados todos iguais a 0,25. Nesta análise, a taxa de descarga considerada é a de 0,33 C, ilustrada na Figura 15. Os índices obtidos para cada alocação estão apresentados na Tabela 17.

A partir da comparação entre a Tabela 17 e a Tabela 13, percebe-se que houve uma piora no desempenho da alocação na barra 814 com relação às demais alocações. $\mathrm{O}$ seu IMP que antes era de 0,759, com uma diferença de 0,034 para a melhor alocação, passou a ser de 0,782, com uma diferença de 0,032 para a melhor alocação. Entretanto, houve uma diminuição menos brusca nas alocações concorrentes, como é o caso da barra 816 . Esta última barra apresentava um IMP de 0,761, com diferença de 0,036 para a melhor alocação, e passou a um IMP de 0,778, com diferença de 0,028 para a melhor alocação. Esta diferença representa uma maior robustez da alocação para com a diminuição da taxa de descarga do SAET e também foi a razão pela qual as barras 824, 828 e 850 passaram a barras 814 na classificação de melhor alocação. 
Tabela 17 - Índice IMP para taxa de descarga 0,33 C, sistema IEEE 34 barras

\begin{tabular}{|c|c|c|c|c|c|}
\hline Barra & IPE & ICH & IMAT & IMIT & IMP \\
\hline 800 & 0,221 & 0,209 & 0,246 & 0,075 & 0,750 \\
\hline 802 & 0,223 & 0,207 & 0,246 & 0,074 & 0,750 \\
\hline 806 & 0,223 & 0,207 & 0,246 & 0,074 & 0,750 \\
\hline 808 & 0,224 & 0,220 & 0,246 & 0,076 & 0,766 \\
\hline 812 & 0,226 & 0,220 & 0,246 & 0,076 & 0,767 \\
\hline 828 & 0,228 & 0,227 & 0,246 & 0,076 & 0,776 \\
\hline 824 & 0,227 & 0,227 & 0,246 & 0,076 & 0,776 \\
\hline 850 & 0,227 & 0,229 & 0,246 & 0,077 & 0,778 \\
\hline 816 & 0,227 & 0,229 & 0,246 & 0,077 & 0,778 \\
\hline 814 & 0,227 & 0,232 & 0,246 & 0,077 & 0,782 \\
\hline 830 & 0,229 & 0,243 & 0,246 & 0,076 & 0,794 \\
\hline 854 & 0,229 & 0,243 & 0,246 & 0,076 & 0,794 \\
\hline 888 & 0,234 & 0,245 & 0,246 & 0,073 & 0,797 \\
\hline 852 & 0,231 & 0,246 & 0,246 & 0,076 & 0,799 \\
\hline 836 & 0,233 & 0,243 & 0,246 & 0,079 & 0,801 \\
\hline 862 & 0,233 & 0,243 & 0,246 & 0,079 & 0,801 \\
\hline 846 & 0,233 & 0,243 & 0,246 & 0,079 & 0,801 \\
\hline 848 & 0,233 & 0,243 & 0,246 & 0,079 & 0,801 \\
\hline 840 & 0,233 & 0,243 & 0,246 & 0,079 & 0,801 \\
\hline 842 & 0,233 & 0,245 & 0,246 & 0,079 & 0,802 \\
\hline 834 & 0,233 & 0,245 & 0,246 & 0,079 & 0,802 \\
\hline 844 & 0,233 & 0,245 & 0,246 & 0,079 & 0,802 \\
\hline 860 & 0,233 & 0,245 & 0,246 & 0,079 & 0,802 \\
\hline 858 & 0,232 & 0,246 & 0,246 & 0,079 & 0,804 \\
\hline 832 & 0,232 & 0,248 & 0,246 & 0,079 & 0,805 \\
\hline 890 & 0,250 & 0,250 & 0,250 & 0,250 & 1,000 \\
\hline
\end{tabular}

c. Taxa de descarga $0,2 C$

A última curva de controle do SAET considerada neste estudo é a da Figura 16, com taxa de descarga de 0,2 C. Os valores dos índices para cada alocação do SAET são apresentados na Tabela 18.

Ao analisar a Tabela 18, percebe-se que alocações como as barras 824 e 828 continuaram a melhorar suas classificações, de modo a ultrapassarem as alocações 808 e 812 que inicialmente ocupavam a quarta e quinta melhores posições, respectivamente (Tabela 13). Por outro lado, destaca-se a barra 862 como uma alocação que passou a apresentar um pior desempenho com relação ao que se verificava com a taxa de descarga de 1 C. A principal causa desta piora no índice IMP e em sua classificação foi o índice IPE, que passou a se aproximar mais do seu respectivo máximo entre as alocações (barra 890). 
Por fim, observa-se que a barra 808 passou a ter um ICH bastante superior ao da barra 800 mesmo estando próxima à esta. O que foi a principal causa de sua queda de classificação baseada no IMP.

Tabela 18 - Índice IMP para taxa de descarga 0,2 C, sistema IEEE 34 barras

\begin{tabular}{|c|c|c|c|c|c|}
\hline Barra & IPE & $\mathrm{ICH}$ & IMAT & IMIT & IMP \\
\hline 800 & 0,221 & 0,215 & 0,249 & 0,075 & 0,761 \\
\hline 806 & 0,224 & 0,213 & 0,249 & 0,074 & 0,761 \\
\hline 802 & 0,224 & 0,213 & 0,249 & 0,074 & 0,761 \\
\hline 824 & 0,229 & 0,222 & 0,249 & 0,076 & 0,777 \\
\hline 828 & 0,229 & 0,222 & 0,249 & 0,076 & 0,777 \\
\hline 812 & 0,227 & 0,226 & 0,249 & 0,076 & 0,778 \\
\hline 814 & 0,228 & 0,228 & 0,249 & 0,077 & 0,782 \\
\hline 808 & 0,225 & 0,233 & 0,249 & 0,076 & 0,784 \\
\hline 830 & 0,230 & 0,232 & 0,249 & 0,075 & 0,787 \\
\hline 854 & 0,230 & 0,232 & 0,249 & 0,076 & 0,787 \\
\hline 850 & 0,228 & 0,233 & 0,249 & 0,077 & 0,788 \\
\hline 816 & 0,228 & 0,233 & 0,249 & 0,077 & 0,788 \\
\hline 852 & 0,232 & 0,244 & 0,249 & 0,073 & 0,799 \\
\hline 888 & 0,235 & 0,246 & 0,249 & 0,069 & 0,800 \\
\hline 848 & 0,234 & 0,244 & 0,249 & 0,073 & 0,801 \\
\hline 846 & 0,234 & 0,244 & 0,249 & 0,073 & 0,801 \\
\hline 836 & 0,234 & 0,244 & 0,249 & 0,073 & 0,801 \\
\hline 840 & 0,234 & 0,244 & 0,249 & 0,073 & 0,801 \\
\hline 862 & 0,234 & 0,244 & 0,249 & 0,073 & 0,801 \\
\hline 844 & 0,234 & 0,246 & 0,249 & 0,073 & 0,803 \\
\hline 842 & 0,234 & 0,246 & 0,249 & 0,073 & 0,803 \\
\hline 834 & 0,234 & 0,246 & 0,249 & 0,073 & 0,803 \\
\hline 860 & 0,234 & 0,246 & 0,249 & 0,073 & 0,803 \\
\hline 858 & 0,234 & 0,248 & 0,249 & 0,073 & 0,804 \\
\hline 832 & 0,233 & 0,250 & 0,249 & 0,073 & 0,806 \\
\hline 890 & 0,250 & 0,248 & 0,250 & 0,250 & 0,998 \\
\hline
\end{tabular}

\subsubsection{Comparação entre taxas de descarga}

Os resultados para cada taxa de descarga considerada são ilustrados na Figura 28, com a finalidade de auxiliar a visualização e o entendimento dos efeitos da variação da taxa de descarga do SAET sobre o desempenho das suas alocações no índice IMP.

A partir da análise da Figura 28, pode-se afirmar que as cinco melhores alocações para a maioria das taxas de descarga analisadas são as barras 800, 802, 806, 808 e 812 . Estas alocações são capazes de conferir o melhor benefício para o sistema quando se considera a operação do SAET. Destaca-se ainda que as barras 824 e 828 ganham posições 
quando a taxa de descarga considerada foi menor do que 0,5 C. Por fim, verifica-se que outras variações ocorrem ao se considerar diferentes taxas de descarga para o SAET. Entretanto a maioria destas acontece em alocações que não figuram entre as cinco melhores.

Figura 28 - Classificação de alocações do SAET por IMP para diferentes taxas de descarga, sistema IEEE 34 barras

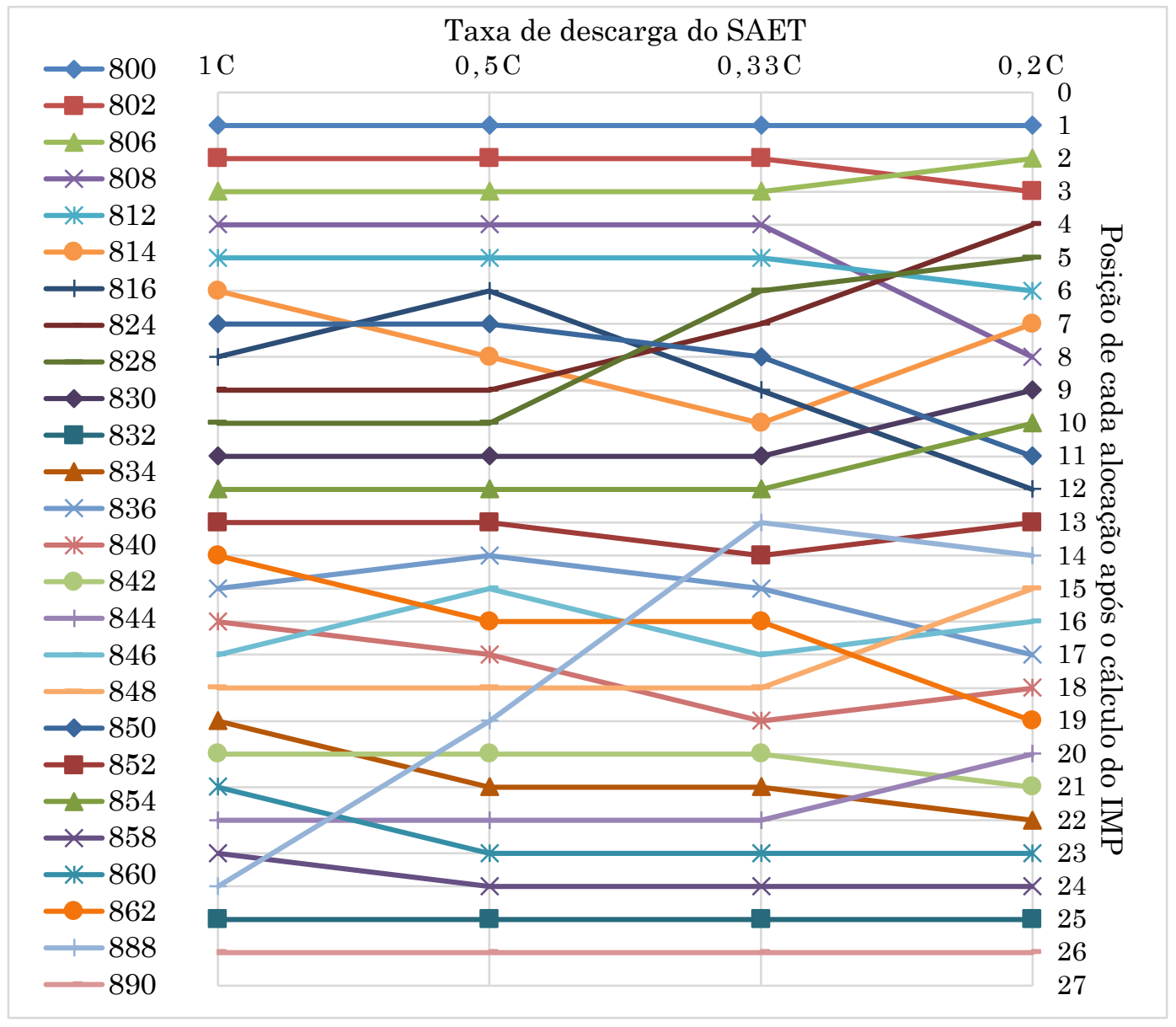

Fonte: Autor.

\subsection{Considerações Finais do Capítulo}

Ao fim deste capítulo, ressalta-se que a operação no SAET no sistema IEEE 34 barras resultou em nenhuma violação nos limites de ampacidade das linhas. Já a ocorrência de violações nos limites de tensão se limitou à barra 890, justamente quando esta é a barra em que o equipamento em estudo está alocado e nos mesmos horários das suas operações de carga e descarga. Com relação ao número de chaveamento de taps dos reguladores de tensão, a tendência observada foi de que as melhores alocações são as mais próximas à 
subestação do sistema. A mesma tendência ocorre quando as perdas são analisadas. Por fim, constatou-se que as barras 830 e 848 são as barras de carga que registraram o menor e maior valor de tensão ao longo do período considerado em simulação, de modo que devem ser evitadas como possíveis alocações para o SAET.

No caso do sistema IEEE 123 barras, constatou-se que as violações de tensão se limitaram às barras 82, 83 e 610 para todas as alocações analisadas. Ressalta-se que as barras 65 e 83 devem ser evitadas para alocação de um SAET, devido as tensões registradas nessas barras. Além disso, constatou-se que o bom desempenho com relação às perdas e ao chaveamento contribuiu para que as barras 149, 150, 1, 7 e 8 apresentassem melhores valores de IMP.

Com relação ao índice IMP, é possível afirmar que os índices incluídos na sua formulação conferem a este a capacidade de mensurar os impactos da operação de um SAET no sistema elétrico no que diz respeito às perdas de energia, ao chaveamento de taps de reguladores de tensão, e às variações de tensão das barras de carga do sistema em estudo. Esta composição garante ao IMP a possibilidade de ser ajustável em sua formulação, de modo a ser personalizável para cada aplicação. Esta característica é apresentada na subseção 4.3.2.1a.

Além disso, verifica-se que o índice IMP é uma ferramenta útil na classificação das melhores alocações para um SAET em um sistema elétrico. Nota-se que a interpretação de seus resultados demanda atenção, uma vez que o IMP é composto de quatro índices distintos. Por este motivo, é possível constatar as razões para uma mudança na classificação de uma alocação quando parâmetros de operação do SAET são variados. Na subseção 4.3.2.2, o parâmetro variado foi a taxa de descarga do SAET. Dentre as razões para as mudanças na classificação das alocações do SAET, pode-se mencionar uma real melhora nos impactos de determinada alocação. Porém, houve situações em que uma alocação se tornou mais vantajosa pelo fato de ter sido menos afetada por efeitos nocivos da variação do parâmetro mencionado. Pode-se afirmar que, neste caso, a melhor alocação é justamente a que se mostrou mais robusta em comparação às demais.

Por fim, a tendência observada por meio do IMP em ambos os sistemas simulados foi de que as melhores alocações para o SAET se localizaram próximas às subestações. Esta tendência se manteve verdadeira para o sistema IEEE 34 barras mesmo considerando as variações nos pesos do IMP e na taxa de descarga do SAET, como pode ser visto nas subseções 4.3.2.1a e 4.3.2.2, respectivamente. 


\section{Capítulo 5}

\section{Método de Análise via Sensibilidades Estendido para Sistemas Trifásicos}

Conforme visto no capítulo anterior, o estudo de impactos da operação do SAET em todas as possíveis alocações do sistema elétrico analisado demandou inúmeros cálculos de fluxo de carga. Mais especificamente, o estudo de cada alocação exigiu 2880 fluxos de cargas, resultando em um total de 74.880 fluxos de carga para o estudo de 26 alocações. Sendo assim, fica evidente a necessidade de se desenvolver uma ferramenta mais prática capaz de indicar a melhor alocação para o equipamento mencionado. Com este objetivo, será utilizado um método baseado nas sensibilidades de tensão nodal com relação à injeção de potência ativa.

Neste capítulo, inicialmente o Método de Análise via Sensibilidades, será brevemente apresentado. Em seguida, sua formulação será estendida para sistemas trifásicos. Por fim, o método desenvolvido será aplicado para o estudo da alocação de um SAET e na determinação de sua máxima injeção de potência.

\subsection{Método de Análise via Sensibilidades}

Uma vez que métodos analíticos facilitam o entendimento do problema e permitem sua investigação de forma mais rápida e simples (AYRES, 2010), o autor mencionado propôs um método desta natureza para o estudo da máxima penetração de GD em redes de distribuição. Este método se baseia no uso de sensibilidades das tensões nodais com relação às injeções de potência ativa e reativa no sistema. Estas sensibilidades podem ser encontradas a partir das matrizes Jacobianas reduzidas obtidas do modelo estático de um sistema de potência linearizado em torno de um ponto de equilíbrio $\left(V^{o}, \theta^{o}\right)$, dado por: 


$$
\left[\begin{array}{l}
\Delta P \\
\Delta Q
\end{array}\right]=\underbrace{\left[\begin{array}{ll}
J_{P \theta} & J_{P V} \\
J_{Q \theta} & J_{Q V}
\end{array}\right]}_{J} \cdot\left[\begin{array}{l}
\Delta \theta \\
\Delta V
\end{array}\right]
$$

Sendo:

$\Delta \theta$ - Vetor de variação incremental do ângulo da tensão nodal;

$\Delta V$ - Vetor de variação incremental do módulo da tensão nodal;

$\Delta P$ - Vetor de variação incremental da potência ativa nodal;

$\Delta Q$ - Vetor de variação incremental da potência reativa nodal;

$J_{P \theta}, J_{P V}, J_{Q \theta}$ e $J_{Q V}$ - submatrizes da matriz Jacobiana $J$ do sistema.

Desta forma, constata-se que na formulação de NR os elementos das submatrizes $J_{P \theta}, J_{P V}, J_{Q \theta}$ e $J_{Q V}$ constituem as sensibilidades do módulo e ângulo das tensões nodais com relação a variação de injeção de potências ativas e reativas.

Em seguida, com a finalidade de se obter a variação do módulo da tensão devida à injeção de potência ativa no sistema, supõe-se que $\Delta Q=0$ na Eq. (6). Desta forma, $\Delta P$ pode ser calculado como:

$$
\Delta P=\left(J_{P V}-J_{P \theta} J_{Q \theta}^{-1} J_{Q V}\right) \Delta V=J_{R P V} \Delta V
$$

E então $\Delta V$ pode ser escrito da seguinte forma:

$$
\Delta V=J_{R P V}^{-1} \Delta P
$$

Sendo a matriz $J_{R P V}$ responsável por relacionar a variação do módulo da tensão nodal com a injeção de potência ativa nodal.

Destaca-se que esta formulação só pode ser aplicada caso todas as barras estejam modeladas como barras $\mathrm{PQ}$, situação que ocorre para a maioria dos sistemas de distribuição visto que nestes geralmente a subestação é a única responsável pelo controle da tensão (barra de referência - barra $V \theta$ ).

É importante ressaltar que a Eq. (8) pode ser escrita e usada de duas formas. Estas formas serão apresentadas considerando que um gerador corresponde a uma injeção de potência no sistema de distribuição. São elas: 


\section{Representação vetorial}

Neste caso, $\Delta P$ é escrito como vetor de dimensão $n$, sendo $n$ o número de barras do sistema. Já os valores não nulos de $\Delta P$ correspondem às injeções de potência nas barras em que estas ocorrem. Portanto, o $\Delta V$ obtido também será um vetor de dimensão $n$, que corresponde às variações no módulo das tensões que resultam das injeções de potência consideradas em $\Delta P$. Essa representação permite o estudo do impacto de múltiplos geradores instalados simultaneamente.

\section{Representação matricial}

Nesta formulação, $\Delta P$ é escrito como matriz diagonal de dimensão $n x n$, em que cada elemento não nulo (valor constante) representa a injeção de potência de um mesmo gerador em alocações distintas. Como consequência, $\Delta V$ é uma matriz de dimensões $n \times n$ em que cada coluna corresponde a variação do perfil de tensão relacionada com cada opção de alocação do gerador em análise. Sendo assim, esta representação permite a avaliação do impacto de um mesmo gerador em várias possíveis alocações de uma única vez.

A mesma análise feita para injeções de potência ativa pode ser aplicada para potência reativa. Para tanto, considera-se $\Delta P=0$ na Eq. (6) de modo que $\Delta Q$ pode ser calculado da seguinte forma:

$$
\Delta Q=\left(J_{Q V}-J_{Q \theta} J_{P \theta}^{-1} J_{P V}\right) \Delta V=J_{R Q V} \Delta V
$$

Neste caso, $\Delta V$ pode ser escrito como:

$$
\Delta V=J_{R Q V}^{-1} \Delta Q
$$

Sendo $J_{R Q V}$ a matriz responsável por relacionar a variação do módulo da tensão nodal com a injeção de potência reativa nodal. As representações vetorial e matricial também são aplicáveis nesta análise.

Considerando $P_{G D}$ como sendo um vetor ou uma matriz diagonal cujos elementos nãonulos representam as injeções de potência ativa nodais, adotando a representação vetorial ou matricial, respectivamente, e $Q_{G D}$ como sendo um vetor ou uma matriz diagonal cujos elementos não-nulos representam as injeções de potência reativa nodais, adotando a representação vetorial ou matricial, respectivamente, a variação do perfil de tensão de um sistema em estudo pode ser calculada pela Eq. (11). 


$$
\Delta V_{\left(P_{G D}\right)}=J_{R P V}^{-1} P_{G D} \quad \text { e } \quad \Delta V_{\left(Q_{G D}\right)}=J_{R Q V}^{-1} Q_{G D}
$$

Em que $\Delta V_{\left(P_{G D}\right)}$ e $\Delta V_{\left(Q_{G D}\right)}$ são vetores ou matrizes, a depender da representação adotada, que indicam a variação do perfil de tensão de um sistema devida a injeções de potências ativa e reativa, respectivamente, com relação ao caso base.

Utilizando-se do princípio da superposição é possível estimar a variação do perfil de tensão de um sistema causada pela instalação de um ou mais geradores com fatores de potência distintos. $O$ perfil de tensão resultante após a instalação de uma um mais injeções de potências é dado pela Eq. (12).

$$
V=V^{0}+\Delta V_{\left(P_{G D}\right)}+\Delta V_{\left(Q_{G D}\right)}
$$

Sendo:

$V^{0}$ - Vetor de dimensão $n$ com o perfil de tensão do caso base ou matriz de dimensão $n x n$ cujas colunas contêm o perfil de tensão do caso base, a depender da representação escolhida (vetorial ou matricial, respectivamente);

$V$ - Vetor de dimensão $n$ com o perfil de tensão resultante das injeções de potência consideradas ou matriz de dimensão $n \times n$ cujas colunas contêm o perfil de tensão resultante para cada alocação de injeção de potência em estudo, a depender da representação escolhida (vetorial ou matricial, respectivamente).

\subsection{Método de Análise via Sensibilidades Estendido para Sistemas Trifásicos}

Nesta subseção, a formulação do Método de Análise via Sensibilidades será estendida para sistemas trifásicos. O método proposto será denominado resumidamente de Método de Sensibilidades, de agora em diante. Inicialmente, a Eq. (6) aplicada a um sistema trifasico é apresentada da seguinte maneira, com suas devidas dimensões:

$$
\left[\begin{array}{l}
\Delta P \\
\Delta Q
\end{array}\right]_{6 n b \times 1}=\left[\begin{array}{ll}
J_{P \theta} & J_{P V} \\
J_{Q \theta} & J_{Q V}
\end{array}\right]_{6 n b \times 6 n b} \cdot\left[\begin{array}{c}
\Delta \theta \\
\Delta V
\end{array}\right]_{6 n b \times 1}
$$

Já as submatrizes da matriz Jacobiana $J$ do sistema para barras trifásicas são de dimensões $3 n b \times 3 n b$, sendo $n b$ o número de barras do sistema modelado, visto que a 
magnitude e o ângulo das tensões referente às três fases devem ser calculados. Para melhor compreensão, a submatriz $J_{P V}$ trifásica da Jacobiana está ilustrada a seguir:

$$
\left[\begin{array}{lllll}
\frac{\partial P_{1}^{a}}{\partial V_{1}^{a}} \frac{\partial P_{1}^{a}}{\partial V_{1}^{b}} \frac{\partial P_{1}^{a}}{\partial V_{1}^{c}} & \\
\frac{\partial P_{1}^{b}}{\partial V_{1}^{a}} \frac{\partial P_{1}^{b}}{\partial V_{1}^{b}} \frac{\partial P_{1}^{b}}{\partial V_{1}^{c}} & \\
\frac{\partial P_{1}^{c}}{\partial V_{1}^{a}} \frac{\partial P_{1}^{c}}{\partial V_{1}^{b}} \frac{\partial P_{1}^{c}}{\partial V_{1}^{c}} & \\
& \ddots & \\
& & \frac{\partial P_{n b}^{a}}{\partial V_{n b}^{a}} \frac{\partial P_{n b}^{a}}{\partial V_{n b}^{b}} & \frac{\partial P_{n b}^{a}}{\partial V_{n b}^{c}} \\
& \frac{\partial P_{n b}^{b}}{\partial V_{n b}^{a}} \frac{\partial P_{n b}^{b}}{\partial V_{n b}^{b}} & \frac{\partial P_{n b}^{b}}{\partial V_{n b}^{c}} \\
& \frac{\partial P_{n b}^{c}}{\partial V_{n b}^{a}} \frac{\partial P_{n b}^{c}}{\partial V_{n b}^{b}} & \frac{\partial P_{n b}^{c}}{\partial V_{n b}^{c}}
\end{array}\right]_{3 n b \times 3 n b}
$$

É importante mencionar que para efeito de cálculos as barras monofásicas ou bifásicas devem ser consideradas como barras trifásicas cujas fases inexistentes são preenchidas com valor nulo. Entretanto, tais fases devem ser retiradas da Jacobiana, de suas submatrizes e de demais variáveis sempre que essas forem ser utilizadas em operações de inversão. Nestes casos, os cálculos devem também desconsiderar as fases referentes à barra de referência de tensão do sistema.

Considerando as observações mencionadas no parágrafo anterior, o método proposto segue a formulação indicada na subseção 5.1. Como se trata de um problema trifásico, as dimensões envolvidas nas duas formas de representação da Eq. (8) serão apresentadas.

\section{Representação vetorial}

$$
\Delta V_{3 n b \times 1}=J_{R P V_{3 n b \times 3 n b}}^{-1} \Delta P_{3 n b \times 1}
$$

\section{Sendo:}

$\Delta P$ - Vetor em que os elementos não nulos correspondem às injeções de potência nas barras em que estas ocorrem.

$\Delta V$ - Vetor em que corresponde à variação do perfil de tensão relacionada com a opção de alocação do SAET em análise.

$J_{R P V}^{-1}$ - Matriz responsável por relacionar a variação do módulo da tensão nodal com a injeção de potência ativa nodal. 


\section{Representação matricial}

$$
\Delta V_{3 n b \times 3 n b}=J_{R P V_{3 n b} \times 3 n b}^{-1} \Delta P_{3 n b \times 3 n b}
$$

Sendo:

$\Delta P$ - Matriz diagonal em que cada elemento não nulo (valor constante) representa a injeção de potência de um mesmo SAET em alocações distintas.

$\Delta V$ - Matriz em que cada coluna corresponde a variação do perfil de tensão relacionada com cada opção de alocação do SAET em análise.

A formulação para a potência reativa é análoga à demonstração feita para a potência ativa. Pelo princípio da superposição, a Eq. (12) continua válida, porém com as dimensões apropriadas para a formulação trifásica. Sendo assim, as dimensões adequadas para cada representação estão apresentadas a seguir.

\section{Representação vetorial}

$$
V_{3 n b \times 1}=V_{3 n b \times 1}^{0}+\Delta V_{\left(P_{S A E}\right)_{3 n b \times 1}}+\Delta V_{\left(Q_{S A E}\right)_{3 n b \times 1}}
$$

Sendo:

$V^{0}-$ Vetor de dimensão $3 n b \times 1$ com o perfil de tensão do caso base;

$V$ - Vetor de dimensão $3 n b \times 1$ com o perfil de tensão resultante das injeções de potência consideradas.

\section{Representação matricial}

$$
V_{3 n b \times 3 n b}=V^{0}{ }_{3 n b \times 3 n b}+\Delta V_{\left(P_{S A E}\right)_{3 n b \times 3 n b}}+\Delta V_{\left(Q_{S A E}\right)_{3 n b \times 3 n b}}
$$

Sendo:

$V^{0}-$ Matriz de dimensão $3 n b \times 3 n b$ cujas colunas contêm o perfil de tensão do caso base;

$V$ - Matriz de dimensão $3 n b \times 3 n b$ cujas colunas contêm o perfil de tensão resultante para cada alocação de injeção de potência em estudo. 


\subsubsection{Aplicação do Método de Sensibilidades na alocação de um SAET}

Uma vez apresentado, nesta subseção o Método de Sensibilidades será utilizado para a determinação da melhor alocação para um SAET. Considerando uma potência especificada, como é o caso deste estudo, a tarefa de alocação do SAET pode ser feita por meio de vários fluxos de potência sequenciais. Se for considerada a análise em um determinado instante de tempo, seria necessário um fluxo de potência para cada possível alocação do SAET no sistema. Já o Método de Sensibilidades pode realizar a mesma tarefa, porém com a demanda de um único fluxo de potência.

Para tanto, segue o passo a passo de sua aplicação:

- Passo 1 - Executar um fluxo de carga usando NR para o sistema em estudo sem considerar a presença do SAET, apenas considerando as cargas do sistema;

- Passo 2 - A partir da matriz Jacobiana obtida no passo 1, executar o Método de Sensibilidades considerando a presença do SAET, juntamente com as cargas do sistema;

- Passo 3 - De posse do resultado do Método de Sensibilidade, o operador do sistema deve escolher a alocação do SAET que resultou no perfil de tensão mais adequado para o sistema, respeitando os limites de tensão.

Adicionalmente, do ponto de vista da variação de tensão, os seguintes passos são indicados caso se deseje encontrar a alocação do SAET com menor impacto na tensão do sistema:

- Passo 1 - Executar um fluxo de carga usando NR para o sistema em estudo sem considerar a presença do SAET;

- Passo 2 - A partir da matriz Jacobiana obtida no passo 1, executar o Método de Sensibilidades considerando a presença do SAET;

- Passo 3 - Subtrair o resultado do passo 1 do resultado do passo 2;

- Passo 4 - Com o resultado do passo 3, escolher a alocação do SAET que resulta em menor variação da tensão original do sistema, obtida via passo 1.

Como o SAET realiza carga e descarga ao longo do dia, ao menos duas situações devem ser estudadas. São elas: descarga em demanda mínima e carga em demanda máxima. Uma vez que a alocação do SAET apresente bons resultados para esses cenários, os resultados para os demais cenários serão adequados também. 


\subsubsection{Aplicação do Método de Sensibilidades na determinação da máxima injeção de potência ativa de um SAET}

Nesta subseção, o Método de Sensibilidades será aplicado na determinação da máxima injeção de potência nodal para sistemas trifásicos. Esta tarefa pode ser feita a partir da manipulação da Eq. (12), que descreve simultaneamente o efeito da alocação de uma injeção de potência em várias barras. Por ser a mais complexa, a representação matricial é considerada nesta subseção. Sendo assim, a equação mencionada pode ser expressa em sua forma trifásica do seguinte modo:

$$
V_{3 n b \times 3 n b}=V_{3 n b \times 3 n b}^{0}+J_{R P V_{3 n b \times 3 n b}}^{-1} P_{S A E_{3 n b \times 3 n b}}+J_{R Q V_{3 n b \times 3 n b}}^{-1} Q_{S A E_{3 n b \times 3 n b}}
$$

Escrevendo a potência reativa em função do fator de potência $(f p)$ e reagrupando devidamente os termos, obtém`se:

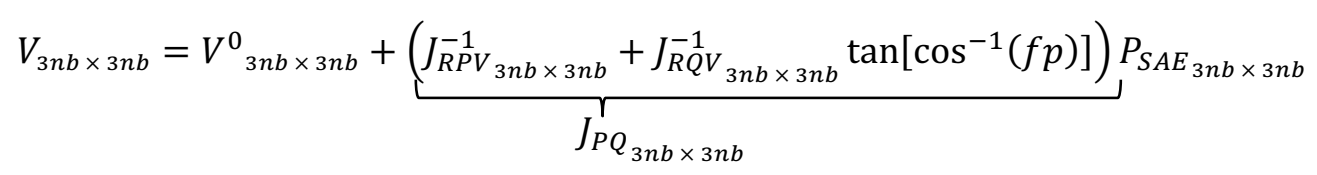

A aplicação da Eq. (20) para um caso particular pode ser escrita como a Eq. (21). Nesta, calcula-se o efeito que a injeção de potência na barra $k$ possui sobre a tensão na barra $m$.

$$
V_{m_{3 \times 1}}=V_{m_{3 \times 1}}^{0}+J_{P Q_{m k_{3 \times 3}}} P_{S A E_{k_{3 \times 1}}}
$$

Sendo assim, a máxima injeção de potência na barra $k$ que pode ocorrer sem que haja violação do limite superior de tensão na barra $m$ é obtida a partir da Eq. (22).

$$
P_{S A E_{k_{3} \times 1}}^{m}=\operatorname{inv}\left(J_{P Q_{m k_{3} \times 3}}\right) \Delta V_{m_{3 \times 1}}
$$

Sendo $\Delta V_{m}=V_{m}^{\max }-V_{m}^{0}$. Em que $V_{m}^{\max }$ é o limite superior de tensão da barra $m$, geralmente 1,05 p.u., e $V_{m}^{0}$ a tensão inicial na barra $m$, isto é, a tensão desconsiderando a injeção de potência na barra $k$.

Por se tratar de um sistema como um todo, sabe-se que a injeção de potência na barra $k$ afeta não somente uma, mas todas as barras deste. Sendo assim, para calcular a máxima injeção de potência na barra $k$, representada por $P_{S A E_{k}}^{\max }$, deve-se considerar a mínima quantidade de injeção suficiente para causar violação de tensão em qualquer uma das barras do sistema. Esta ideia é expressa na Eq. (23), na qual o operador min fornece o 
menor valor dentre os que estão sendo comparados e $P_{S A E_{k}}^{1}$ representa a soma das potencias injetadas nas três fases da barra $k$ considerando as tensões da barra 1.

$$
P_{S A E_{k}}^{\max }=\min \left(P_{S A E_{k}}^{1}, P_{S A E_{k}}^{2}, P_{S A E_{k}}^{3}, \ldots, P_{S A E_{k}}^{n}\right)
$$

A generalização da Eq. (23) para todas as fases do sistema considerando a representação matricial pode ser feita da seguinte maneira:

$$
\begin{aligned}
& P_{S A E}^{\max }{ }_{3 n b \times 3 n b}=\min \left(J_{P Q_{3 n b} \times 3 n b}^{*} . \Delta V_{3 n b \times 3 n b}\right) \\
& =\min \left(\left[\begin{array}{ccc}
J_{P Q_{11}} & \cdots & J_{P Q_{1 n}} \\
\vdots & \ddots & \vdots \\
J_{P Q_{n 1}} & \cdots & J_{P Q_{n n}}
\end{array}\right]_{3 n b \times 3 n b} \cdot\left[\begin{array}{ccc}
\Delta V_{1} & 0 & 0 \\
0 & \ddots & 0 \\
0 & 0 & \Delta V_{n}
\end{array}\right]_{3 n b \times 3 n b}\right) \\
& =\min \left(\left[\begin{array}{cccc}
P_{S A E_{1}}^{1} & P_{S A E_{1}}^{2} & \cdots & P_{S A E_{1}}^{n} \\
\vdots & \vdots & \vdots & \vdots \\
P_{S A E_{n}}^{1} & P_{S A E_{n}}^{2} & \cdots & P_{S A E_{n}}^{n}
\end{array}\right]_{3 n b \times 3 n b}\right) \\
& =\left[\begin{array}{c}
\min \left\{P_{S A E_{1}}^{1}, P_{S A E_{1}}^{2}, \ldots, P_{S A E_{1}}^{n}\right\} \\
\vdots \\
\min \left\{P_{S A E_{n}}^{1}, P_{S A E_{n}}^{2}, \ldots, P_{S A E_{n}}^{n}\right\}
\end{array}\right]_{3 n b \times 1}=\left[\begin{array}{c}
P_{S A E_{1}}^{\max } \\
P_{S A E_{2}}^{\max } \\
\vdots \\
P_{S A E_{n}}^{\max }
\end{array}\right]_{3 n b \times 1}
\end{aligned}
$$

Em que $J_{P Q}^{*}$ é uma matriz cujos elementos são definidos como $J_{P Q_{(m, k)}}^{*}=\operatorname{inv}\left(J_{P Q_{(k, m)}}\right)$, caso as barras $k$ e $m$ sejam ambas trifásicas, sendo inv o operador correspondente à inversão de uma matriz. Para os casos em que as barras $k$ e $m$ não sejam ambas trifásicas, $J_{P Q_{(m, k)}}^{*}=1 / J_{P Q_{(k, m)}}$. Ainda na Eq. (24), $\Delta V$ é uma matriz diagonal formada pelos elementos $\Delta V_{n}$, sendo $n=1,2, \ldots, 3 n b$, o número de fases e min o mesmo operador usado na Eq. (23). Sendo assim, por meio da Eq. (24) é possível obter a matriz $P_{S A E}^{\max }$, cujos elementos fornecem a máxima injeção de potência para cada fase do sistema. Assim, para que a máxima injeção de potência de uma determinada barra seja calculada, a soma das máximas injeções de potência de suas fases é realizada.

Destaca-se que o presente trabalho considerou um sistema trifásico e desequilibrado. Por esse motivo, barras monofásicas e trifásicas foram tratadas de modo individual seguindo a formulação descrita no parágrafo anterior. Nesta etapa, o resultado do tratamento individual de cada barra foi organizado em matrizes para maior organização e facilidade no processamento dos cálculos. Assim, o método fornece os valores de máxima injeção de potência nodais para dado fator de potência e configuração de carregamento do sistema. 


\subsection{Resultados}

Nesta subseção, o sistema utilizado na aplicação do Método de Sensibilidades é descrito. Além disso, sua validação é realizada em comparação com o Método de NR. Posteriormente, são apresentados os resultados da aplicação do método proposto no estudo de alocações de um SAET e no cálculo da máxima injeção de potência nodal para este equipamento.

\subsubsection{Sistema IEEE 34 barras modificado}

Para a aplicação do Método de Sensibilidades no estudo de alocação de um SAET e na determinação da máxima injeção de potência de um SAET por barra, o sistema de testes apresentado na subseção 3.1 foi modificado. As simplificações adotadas foram:

- Remoção de cargas distribuídas;

- Remoção de capacitores, bem como das capacitâncias das linhas;

- Remoção do transformador entre as barras 832 e 888 e desta última barra;

- Adição de linha que liga barra 832 diretamente com a barra 890;

- Remoção dos reguladores de tensão.

As demandas máximas de potência ativa e reativa desse sistema modificado são próximas de $1.143 \mathrm{~kW}$ e $735 \mathrm{kVAr}$, respectivamente. Sendo assim, a potência aparente desse sistema é de aproximadamente 1.359 kVA. Ademais, a tensão adotada na subestação foi de 1,05 p.u..

\subsubsection{Validação do Método de Sensibilidades}

Para validação do método proposto neste trabalho, o sistema mencionado na subseção 5.3.1 foi implementado e simulado em MATLAB com o algoritmo de NR e via Método de Sensibilidades. Como forma de mensurar a exatidão deste método, as tensões nodais obtidas por meio do seu uso foram comparadas com as obtidas via NR. Nesta etapa, a tensão na subestação foi ajustada em 1,06 p.u.. Destaca-se ainda que o fator de potência do SAET simulado é unitário. O processo de simulação é detalhado a seguir.

Por se tratar de um estudo de alocação de um único SAET, o presente trabalho considerou injeções de potência negativas e positivas, representando suas operações de carga e descarga, respectivamente. As injeções de potência simuladas vão de 0 a $1 \mathrm{MW}$, 
com passos de $100 \mathrm{~kW}$, por essa ser a potência máxima do SAET considerado neste estudo. A aplicação do NR consiste em executar um fluxo de carga para cada alocação e valor de injeção de potência considerado. Este processo se inicia no começo do alimentador e vai até o seu final, considerando uma única alocação do SAET por vez. Sendo assim, inicialmente uma dada injeção de potência, por exemplo $0 \mathrm{~kW}$, é considerada na barra 800 do sistema e as tensões nodais do sistema são registradas. Em seguida, um novo valor de injeção de potência, por exemplo $100 \mathrm{~kW}$, é simulado para a mesma barra e as tensões são, novamente, registradas. Esta rotina se repete até que os valores de injeção de potência que se deseja estudar sejam esgotados na alocação em estudo, neste caso a barra 800 . Em seguida, o mesmo procedimento é adotado para a barra seguinte, individualmente, até que todas as alocações possíveis para o SAET sejam esgotadas. Em cada fluxo de potência, os valores das tensões nodais são registrados e armazenados.

Em seguida, o Método de Sensibilidades é aplicado considerando os passos mencionados na subseção 5.2.1 para a obtenção das tensões nodais do sistema. Por fim, as tensões nodais obtidas por ambos os métodos para cada valor de injeção de potência são comparadas, considerando todas as alocações. Os erros são obtidos para cada fase segundo a Eq. (25) e estão expostos nas Figura 29, Figura 30 e Figura 31, considerando a carga nominal do sistema. Nas figuras mencionadas, os eixos "Alocações" e "Barras" dizem respeito à barra na qual a injeção de potência está simulada e às barras cujas tensões nodais são registradas, respectivamente. Em ambos os eixos, as barras estão ordenadas por distância crescente da subestação.

$$
\operatorname{Erro}_{i}=\left(\frac{V_{k_{i}}^{\text {Sens. }}-V_{k_{i}}^{F C}}{V_{k_{i}}^{F C}}\right) \cdot 100
$$

Sendo:

$i=a, b$ e $c-0$ indicador da fase analisada;

$k=1,2, \ldots, n b-\mathrm{o}$ indicador da barra em estudo. 
Figura 29 - Erro entre Método de Sensibilidades e Método de NR, Fase A $\left(P_{S A E}=-1000 \mathrm{~kW}\right)$

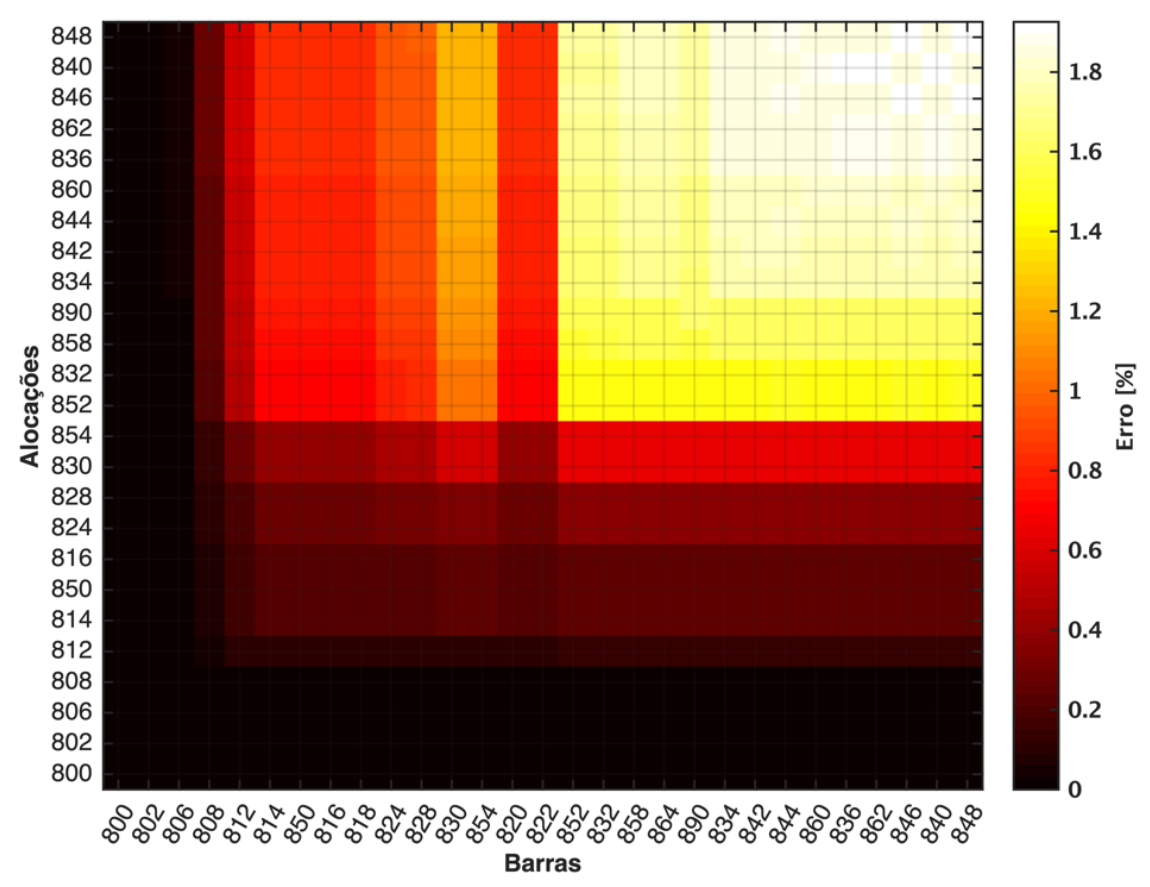

Fonte: Autor.

Figura 30 - Erro entre Método de Sensibilidades e Método de NR, Fase B $\left(P_{S A E}=-1000 \mathrm{~kW}\right)$

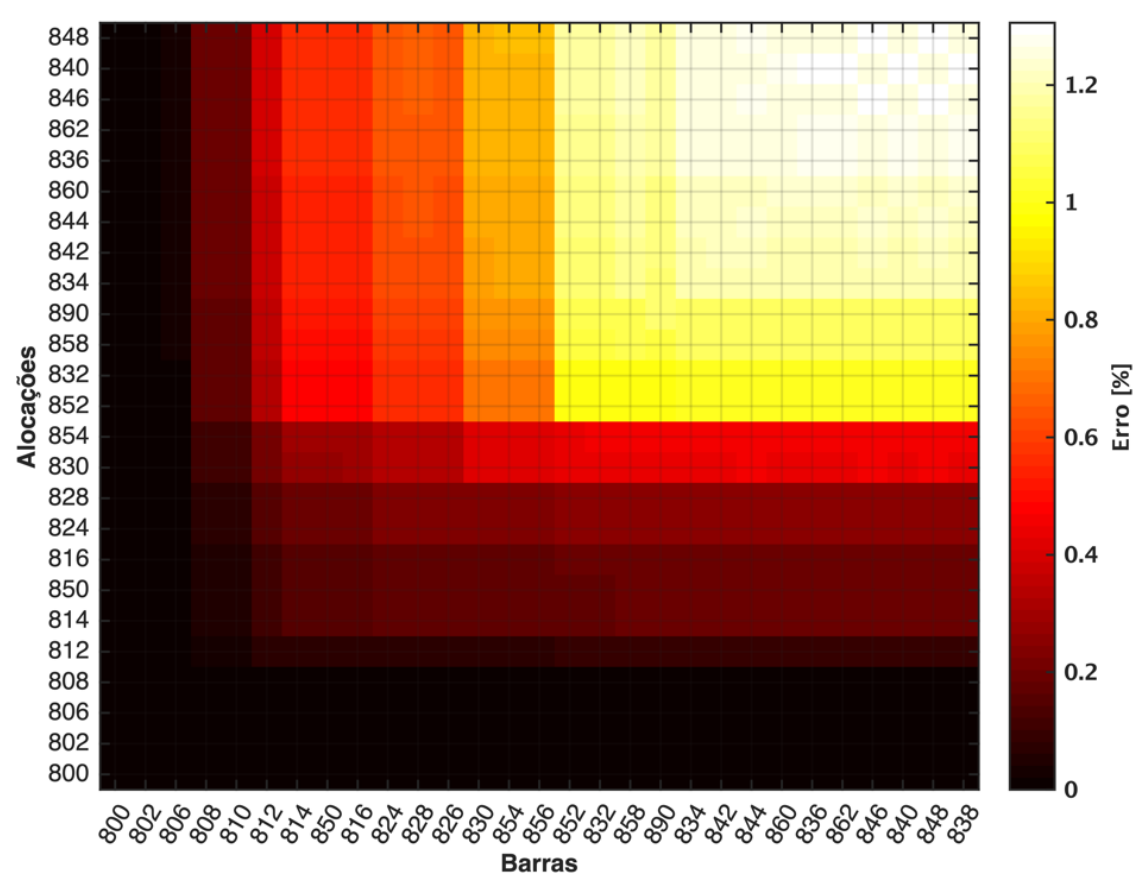

Fonte: Autor. 
Figura 31 - Erro entre Método de Sensibilidades e Método de NR, Fase C $\left(P_{S A E}=-1000 \mathrm{~kW}\right)$

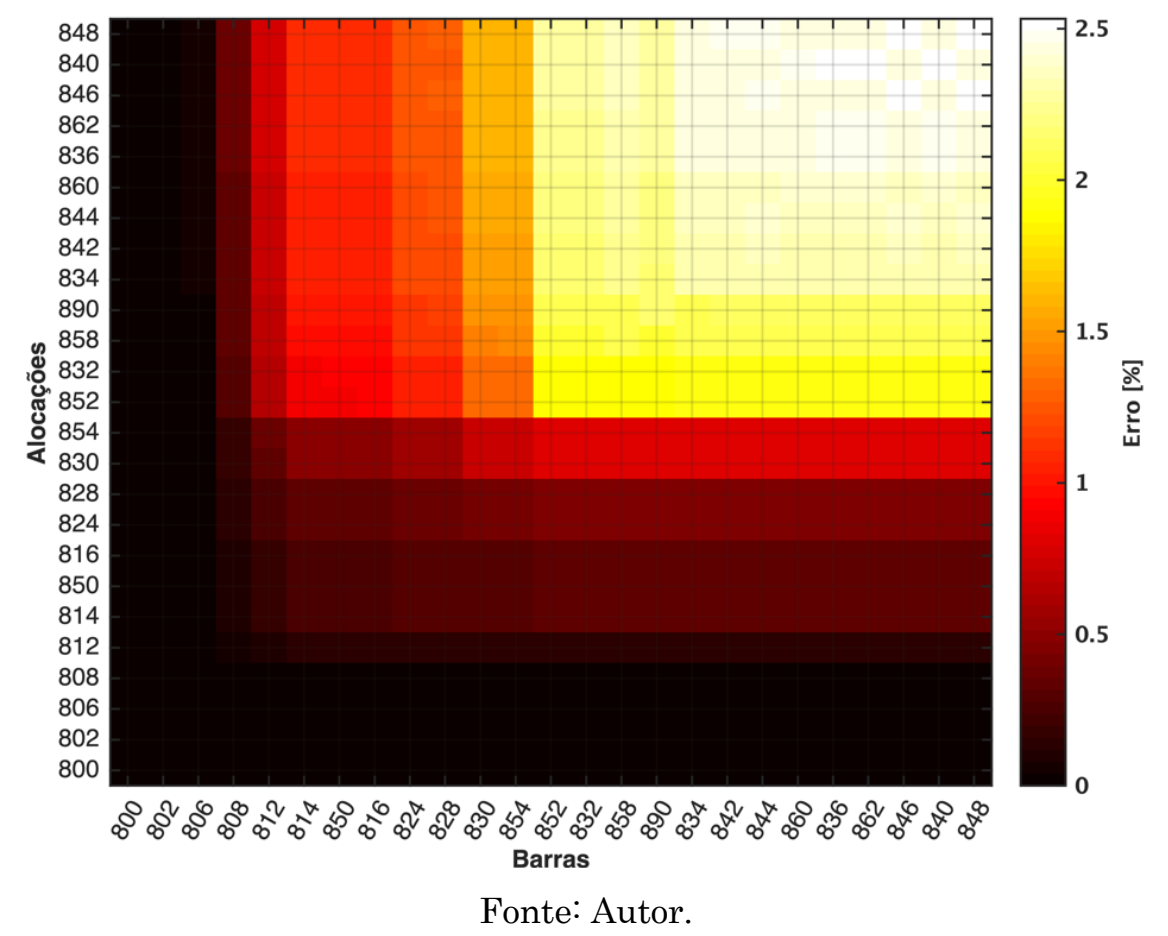

A partir da análise das figuras acima, percebe-se que o erro entre os métodos se eleva à medida em que a distância com relação à subestação (barra 800) aumenta. Isto se comprova pelo fato de a barra 848 ter o maior erro em relação as demais barras do sistema para a maioria das alocações do SAET. Isso pode ser mais bem observado a partir da alocação na barra 814, em que a coloração mais clara passa a aumentar na direção da barra 848. Adicionalmente, quando se observa uma mesma barra constata-se que quanto mais distante for a alocação do SAET, maiores os erros verificados. Por exemplo, observando as leituras na barra 842 verifica-se um aumento no erro à medida em que a alocação do equipamento mencionado se desloca para o fim do sistema.

Uma vez que este trabalho aborda a operação diária do sistema de distribuição, a análise descrita foi realizada para as suas condições de demanda máxima e mínima, determinadas a partir da Figura 9. Os resultados obtidos para as condições mencionadas estão a mostra na Figura 32 e Figura 33, respectivamente. Ressalta-se que nesta etapa apenas o maior erro obtido para uma dada condição entre as três fases é registrado. Sendo assim, para cada valor de injeção de potência, tem-se o pior erro considerando todas as alocações do sistema e todas as três fases. 
Figura 32 - Erro entre Método de Sensibilidades e Método de NR (Demanda máxima)

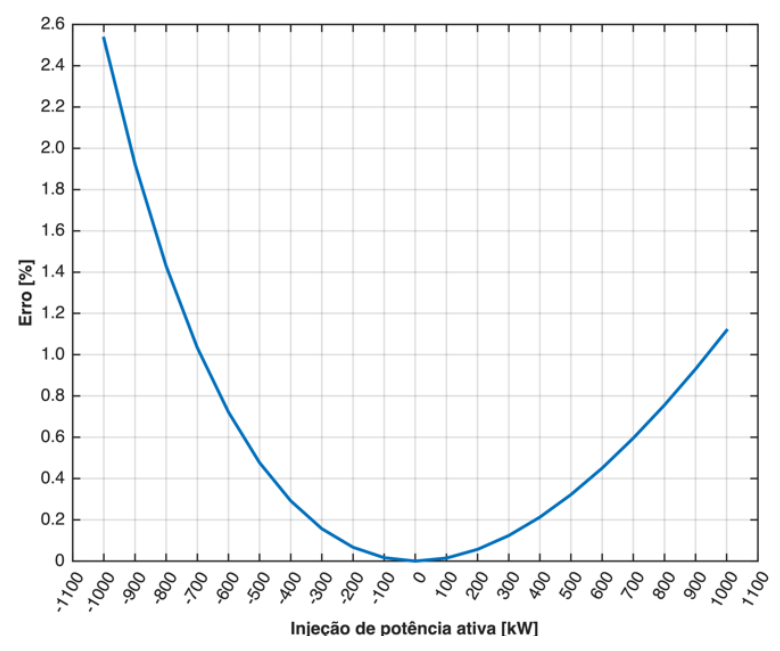

Fonte: Autor.

Figura 33 - Erro entre Método de Sensibilidades e Método de NR (Demanda mínima)

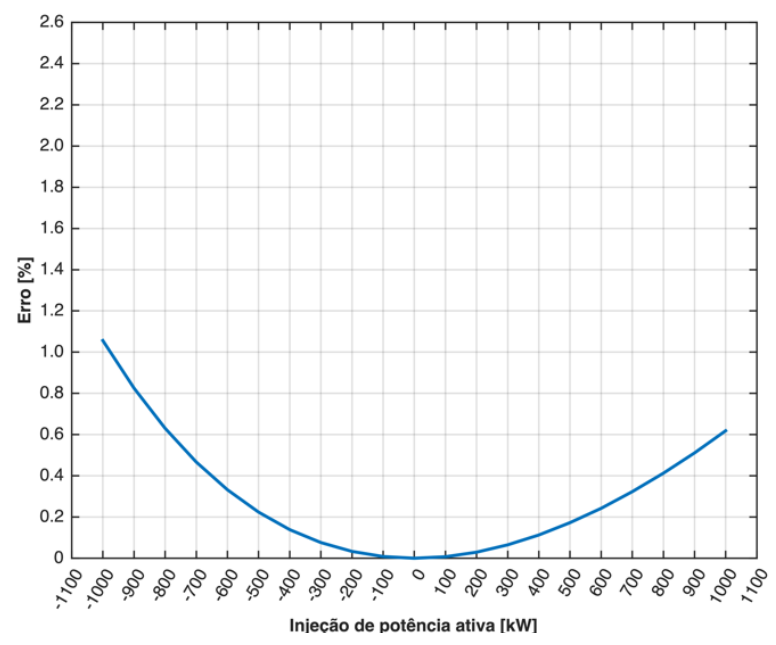

Fonte: Autor.

Observa-se que em ambos os cenários, os erros aumentam à medida em que os valores de injeção de potência simulados se afastam de zero. O pior erro registrado foi o referente a injeção de potência de $-1000 \mathrm{~kW}$, o que se refere à carga do SAET em sua potência máxima. Neste caso, verifica-se que o erro registrado atingiu aproximadamente $2,6 \%$ e corresponde ao cenário cujos resultados foram apresentados na Figura 29, Figura 30 e Figura 31. Desta forma, é possível afirmar que o Método de Sensibilidades produziu resultados satisfatórios para todos os casos simulados e com menor esforço em comparação ao Método de NR, pois demandou apenas um fluxo de carga. 


\subsubsection{Alocação de um SAET}

Conforme o descrito na subseção 5.2.1, o Método de Sensibilidades foi aplicado no estudo da alocação de um SAET no sistema apresentado na subseção 5.3.1. Os cenários considerados levam em conta as demandas máximas e mínimas do sistema determinadas a partir da Figura 9. As operações de carga e descarga do SAET são simuladas com potência nominal, isto é, $1 \mathrm{MW}$. Para efeito didático, a análise será feita somente para a fase A. As demais fases podem ser analisadas de modo análogo.

Inicialmente, considerou-se o cenário de demanda mínima. Neste cenário, a operação do SAET foi simulada via Método de Sensibilidades. O resultado considerando a operação de carga está a mostra na Figura 34.

Figura 34 - Tensões nodais em função da alocação do SAET (Fase A) - Carga em demanda mínima

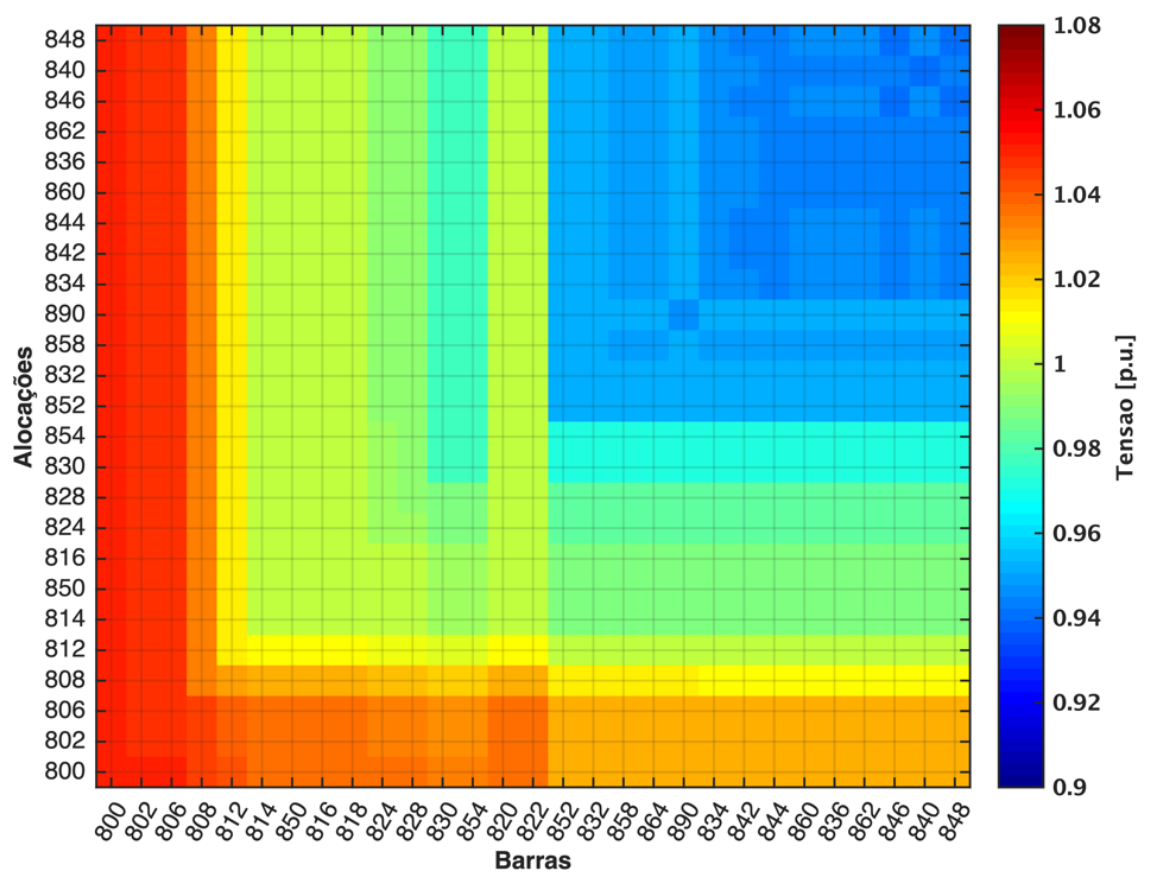

Fonte: Autor.

A Figura 34 apresenta em seu eixo vertical ("Alocações") as diversas alocações do SAET em estudo. Cada uma destas resulta em um perfil de tensão. Este por sua vez é apresentado ao longo do eixo horizontal ("Barras"). Sendo assim, para analisar a alocação do SAET na barra 848, basta localizá-la no eixo vertical e observar o perfil de tensão resultante ao longo do eixo horizontal. Para melhor compreensão, o caso mencionado está ilustrado na Figura 35. Este caso é o mesmo observado na Figura 34, na Alocação 848. 
Figura 35 - Tensões nodais para SAET na barra 848 (Fase A) - Carga em demanda mínima

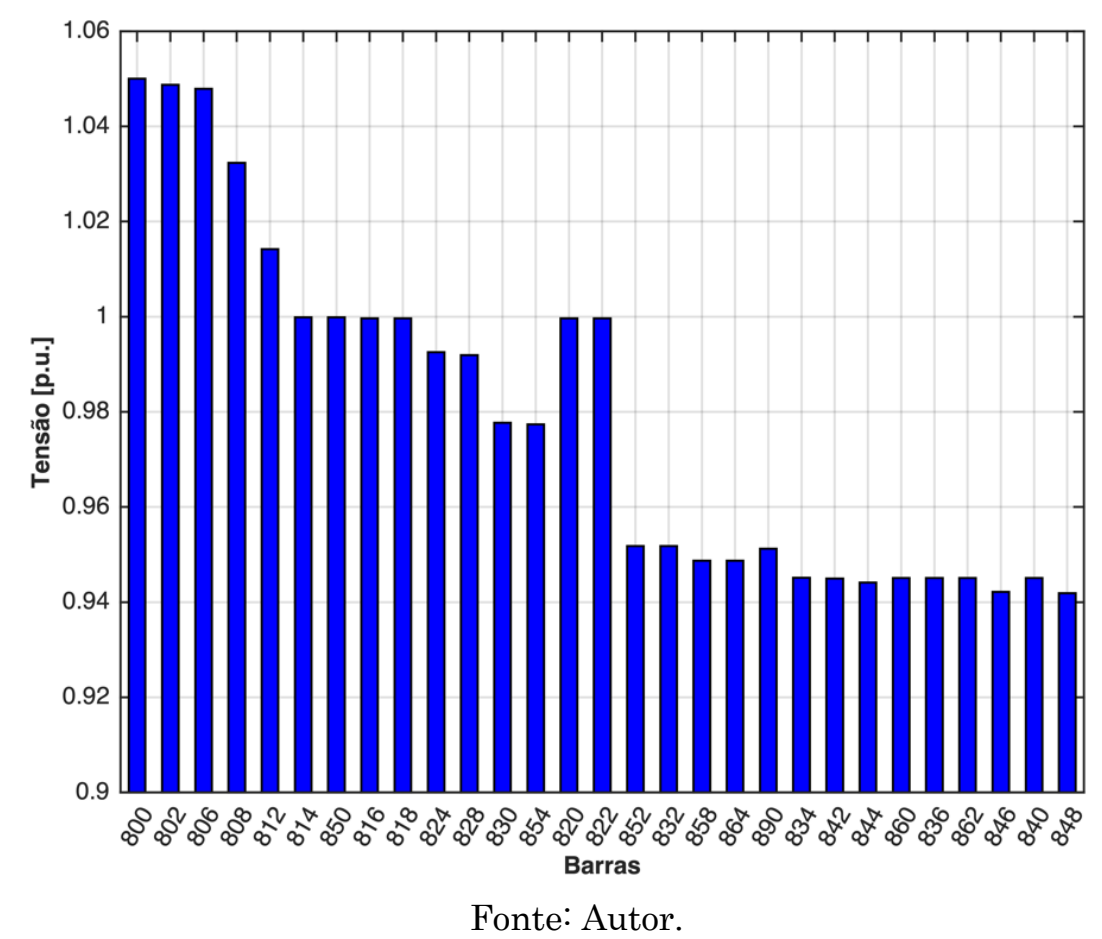

Desta forma, observa-se na Figura 34 que as alocações do SAET que estão no final do sistema produzem uma queda de tensão acentuada ao longo do sistema. Esta situação está demarcada em azul claro e ocorre a partir da alocação na barra 852 até a alocação na barra 848. Esta alocação, por exemplo, resulta em tensões próximas ao limite inferior de tensão, como é visto na Figura 35. Por outro lado, verifica-se que as alocações nas barras mais próximas à subestação resultam em um perfil de tensão mais uniforme. Este é o caso das alocações nas barras 800 até a barra 816, por exemplo. Sendo assim, verifica-se que estas alocações seriam as mais indicadas para a situação apresentada.

Já no caso de descarga do SAET simulado para o cenário de demanda em estudo é uma das situações extremas que deve ser estudada, conforme a subseção 5.2.1. Os resultados para este caso estão ilustrados na Figura 36. 
Figura 36 - Tensões nodais em função da alocação do SAET (Fase A) - Descarga em demanda mínima

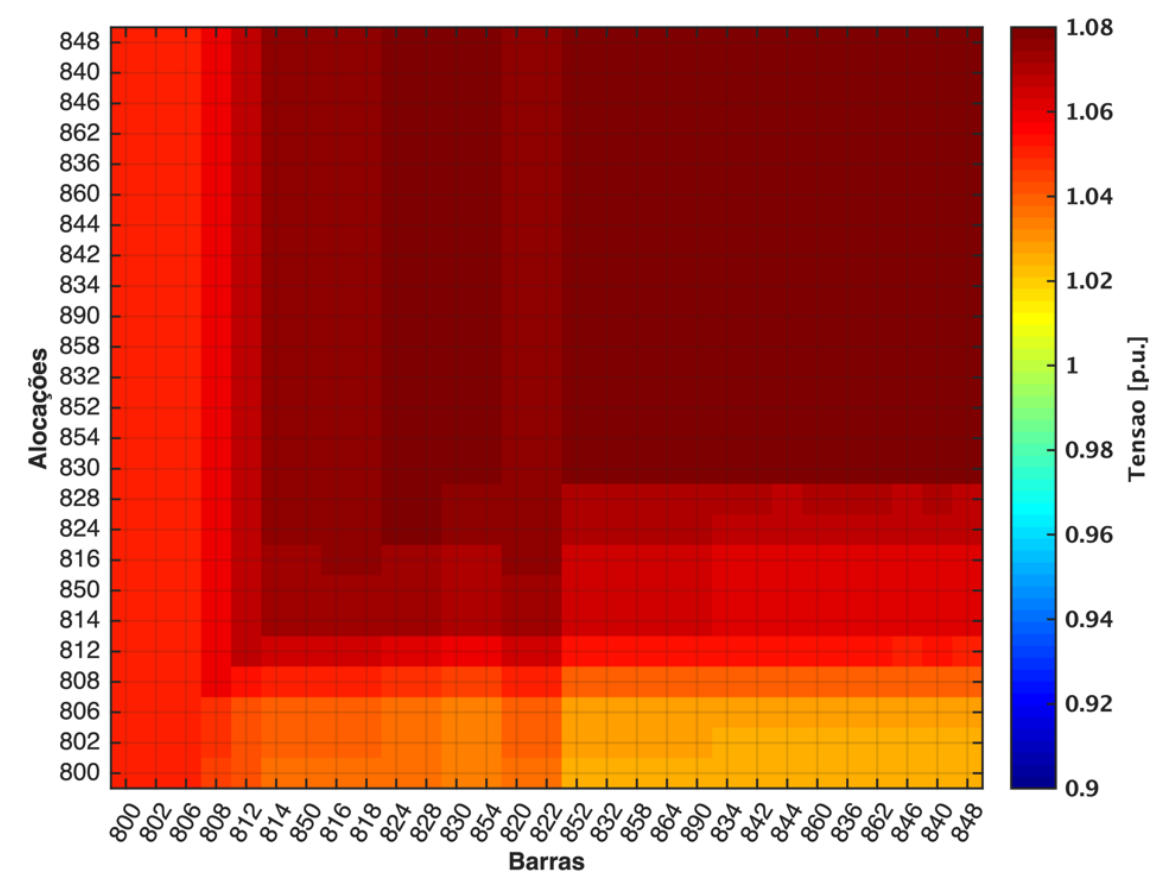

Fonte: Autor.

Conforme observado na Figura 36, as tensões para este caso são elevadas além do limite superior de tensão, para a maioria das alocações estudadas. Isso ocorre devido à tensão na subestação já ser alta por padrão (1,05 p.u.) e pela demanda baixa do sistema. Soma-se a isto o fato de o SAET realizar sua descarga, injetando energia no sistema. Desta forma, verifica-se que as poucas alocações que resultam em um perfil de tensão que respeita os limites adequados são as mais próximas da subestação, como é o caso das alocações nas barras 800, 802, 806 e 808.

Posteriormente, o cenário de demanda máxima do sistema também foi simulado via Método de Sensibilidades. Os resultados para as operações de carga e descarga do SAET são apresentados na Figura 37 e Figura 38, respectivamente.

Como é possível constatar a partir da Figura 37, esta situação é o segundo extremo mencionado na subseção 5.2.1. Isto se deve ao fato de as tensões do sistema já serem baixas devido ao seu alto carregamento e o SAET ainda representar uma injeção negativa de potência para este. Por estes motivos, a maioria das alocações simuladas resultam em quedas bruscas de tensão, de modo a produzir valores que violam o limite inferior adequado. Novamente, constata-se que as alocações mais próximas a subestação são as únicas a fornecerem uma condição de operação adequada ao sistema considerando seu perfil de tensão. Dentre estas alocações, pode-se mencionar as barras 800, 802 e 806. 
Figura 37 - Tensões nodais em função da alocação do SAET (Fase A) - Carga em demanda máxima

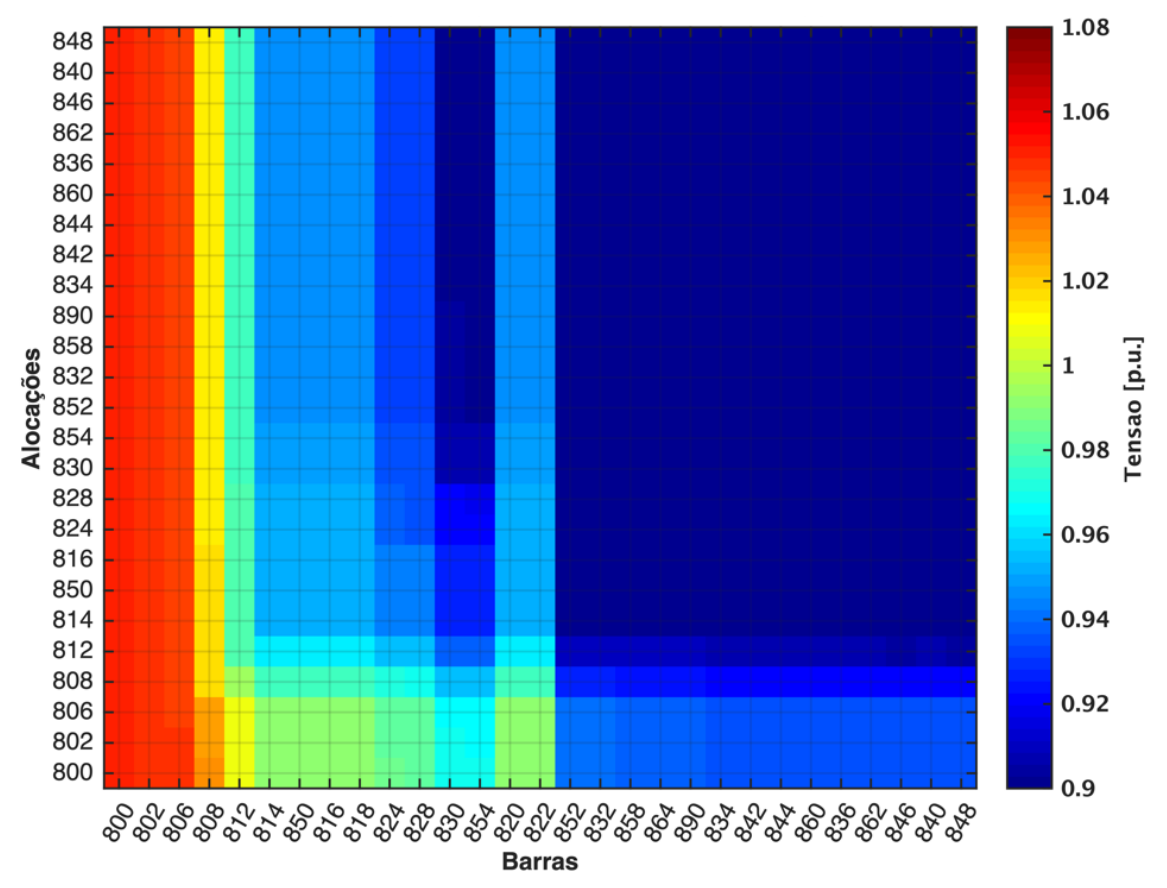

Fonte: Autor.

Figura 38 - Tensões nodais em função da alocação do SAET (Fase A) - Descarga em demanda máxima

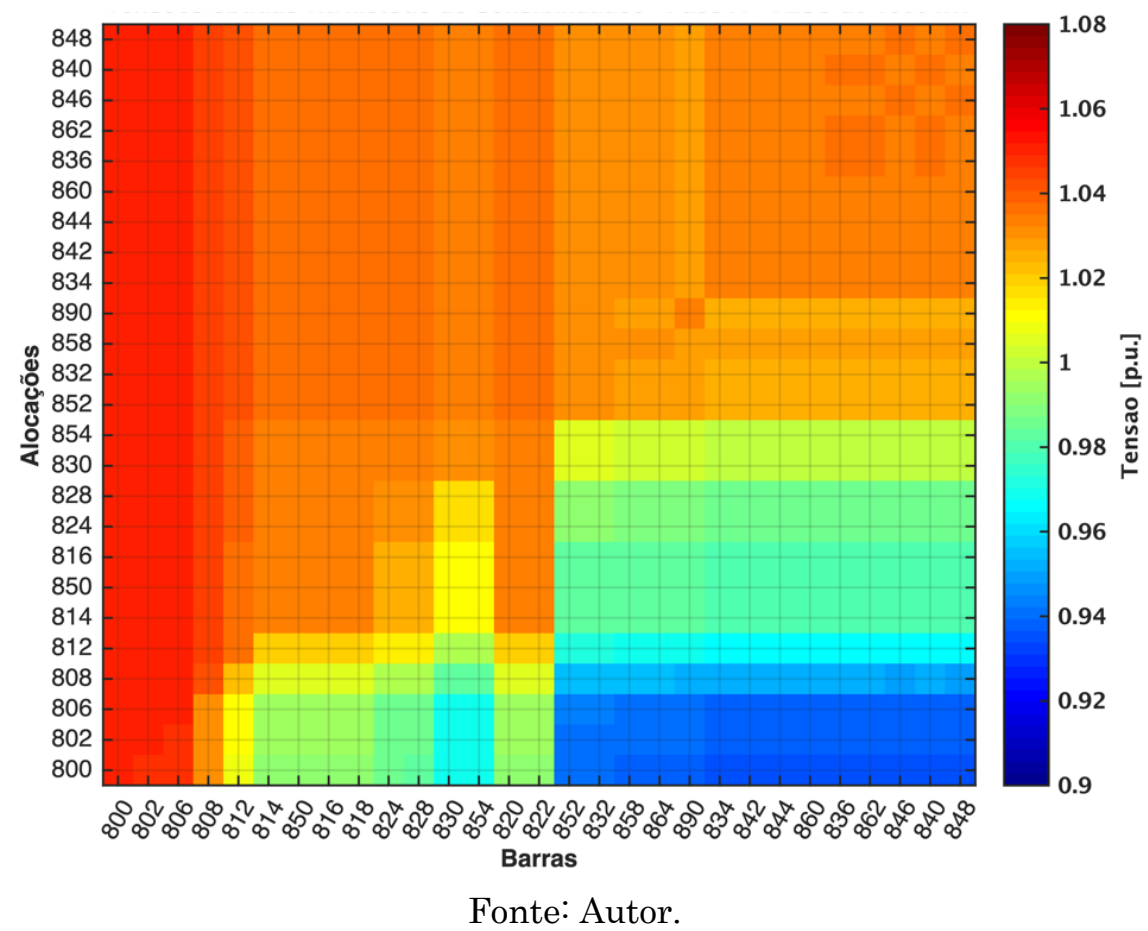

Entretanto, o SAET pode auxiliar o sistema para a demanda considerada quando este realiza a operação de descarga. Isto pode ser observado na Figura 38, em que a grande maioria das alocações para o SAET resultam em valores adequados de tensão. Este efeito 
é constatado nas alocações mais distantes da subestação, isto é, alocações à jusante da barra 808, incluindo esta alocação. Estas alocações permitem que o SAET contribua para um aumento de tensão quando efetua a sua descarga, de modo a proporcionar valores de tensão que respeitam os limites adequados.

Uma vez que os resultados para as demandas mínima e máxima foram obtidos considerando a carga e descarga do SAET em ambas, as alocações que proporcionaram os melhores perfis de tensão para o sistema principalmente nos cenários extremos, isto é, descarga em demanda mínima e carga em demanda máxima, devem ser as selecionadas para a operação do SAET. No caso estudado, as alocações mais adequadas certamente são as que se encontram entre a barra 800 e a barra 812. Isto se deve principalmente aos desempenhos destas nos cenários mais extremos. Nos demais cenários, embora não contribuam de modo mais significativo, ainda garantem tensões adequadas, caso ilustrado na Figura 34, e próximas ao limite adequado, como no caso ilustrado na Figura 38.

Adicionalmente, o índice IMP é aplicado para a determinação da melhor alocação de um SAET para o sistema em estudo nesta subseção, considerando os mesmos cenários analisados via Método de Sensibilidades. Diferente do que foi mencionado na subseção 4.2.5, nesta subseção os valores dos índices que compõem o IMP foram adequados ao intervalo [0,1]. Estes limites correspondem aos seus respectivos menores e maiores valores. Além disso, nesta tarefa os pesos do índice foram ajustados para dar ênfase à diminuição de tensão nas barras de carga (índice IMIT) quando o SAET realiza sua carga e para enfatizar o aumento de tensão nas barras de carga (índice IMAT) quando o SAET realiza sua descarga. Este raciocínio justifica a escolha dos pesos utilizados no cálculo do IMP para esta etapa de estudo. Estes pesos são apresentados na Tabela 19. Em seguida, os valores de IMP para os quatro cenários analisados são apresentados nas colunas da Tabela 20.

Tabela 19 - Pesos do IMP para os diversos cenários em estudo

Demanda mínima Demanda máxima

\begin{tabular}{ccccc}
\hline Pesos & Carga & Descarga & Carga & Descarga \\
P1 & 0 & 0 & 0 & 0 \\
P2 & 0 & 0 & 0 & 0 \\
P3 & 0 & 1 & 0 & 1 \\
P4 & 1 & 0 & 1 & 0
\end{tabular}

Fonte: Autor. 
Tabela 20 - Valores de IMP para os cenários de manda máxima e mínima, considerando operações de carga e descarga do SAET.

\begin{tabular}{ccccc} 
& \multicolumn{2}{c}{ Demanda mínima } & \multicolumn{2}{c}{ Demanda máxima } \\
\hline Barras & Carga & Descarga & Carga & Descarga \\
\hline 800 & 0,000 & 0,000 & 0,000 & 0,000 \\
802 & 0,011 & 0,010 & 0,010 & 0,013 \\
806 & 0,018 & 0,017 & 0,017 & 0,022 \\
808 & 0,154 & 0,156 & 0,144 & 0,193 \\
812 & 0,314 & 0,334 & 0,298 & 0,399 \\
814 & 0,442 & 0,476 & 0,427 & 0,580 \\
850 & 0,442 & 0,476 & 0,427 & 0,580 \\
816 & 0,444 & 0,479 & 0,429 & 0,583 \\
824 & 0,510 & 0,551 & 0,495 & 0,687 \\
828 & 0,516 & 0,557 & 0,501 & 0,696 \\
\hline 830 & 0,648 & 0,702 & 0,638 & 0,907 \\
854 & 0,652 & 0,702 & 0,641 & 0,908 \\
\hline 852 & 0,893 & 0,890 & 0,896 & 0,965 \\
\hline 832 & 0,893 & 0,890 & 0,896 & 0,965 \\
\hline 858 & 0,925 & 0,919 & 0,928 & 0,969 \\
\hline 890 & 0,931 & 0,941 & 0,909 & 0,971 \\
\hline 834 & 0,963 & 0,961 & 0,966 & 0,975 \\
\hline 842 & 0,965 & 0,962 & 0,968 & 0,975 \\
\hline 844 & 0,973 & 0,971 & 0,976 & 0,976 \\
\hline 860 & 0,974 & 0,975 & 0,971 & 0,975 \\
\hline 836 & 0,991 & 0,994 & 0,986 & 0,992 \\
\hline 862 & 0,991 & 0,994 & 0,986 & 0,992 \\
\hline 846 & 0,997 & 0,996 & 0,997 & 0,991 \\
\hline 840 & 0,997 & 1,000 & 0,991 & 1,000 \\
\hline & 1,000 & 1,000 & 1,000 & 0,996 \\
\hline
\end{tabular}

Fonte: Autor.

A partir da análise da Tabela 20, verifica-se que as melhores alocações para o SAET são as barras 800, 802, 806, 808 e 812. Esse resultado coincide com o verificado via Método de Sensibilidades ao destacar as barras mais próximas à subestação como as melhores alocações do sistema analisado. Observa-se, ainda, que o desempenho das alocações no índice IMP piora à medida em que estas se afastam da subestação. Esta tendência coincide com a encontrada por meio do Método de Sensibilidades, em que as alocações mais próximas da subestação foram as que obtiveram melhores desempenho geral.

\subsubsection{Tempo de processamento: Método de Sensibilidades e Índice IMP}

Com a finalidade de comparar o custo computacional exigido pelo Método de Sensibilidades na aplicação descrita na seção 5.3 .3 com o demandado para a aplicação do 
Índice IMP apresentada na seção 0, o tempo de processamento computacional para ambos os métodos foi medido. Os dados referentes a esta comparação são apresentados na Tabela 21, ambos obtidos utilizando o sistema IEEE 34 barras.

Tabela 21 - Comparação de custo computacional entre Índice IMP e Método de Sensibilidades no estudo da alocação de um SAET.

\begin{tabular}{|ccc|}
\hline \multicolumn{3}{c}{ Alocação de um SAET } \\
\hline & Índice IMP & Método de Sensibilidades \\
\hline Programas utilizados & OpenDSS e Python & MATLAB \\
\hline $\begin{array}{c}\text { Quantidade de fluxos de carga } \\
\text { Tempo total de processamento }\end{array}$ & 262 segundos & 1 \\
\hline Configuração utilizada & AMD Ryzen 7 2700 Eight-Core, 16 GB RAM \\
\hline
\end{tabular}

Fonte: Autor.

A partir da análise da Tabela 21, verifica-se que o Método de Sensibilidades demanda 4 segundos de tempo de processamento, aproximadamente 1,5\% do tempo demandado pelo Índice IMP na tarefa analisada. Sendo assim, o Método de Sensibilidades permite uma análise mais rápida, que pode ser útil para uma primeira aproximação do problema. Portanto, a tarefa de alocação de um SAET pode ser realizada a partir da aplicação do Método de Sensibilidades seguida do uso do Índice IMP somente para as alocações que se mostrarem de interesse após o primeiro método fornecer seus resultados. Desta forma, o problema poderia ser resolvido de modo a se beneficiar da agilidade do primeiro método e da precisão do segundo.

\subsubsection{Máxima injeção de potência}

Nesta subseção, são comparados os resultados de máxima injeção de potência por barra obtidos via Método de Sensibilidades e via NR. O sistema em estudo é o mesmo descrito na subseção 5.3.1. Nesta etapa, a tensão na subestação foi ajustada em 1,05 p.u. com a finalidade de respeitar os limites adotados em (ANEEL, 2018). Uma vez que a capacidade do SAET em estudo de $1 \mathrm{MW}$ não ter sido suficiente para gerar violações nas tensões nodais, adotou-se um limite de $2 \mathrm{MW}$ como o máximo a ser testado. Destaca-se que esse limite representa aproximadamente $147 \%$ da potência total do sistema. Os resultados provenientes da aplicação do NR foram obtidos por meio de sucessivos fluxos de carga com passos de injeção de $10 \mathrm{~kW}$, até que o limite mencionado fosse atingido. Uma vez que as barras violadas no NR foram somente as barras em que ocorreram as injeções de potência, apenas as violações que ocorreram nessas barras foram consideradas na aplicação do Método de Sensibilidades. Já este método foi aplicado conforme descrito na subseção 5.2.2 
e considerando apenas as barras trifásicas para a alocação do SAET, que é trifásico. A Figura 39 apresenta ambos os resultados para o cenário de demanda máxima e injeção de potência ativa.

Figura 39 - Máxima injeção de potência ativa via Método de Sensibilidades e NR

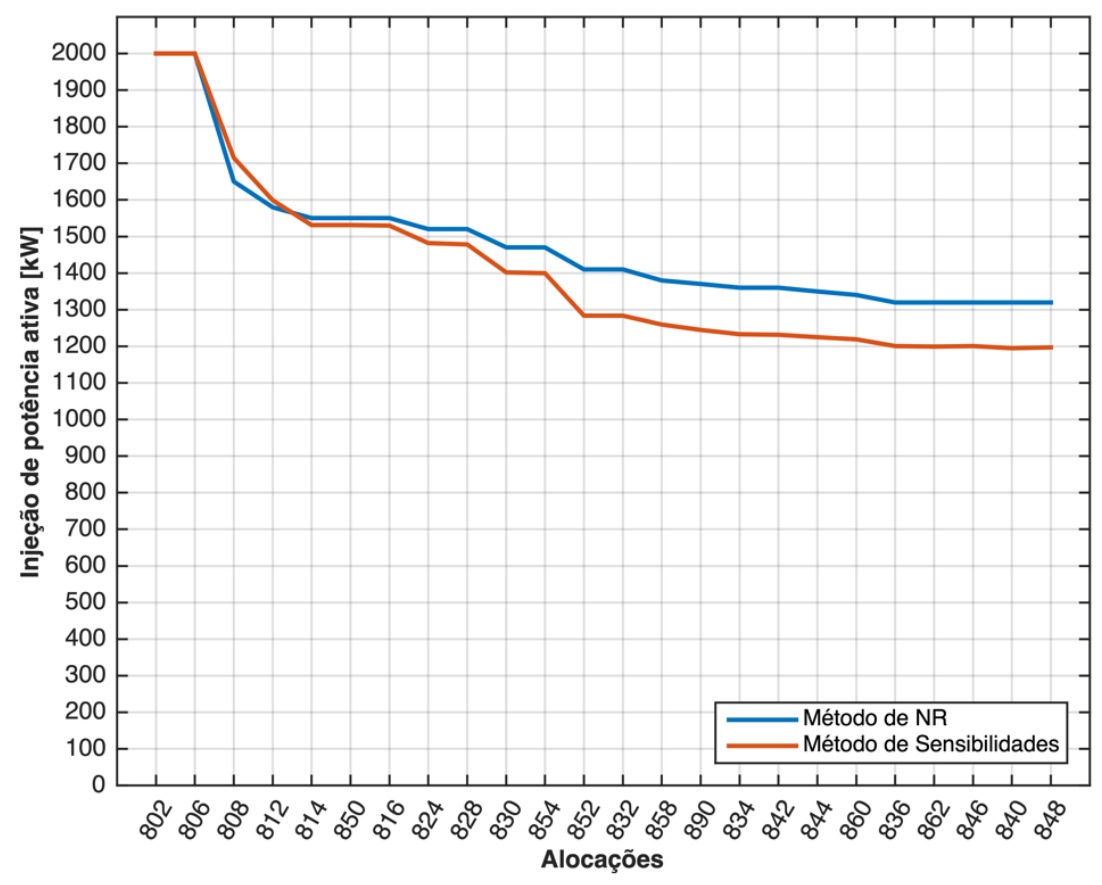

Fonte: Autor.

Na Figura 39, o eixo vertical se refere à máxima injeção de potência que pode ser efetuada em cada uma das barras do sistema. Já o eixo horizontal aponta as barras em que as injeções estão localizadas. Desta forma, ao se analisar a barra 852 pode-se afirmar que a máxima injeção de potência que esta suporta sem que haja violação no limite superior de tensão em qualquer barra do sistema é de $1400 \mathrm{~kW}$, considerando o Método de NR. Essa grandeza é diferente quando o Método de Sensibilidades é usado. Este último aponta o valor de $1300 \mathrm{~kW}$, aproximadamente, como o limite de injeção de potência nos termos mencionados. Observa-se que este método foi mais conservador em comparação ao anterior, visto que limitou mais a injeção de potência para a maioria das barras em análise.

A partir da análise da Figura 39, observa-se ainda que a máxima injeção de potência é maior nas barras mais próximas à subestação e diminui à medida em que as alocações se distanciam desta, considerando ambos os métodos. Este fenômeno era esperado visto que as primeiras barras do sistema são mais eletricamente próximas à subestação e possuem menor sensibilidade de tensão (AYRES, 2010). Além disso, o erro entre os resultados obtidos pelos dois métodos utilizados foi calculado de acordo com a Eq. (26). 


$$
\operatorname{Erro}_{k}=\left(\frac{P_{S A E_{k}}^{\max _{N R}}-P_{S A E_{k}}^{\max _{S e n s}}}{P_{S A E_{k}}^{\max _{N R}}}\right) \cdot 100
$$

Sendo $k$ - índice de barras do sistema $(k=1,2, \ldots, n)$.

Com base na Eq. (26), o erro médio e máximo obtido foram de 5,5\% e 9,47\%, respectivamente. A Figura 40 possibilita uma observação da evolução do erro absoluto ao longo do sistema usado.

Figura 40 - Erro absoluto para máxima injeção de potência via Método de NR e Método de Sensibilidades

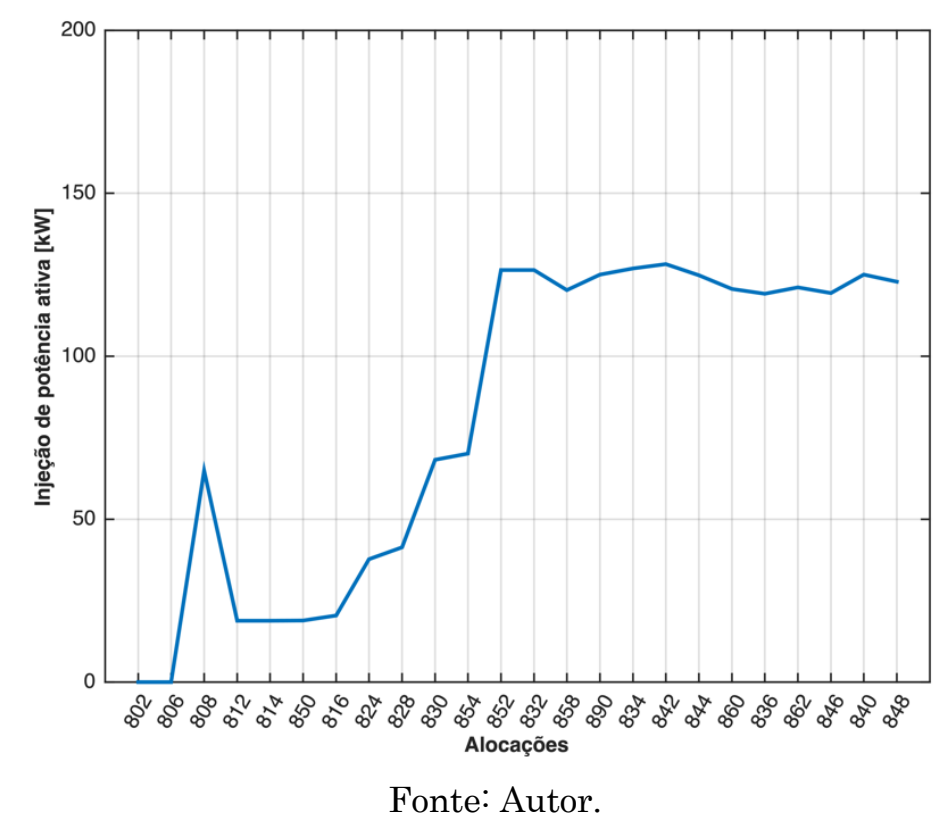

Conclui-se que o fato de o Método de Sensibilidades apresentar resultados geralmente mais conservadores e exigir menor esforço computacional com relação ao Método de NR conferem vantagens ao primeiro na execução de uma análise inicial de um sistema elétrico. A partir desta, uma análise mais detalhada pode ser realizada, caso seja necessária. Ademais, verifica-se que o erro se eleva à medida em que a distância entre as alocações do SAET e a subestação aumenta, como se observa na Figura 40. Isto possivelmente se deve à maior sensibilidade de tensão das barras finais do sistema.

\subsubsection{Tempo de processamento: Método de Sensibilidades e Método NR}

De maneira análoga ao que foi feito na seção 5.3.3.1, o tempo de processamento do Método de Sensibilidades ao desempenhar o cálculo de máxima injeção de potência foi comparado ao tempo demandado pelo Método NR para a mesma tarefa. Os dados referentes à esta comparação são apresentados na Tabela 22. 
Tabela 22 - Comparação de custo computacional entre Método de Sensibilidades e o Método NR no cálculo da máxima injeção de potência nodal.

\begin{tabular}{|ccc|}
\multicolumn{3}{c}{ Alocação de um SAET } \\
\hline & Método NR & Método de Sensibilidades \\
\hline Programas utilizados & MATLAB & MATLAB \\
\hline Quantidade de fluxos de carga & 5.200 & 1 \\
Tempo total de processamento & 4.827 segundos & 3 segundos \\
Configuração utilizada & AMD Ryzen 7 2700 Eight-Core, 16 GB RAM
\end{tabular}

Fonte: Autor.

A partir da análise da Tabela 22, verifica-se que o Método de Sensibilidades demandou aproximadamente $0,06 \%$ do tempo de processamento requerido para a realização da tarefa em questão via Método NR. Sendo assim, constata-se que o primeiro é uma alternativa mais rápida com relação ao segundo, que representa uma estratégia de busca exaustiva para o cálculo da máxima injeção de potência nodal. Destaca-se que o Método de Sensibilidades apresenta resultados mais conservadores para a maioria das barras do sistema e pode ser usado como uma estratégia inicial na resolução do problema.

\subsection{Considerações Finais do Capítulo}

Ao término deste capítulo, pode-se afirmar que o Método de Sensibilidades foi capaz de calcular as tensões nodais do sistema elétrico considerando a operação de um SAET e as máximas injeções de potência nodais que este pode realizar. Destaca-se que em sua formulação trifásica as barras monofásicas ou bifásicas foram tratadas como barras monofásicas cujas fases não existentes foram preenchidas com elementos nulos. Estas fases devem ser desconsideradas em operações de inversão de matrizes. A barra de referência do sistema também deve ser desconsiderada na formulação do método mencionado. Isto se deve ao fato de que a aplicação deste requer a existência de barras PQ, apenas. Ademais, o sistema IEEE 34 barras foi modificado para a aplicação do método em questão por motivo de simplificação da programação via MATLAB. Este programa foi utilizado para a obtenção da matriz Jacobiana do sistema elétrico, parte da formulação do Método de Sensibilidades.

Em sua etapa de validação, o erro máximo obtido foi de aproximadamente 2,6\%. Este valor indica um desempenho satisfatório do método, uma vez que até equipamentos de medição podem ter erros com ordem de grandeza maiores do que esta. Em sua aplicação apresentada na seção 5.2.1, o Método de Sensibilidades permitiu o estudo da alocação de 
um SAET com apenas 26 fluxos de carga e demandou um tempo de processamento menor do que o Índice IMP. Apesar disso, o método mencionado apresentou a mesma tendência que este índice: as melhores alocações são as que se encontram eletricamente próximas a subestação do sistema em estudo. Já na tarefa de cálculo das máximas injeções de potência nodais, abordada na seção 5.3.4, o Método de Sensibilidades foi mais rápido e conservador em comparação ao NR para a maioria das barras e apresentou erros médio e máximo de 5,5\% e 9,47\%, respectivamente. Observa-se que as maiores máximas injeções de potência nodais ocorrem no início do sistema analisado. 


\section{Capítulo 6}

\section{Conclusões}

No decorrer deste trabalho, constatou-se que a capacidade de mobilidade faz com que um SAET seja capaz de resolver problemas locais em sistemas elétricos e, como consequência, figure como alternativa capaz de ampliar a variedade de serviços já prestados pelos SAEs estacionários. Adicionalmente, verificou-se que o sucesso das aplicações de um SAET está intimamente ligado à sua correta alocação. Neste contexto, o índice IMP e o Método de Sensibilidades podem auxiliar o planejamento de sistemas de distribuição que contam com tais armazenadores de energia.

Ao aplicar o índice IMP verificou-se que as alocações mais benéficas para o sistema elétrico são as mais próximas eletricamente à subestação. Além disso, este índice possibilitou a identificação de quais eram os benefícios e os malefícios que a operação de um SAET em cada alocação traria ao sistema, bem como a comparação entre estas. Adicionalmente, o fato deste índice ser ponderado e ajustável permitiu o estudo do impacto do SAET em uma mesma alocação considerando relevâncias distintas entre os aspectos técnicos observados. Por fim, por meio da análise de taxas de descargas diferentes foi possível observar que as alocações mais próximas a subestação foram as melhores na maioria das análises, o que permite afirmar que estas foram as alocações mais robustas.

O Método de Sensibilidades teve sua eficácia comprovada. Em sua aplicação, constatou-se que as alocações de SAET mais próximas à subestação foram aquelas que forneceram tensões mais adequadas ao sistema, sobretudo nas condições mais extremas. O mesmo resultado foi confirmado por meio do Índice IMP. Adicionalmente, verificou-se que o Método de Sensibilidades foi capaz de realizar o cálculo da máxima injeção de potência por barras, porém com erros significativos. Erros estes que não impediram a conclusão de que as barras mais próximas da subestação são as que apresentam maiores valores de injeção de potência máxima. Vale ressaltar que o uso Método de Sensibilidades foi mais rápido do que o uso do Índice IMP e do Método de NR nas tarefas de alocação de um SAET e cálculo de máxima injeção de potência nodais, respectivamente. 


\subsection{Trabalhos futuros}

O estudo da alocação de um SAET e a determinação da máxima injeção de potência nas barras de um sistema de distribuição são tarefas importantes e desafiadoras. Por estes motivos, existe a demanda por estudos mais aprofundados para que conclusões mais sólidas possam ser tecidas. Dentre os passos que podem ser tomados para uma abordagem mais abrangente sobre o assunto, destacam-se simulações de vários modos de operação de um SAET simultaneamente e estudos usando a aplicação sequencial do Método de Sensibilidades e Índice IMP. Adicionalmente, a reaplicação dos estudos em um sistema de baixa tensão contribuiria para a investigação da generalização dos impactos da operação de um SAET abordados neste trabalho. Por fim, algumas outras sugestões para trabalhos futuros são:

- Estudo do impacto da taxa de carga e descarga na vida útil de um SAET;

- Estudo do impacto da profundidade de descarga na vida útil de um SAET;

- Simulação da operação do SAET em outros fatores de potência, que não o unitário.

- Elaboração de uma formulação do Método de Sensibilidades para alocação do SAET considerando as perdas elétricas;

- Elaboração de uma formulação do Método de Sensibilidades para alocação do SAET considerando o chaveamento dos taps dos reguladores de tensão;

- Elaboração de uma formulação do Método de Sensibilidades para alocação do SAET considerando tensão, perdas e chaveamento dos taps dos reguladores de tensão tudo junto, unindo os impactos mencionados de forma semelhante à do índice IMP. 


\section{Referências Bibliográficas}

ABDELTAWAB, Hussein Hassan; MOHAMED, Yasser Abdel-Rady I. Mobile Energy Storage Scheduling and Operation in Active Distribution Systems. IEEE Transactions on Industrial Electronics, [S. 1.], v. 64, n. 9, p. 6828-6840, 2017. DOI: 10.1109/TIE.2017.2682779.

Disponível

em:

http://ieeexplore.ieee.org/document/7879208/.

AES ENERGY STORAGE. Deployments. 2017. Disponível em: http://aesenergystorage.com/deployments/. Acesso em: 31 out. 2017.

AKHAVAN-HEJAZI, Hossein; MOHSENIAN-RAD, Hamed. Optimal Operation of Independent Storage Systems in Energy and Reserve Markets With High Wind Penetration. IEEE Transactions on Smart Grid, [S. 1.], v. 5, n. 2, p. 1088-1097, 2014. DOI: 10.1109/TSG.2013.2273800. Disponível em: http://ieeexplore.ieee.org/document/6576293/.

AKHIL, Abbas A.; HUFF, Georgianne; CURRIER, Aileen B.; KAUN, Benjamin C.; RASTLER, Dan M.; CHEN, Stella Bingqing; COTTER, Andrew L.; BRADSHAW, Dale T.; GAUNTLETT, William D. SANDIA REPORT DOE / EPRI Electricity Storage Handbook in Collaboration with NRECA. [S. 1.], n. February, 2015.

ANEEL. Procedimentos de Distribuição de Energia Elétrica no Sistema Elétrico Nacional - PRODIST Módulo 8 - Qualidade da Energia Elétrica. [s.l: s.n.]. Disponível em: http://www.aneel.gov.br/documents/656827/14866914/Módulo_8Revisão_10/2f7cb862-e9d7-3295-729a-b619ac6baab9.

ATWA, Yasser Moustafa; EL-SAADANY, E. F. Optimal allocation of ESS in distribution systems with a high penetration of wind energy. IEEE Transactions on Power Systems, [S. l.J, v. 25, n. 4, p. 1815-1822, 2010. DOI: 10.1109/TPWRS.2010.2045663.

AYRES, H. M.; FREITAS, W.; DE ALMEIDA, M. C.; DA SILVA, L. C. P. Method for determining the maximum allowable penetration level of distributed generation without steady-state voltage violations. IET Generation, Transmission \& Distribution, [S. I.], v. 4, n. 4, p. 495, 2010. DOI: 10.1049/iet-gtd.2009.0317. Disponível em: https://digital-library.theiet.org/content/journals/10.1049/ietgtd.2009.0317.

AYRES, Hugo Murici. Desenvolvimento de Metodologias de Análise de Geradores Distribuídos em Sistemas de Distribuição de Energia Elétrica. [S. 1.], p. 176, 2010. Disponível em: http://repositorio.unicamp.br/handle/REPOSIP/261207.

BABACAN, Oytun; TORRE, William; KLEISSL, Jan. Optimal allocation of battery energy storage systems in distribution networks considering high PV penetration. 
In: 2016 IEEE POWER AND ENERGY SOCIETY GENERAL MEETING (PESGM) 2016, Anais [...]. : IEEE, 2016. p. 1-5. DOI: 10.1109/PESGM.2016.7741191. Disponível em: http://digitallibrary.theiet.org/content/journals/10.1049/iet-rpg.2015.0542.

BELFORTE, Guido; GUZZONI, Gianfranco. L'energia viene dal vento. 2013. Disponível em: http://www.oleodinamicapneumatica.it/2013/08/23/lenergia-vienedal-vento/. Acesso em: 2 ago. 2018.

BUSINESS WIRE, Company. PSE\&G Installs and Commissions 1 MWh Eos Aurora Battery System for Solar $4 \mathrm{All} @$ Microgrid Project at New Jersey Water Treatment Facility. 2017. Disponível em: https://www.businesswire.com/news/home/20171025005889/en/PSEG-InstallsCommissions-1-MWh-Eos-Aurora.

CANALES, Fausto Alfredo; BELUCO, Alexandre; MENDES, Carlos André Bulhões. Usinas hidrelétricas reversíveis no Brasil e no mundo: aplicação e perspectivas. Revista Eletrônica em Gestão, Educação e Tecnologia Ambiental Revista do Centro de Ciências Naturais e Exatas - UFSM, [S. 1.], v. 19, n. 2, p. 1230-1249, 2015. Disponível em: http://cascavel.ufsm.br/revistas/ojs2.2.2/index.php/reget/article/download/16002/pdf.

CHEVRON ENERGY SOLUTIONS COMPANY. CERTS Microgrid demonstration with large-scale energy storage and renewables at Santa Rita Jail. [s.l: s.n.].

COHN, Lisa. The Microgrid Way: Going Green with Solar \& Supercapacitor-based Energy Storage. 2018. Disponível em: https://microgridknowledge.com/supercapacitor-based-energy-storage/. Acesso em: 2 ago. 2018.

CON EDISON, Inc. Our Businesses. 2016. Disponível em: https://www.conedison.com/en/about-us/our-businesses. Acesso em: 1 nov. 2017.

CON EDISON, Inc. REV Demonstration Project Outline - Storage On Demand. [s.l: s.n.].

CON EDISON, Inc. Episode 15: Storing for the Future With Batteries de Con Edison Plugged In. 2017b. Disponível em: https://soundcloud.com/conedison/plugged-in-storing-for-the-future. Acesso em: 1 nov. 2017.

CON EDISON, Inc. Investor Relations - Press Release. 2017c. Disponível em: http://investor.conedison.com/phoenix.zhtml?c=61493\&p=irol-

newsArticle\&ID=2264550. Acesso em: 1 nov. 2017.

DE MORAIS FILHO, Sergio Augusto; DIAS, Leandro Rosa; DE MELO VIEIRA, Jose Carlos. Mitigation of voltage variations during cloud transients by using energy storage systems. In: 2018 SIMPOSIO BRASILEIRO DE SISTEMAS ELETRICOS (SBSE) 2018, Anais [...]. : IEEE, 2018. p. 1-6. DOI: 10.1109/SBSE.2018.8395538. Disponível em: https://ieeexplore.ieee.org/document/8395538/. 
DEPARTMENT OF PUBLIC SERVICES - STATE OF NY. About the initiative. 2017. Disponível em: http://www3.dps.ny.gov/W/PSCWeb.nsf/All/CC4F2EFA3A23551585257DEA007D CFE2?OpenDocument. Acesso em: 1 nov. 2017.

DIOUF, Boucar; PODE, Ramchandra. Potential of lithium-ion batteries in renewable energy. Renewable Energy, [S. 1.J, v. 76, p. 375-380, 2015. DOI: 10.1016/j.renene.2014.11.058.

em: http://dx.doi.org/10.1016/j.renene.2014.11.058.

DIVYA, K. C.; ØSTERGAARD, Jacob. Battery energy storage technology for power systems-An overview. Electric Power Systems Research, [S. 1.], v. 79, n. 4, p. 511520, 2009. DOI: 10.1016/j.epsr.2008.09.017. Disponível em: http://linkinghub.elsevier.com/retrieve/pii/S0378779608002642.

DOE GLOBAL ENERGY STORAGE DATABASE. Los Andes Substation Battery Energy Storage System - AES Gener. 2016a. Disponível em: https://www.energystorageexchange.org/projects/24. Acesso em: 31 out. 2017.

DOE GLOBAL ENERGY STORAGE DATABASE. Santa Rita Jail Smart Grid Alameda County RDSI CERTS Microgrid Demonstration. 2016b. Disponível em: https://www.energystorageexchange.org/projects/91. Acesso em: 1 nov. 2017.

DOE GLOBAL ENERGY STORAGE DATABASE. Smarter Network Storage. 2016c. Disponível em: https://www.energystorageexchange.org/projects/411. Acesso em: 1 nov. 2017.

DOE GLOBAL ENERGY STORAGE DATABASE. Fujian Electric Power Research Institute Mobile Energy Storage Station I. 2016d. Disponível em: http://www.energystorageexchange.org/projects/153. Acesso em: 1 nov. 2017.

DOE GLOBAL ENERGY STORAGE DATABASE. $250 \mathrm{~kW} / 1 \mathrm{MWh}$ ElChe Wettringen. 2016e. Disponível em: http://www.energystorageexchange.org/projects/1870. Acesso em: 1 nov. 2017.

DOE GLOBAL ENERGY STORAGE DATABASE. Notrees Battery Storage Project - Duke Energy. 2017. Disponível em: https://www.energystorageexchange.org/projects/11. Acesso em: 1 nov. 2017.

DONOVAN, Aaron. Hardenbergh Database I ConEd Headquarters. 2008. Disponível em: http://www.startsandfits.com/hardenbergh/coned.html. Acesso em: 1 nov. 2017.

DUGAN, Roger C.; EPRI. Modeling Multi-Winding Transformers, 2013. Disponível em: http://svn.code.sf.net/p/electricdss/code/trunk/Distrib/Doc/.

DUGAN, Roger C.; MONTENEGRO, Davis; BALLANTI, Andrea; EPRI. Reference Guide: The Open Distribution System Simulator (OpenDSS). [S. 1.], n. April, p. 1199, 2018. Disponível em: http://svn.code.sf.net/p/electricdss/code/trunk/Distrib/Doc/. 
DUGAN, Roger C.; TAYLOR, Jason A.; MONTENEGRO, Davis. Energy Storage Modeling for Distribution Planning. IEEE Transactions on Industrial Applications, [S. 1.], v. 53, n. 2, p. 954-962, 2017. DOI: 10.1109/REPC.2016.11.

EASE/EERA. EASE/EERA Energy Storage Technology Development Roadmap towards 2030. [s.l: s.n.]. Disponível em: https://ease-storage.eu/wpcontent/uploads/2015/10/EASE-EERA-recommendations-Annex-LR.pdf.

ELECTROVAYA. Electrovaya to Deliver Portable, High Capacity Battery Storage System to Con Edison for Clean Energy Grid Support. [S. 1.], 2015. Disponível em: http://www.electrovaya.com/pdf/PR/2015/PR20150914.pdf. Acesso em: 1 nov. 2017.

ELECTROVAYA. Press Releases. 2016. Disponível em: http://electrovaya.com/press-releases/. Acesso em: 1 nov. 2017.

ENERGY STORAGE ASSOCIATION. Frequency Regulation Services and a Firm Wind Product: AES Energy Storage Laurel Mountain Battery Energy Storage (BESS) | Energy Storage Association. 2017a. Disponível em: http://energystorage.org/energy-storage/case-studies/frequency-regulationservices-and-firm-wind-product-aes-energy-storage. Acesso em: 1 nov. 2017.

ENERGY STORAGE ASSOCIATION. S\&C Electric Company: PureWave® Storage Management System Fortifies California Jail's Microgrid. 2017b. Disponível em: http://energystorage.org/energy-storage/case-studies/sc-electriccompany-purewave ${ }^{\circledR-}$-storage-management-system-fortifies. Acesso em: 1 nov. 2017.

ENGADGET. Gallery: Beacon Power's Stephentown, NY flywheel plant. 2018. Disponível em: https://www.engadget.com/gallery/beacon-powers-stephentown-nyflywheel-plant/\#gallery=53024\&slide=590076\&index=0. Acesso em: 2 ago. 2018 .

EPRI. Multi-Mode Transportable Battery Energy System for Salt River Project Volume1: Design and Installation. Palo Alto, CA. Disponível em: https://www.epri.com/\#/pages/product/TR-110859-V1 /.

EPRI. OpenDSS STORAGE Element and STORAGECONTROLLER Element, 2011. Disponível em: http://svn.code.sf.net/p/electricdss/code/trunk/Distrib/Doc/.

EPRI. Quick Insights: Evolution in the Lithium-Ion Battery Industry. [s.l: s.n.]. Disponível em: https://www.epri.com/\#/pages/product/000000003002010978/?lang=en.

EPRI. Energy Storage Technology and Cost Assessment: Executive Summary. [S. l.], n. December, 2018. Disponível em: https://www.epri.com/research/products/000000003002013958.

FITZGERALD, Garrett; MANDEL, James; MORRIS, Jesse; TOUATI, Hervé. The Economics of Battery Energy Storage: how multi-use, customer-sted batteries deliver the most services and value to customers and the grid. [s.l: s.n.]. Disponível em: http://www.rmi.org/electricity_battery_value. 
GALLARDO, Jesús Armando Morán. Impacto De Geradores Síncronos No Desempenho De Regime Permanente De Sistemas De Distribuição De Energia Elétrica. Universidade Estadual de Campinas - UNICAMP, [S. 1.], n. D, 2005.

GIANNITRAPANI, Antonio; PAOLETTI, Simone; VICINO, Antonio; ZARRILLI, Donato. Optimal Allocation of Energy Storage Systems for Voltage Control in LV Distribution Networks. IEEE Transactions on Smart Grid, [S. 1.], v. 8, n. 6, p. 2859-2870, 2017. DOI: 10.1109/TSG.2016.2602480. Disponível em: http://ieeexplore.ieee.org/document/7552579/.

GOLDMAN, Steven. SDG\&E and AES Energy Storage Unveil World's Largest Lithium Ion Battery-Based Energy Storage Installation. 2017. Disponível em: http://blog.fluenceenergy.com/sdge-and-aes-energy-storage-unveil-worlds-largestbattery-storage-installation. Acesso em: 2 ago. 2018.

GREENTECH MEDIA. The Risks of Novel Batteries Wearing Out Before Their Time. 2015. Disponível em: https://www.greentechmedia.com/articles/read/therisks-of-novel-batteries-wearing-out-before-their-time\#gs.=M8qMCs. Acesso em: 1 nov. 2017.

GREENTECH MEDIA. U.S. Energy Storage Monitor: Q2 2017 Executive Summary. [S. 1.], n. June, 2017.

HATZIARGYRIOU, Nikos D.; ŠKRLEC, Davor; CAPUDER, Tomislav; GEORGILAKIS, Pavlos S.; ZIDAR, Matija. Review of energy storage allocation in power distribution networks: applications, methods and future research. IET Generation, Transmission \& Distribution, [S. I.J, v. 10, n. 3, p. 645-652, 2016. DOI: 10.1049/iet-gtd.2015.0447. Disponível em: http://digitallibrary.theiet.org/content/journals/10.1049/iet-gtd.2015.0447.

KALKHAMBKAR, Vaiju; KUMAR, Rajesh; BHAKAR, Rohit. Joint optimal allocation methodology for renewable distributed generation and energy storage for economic benefits. IET Renewable Power Generation, [S. 1.], v. 10, n. 9, p. 14221429, 2016. DOI: 10.1049/iet-rpg.2016.0014. Disponível em: http://digitallibrary.theiet.org/content/journals/10.1049/iet-rpg.2016.0014.

KARANKI, Srinivas Bhaskar; XU, David. Optimal capacity and placement of battery energy storage systems for integrating renewable energy sources in distribution system. In: 2016 NATIONAL POWER SYSTEMS CONFERENCE (NPSC) 2016, Anais [...]. : IEEE, 2016. p. 1-6. DOI: 10.1109/NPSC.2016.7858983. Disponível em: http://ieeexplore.ieee.org/document/7858983/.

KERSTING, W. H. Radial distribution test feeders. In: 2001 IEEE POWER ENGINEERING SOCIETY WINTER MEETING. CONFERENCE PROCEEDINGS (CAT. NO.01CH37194) 2001, Anais [...]. : IEEE, 2001. p. 908912. DOI: 10.1109/PESW.2001.916993. Disponível em: http://ieeexplore.ieee.org/document/916993/.

KHALID MEHMOOD, Khawaja; KHAN, Saad Ullah; LEE, Soon-Jeong; HAIDER, 
Zunaib Maqsood; RAFIQUE, Muhammad Kashif; KIM, Chul-Hwan. Optimal sizing and allocation of battery energy storage systems with wind and solar power DGs in a distribution network for voltage regulation considering the lifespan of batteries. IET Renewable Power Generation, [S. 1.], v. 11, n. 10, p. 1305-1315, 2017. DOI: 10.1049/iet-rpg.2016.0938. Disponível em: http://digitallibrary.theiet.org/content/journals/10.1049/iet-rpg.2016.0938.

KRIEGER, Elena M.; CANNARELLA, John; ARNOLD, Craig B. A comparison of lead-acid and lithium-based battery behavior and capacity fade in off-grid renewable charging applications. Energy, [S. 1.J, v. 60, p. 492-500, 2013. DOI: 10.1016/j.energy.2013.08.029.

Disponível

em:

http://dx.doi.org/10.1016/j.energy.2013.08.029.

MOEINI, A.; KAMWA, I.; DE MONTIGNY, M. Optimal multi-objective allocation and scheduling of multiple battery energy storages for reducing daily marginal losses. In: 2015 IEEE POWER AND ENERGY SOCIETY INNOVATIVE SMART GRID TECHNOLOGIES CONFERENCE, ISGT 2015 2015, Anais [...]. [s.l: s.n.] DOI: 10.1109/ISGT.2015.7131909.

NAKASHIMA, Victor Makida. Análise dos impactos da implementação de sistemas de armazenamento de energia em redes de distribuição de energia elétrica operando em regime permanente. 2018. Universidade de São Paulo, [S. 1.], 2018. Disponível em: http://www.tcc.sc.usp.br/tce/disponiveis/18/180500/tce31072018-112547/?\&lang=br.

PARKER HANNIFIN CORPORATION. Renewable Energy Generation: The Importance of Energy Storage. 2016. Disponível em: http://blog.parker.com/renewable-energy-generation:-the-importance-of-energystorage?hootPostID=5adc67bd8af2be6344b383f8f48a546d. Acesso em: 1 nov. 2017.

RADATZ, Paulo. Modelos avançados de análise de redes elétricas inteligentes utilizando o software OpenDSS. 2015. Universidade de São Paulo, [S. 1.], 2015.

SAMPER, Mauricio E.; VARGAS, Alberto; ELDALI, Fathalla; SURYANARAYANAN, Siddharth. Assessments of battery storage options for distribution expansion planning using an OpenDSS-based framework. 2017 IEEE Manchester PowerTech, Powertech 2017, [S. 1.], 2017. DOI: 10.1109/PTC.2017.7981220.

SEXAUER, Jason; EPRI. New User Primer: The Open Distribution System Simulator (OpenDSS). [S. 1.J, n. September, p. 1-35, 2012. Disponível em: http://svn.code.sf.net/p/electricdss/code/trunk/Distrib/Doc/.

SOLAR POWER PLANT BUSINESS. Tohoku-Electric Power Begins Operation of 40MWh Li-ion Battery System. 2016. Disponível em: http://techon.nikkeibp.co.jp/atclen/news_en/15mk/030900431/?ST=msbe. Acesso em: 1 nov. 2017.

SOURCEFORGE. Download Statistics. 2018. Disponível em: 
https://sourceforge.net/projects/electricdss/files/stats/map?dates=2017-0101+to+2017-12-31. Acesso em: 21 ago. 2018.

TOSHIBA. Spain's Gas Natural Fenosa and Toshiba to Demonstrate Use of Transportable Lithium-ion Battery Energy Storage System in Power Distribution Network. 2014. Disponível em: https://www.toshiba.co.jp/about/press/2014_01/pr0704.htm\#PRESS. Acesso em: 1 nov. 2017.

TOSHIBA. Toshiba to Supply Japan's Largest Lithium-ion Battery Energy Storage System For Tohoku Electric Power Company. 2015. Disponível em: https://www.toshiba.co.jp/about/press/2015_05/pr2901.htm\#PRESS. Acesso em: 1 nov. 2017.

UTILITY DIVE. How ConEd's mobile battery REV demo could build a new storage business model. 2017. Disponível em: https://www.utilitydive.com/news/howconeds-mobile-battery-rev-demo-could-build-a-new-storage-businessmode/437364/. Acesso em: 1 nov. 2017.

YOUNICOS. Improving Grid Stability and Integrating Renewable Energy in a Major North American Market. [S. 1.], 2017. a. Disponível em: https://www.younicos.com/wp-

content/uploads/2016/07/Younicos_Reference_Project_Notrees_US.pdf. Acesso em: 1 nov. 2017.

YOUNICOS. Intelligence for Europe's Biggest Storage Project. [S. 1.], 2017. b. Disponível em: https://www.younicos.com/wpcontent/uploads/2016/07/Younicos_Reference_Project_LeightonBuzzard_EUR.pdf. Acesso em: 6 nov. 2017.

ZHENG, Yu; MEMBER, Student; DONG, Zhao Yang; MEMBER, Senior; LUO, Feng Ji; MEMBER, Student. Optimal Allocation of Energy Storage System for Risk Mitigation of DISCOs With High Renewable Penetrations. [S. 1.], v. 29, n. 1, p. 212-220, 2014. 


\section{Apêndice}

\section{A. Instalações de sistemas de baterias - Estado da arte}

As informações obtidas referentes aos sistemas de baterias já em operação atualmente serão apresentadas nesta seção. Para melhor compreensão, tais sistemas estão organizados em não transportáveis e transportáveis, respectivamente, e serão descritos com relação as suas características: localização, tipo de tecnologia das baterias utilizadas, potência, capacidade de armazenamento, data de início de operação, aplicações e proprietários. Vale destacar que as imagens referentes às localizações de tais sistemas foram obtidas através da ferramenta Google Maps, caso suas fontes não forem especificadas.

\section{1) Instalações de sistemas de baterias não transportáveis}

\section{a) Copiato, Atacama, Chile}

Localizado no Atacama, Chile, este sistema é responsável pelo suprimento reserva de energia e regulação de frequência em uma área caracterizada pela atividade de mineração. Para tanto, emprega, desde dezembro de 2009, $12 \mathrm{MW}$ de potência e $4 \mathrm{MWh}$ de capacidade fornecidos por baterias de íons de Lítio (DOE GLOBAL ENERGY STORAGE DATABASE, 2016a). Desenvolvido pela AES Energy Storage e de propriedade da AES Gener (DOE GLOBAL ENERGY STORAGE DATABASE, 2016a), este sistema se destaca como um dos melhores em atividade na região (AES ENERGY STORAGE, 2017).

A instalação em questão e sua localização podem ser observadas na Figura 41 e na Figura 42, respectivamente. 
Figura 41 - Sistema de baterias de $12 \mathrm{MW} / 4 \mathrm{MWh}$

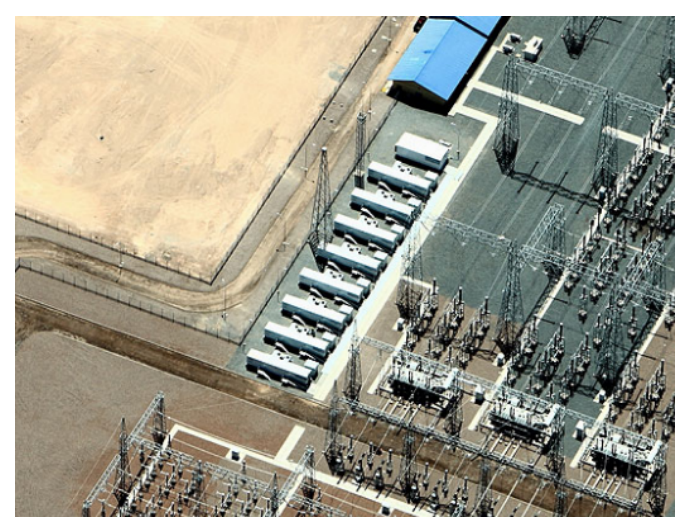

Fonte: (AES ENERGY STORAGE, 2017)
Figura 42 - Copiato, Atacama, Chile

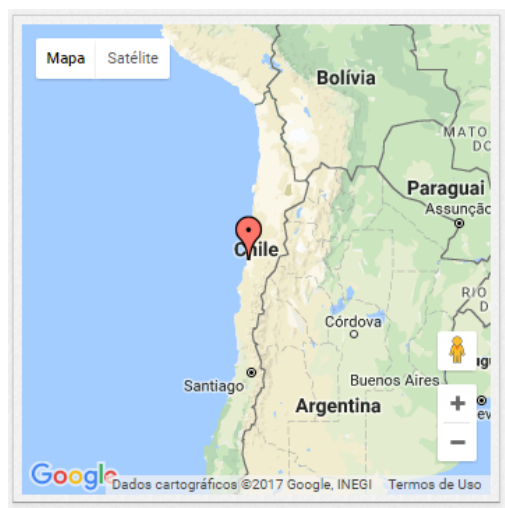

\section{b) Elkins, Virgínia do Oeste, Estados Unidos da América (EUA)}

Com 32 MW de potência e 8 MWh de capacidade, este sistema de armazenamento de energia opera integrado a uma planta de geração eólica de $98 \mathrm{MW}$ de potência instalada, localizado no estado da Virgínia do Oeste, nos EUA (AES ENERGY STORAGE, 2017). Além de atuar na regulação da frequência, este sistema permite um controle na potência fornecida pelo parque eólico ao qual está conectado à rede elétrica. Também desenvolvido pela AES Energy Storage e em operação desde outubro de 2011, este sistema conta com baterias de íons de Lítio e é de propriedade da AES Wind Generation (ENERGY STORAGE ASSOCIATION, 2017a).

A Figura 43 e a Figura 44 apresentam o sistema mencionado e sua localização geográfica, respectivamente.

Figura 43 - Sistema de baterias de $32 \mathrm{MW} / 8 \mathrm{MWh}$

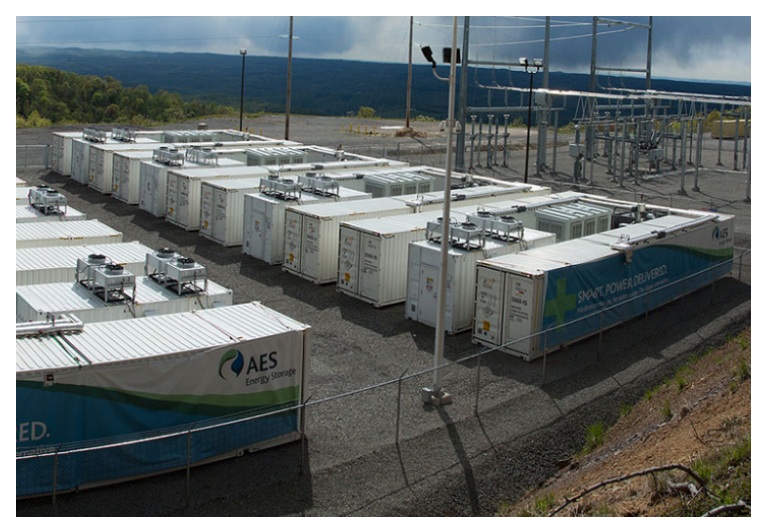

Fonte: (AES ENERGY STORAGE, 2017)
Figura 44 - Elkins, EUA

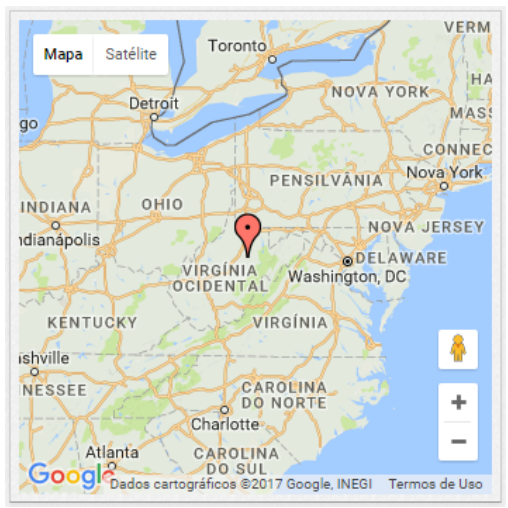


Instalado como parte de uma microrrede composta por geradores a diesel, células combustíveis, painéis fotovoltaicos e turbinas eólicas, conforme ilustra a Figura 45, este sistema de baterias de íon de Lítio tem como funções garantir que o excedente de energia gerado quando em operação ilhada seja armazenado (ENERGY STORAGE ASSOCIATION, 2017b) e ainda aliviar o carregamento dos alimentadores internos (CHEVRON ENERGY SOLUTIONS COMPANY, 2014).

Adicionalmente, as baterias armazenam energia comprada em períodos de baixa demanda, a baixo custo, e posteriormente usada em períodos de pico, quando o sistema opera conectado à rede. Tal aplicação é comumente denominada como peak shaving e, neste caso, foi projetada para economizar cerca de 100 mil dólares por ano (ENERGY STORAGE ASSOCIATION, 2017b).

Tal sistema se encontra em operação desde meados de março de 2012, em Dublin, estado da Califórnia, EUA, conforme apresenta a Figura 46. Destaca-se, ainda, que este foi desenvolvido pela Chevron Energy e pertence à Penitenciária de Santa Rita (DOE GLOBAL ENERGY STORAGE DATABASE, 2016b).

Figura 45 - Componentes da microrrede pertencente à Penitenciária de Santa Rita

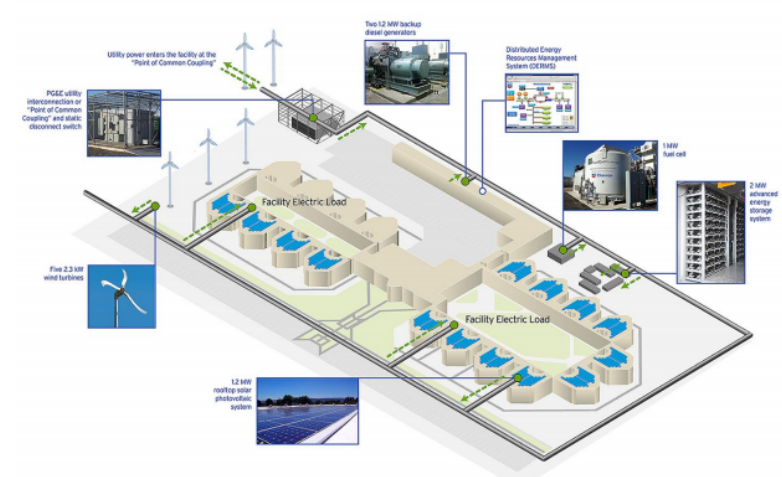

Fonte: (CHEVRON ENERGY SOLUTIONS

COMPANY, 2014)
Figura 46 - Dublin, Califórnia, EUA

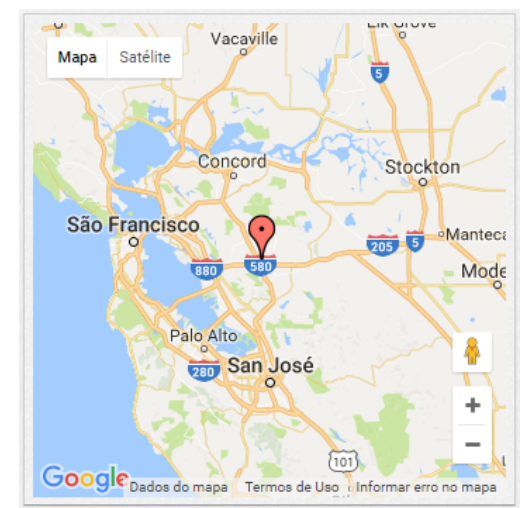

\section{d) Notrees, Texas, EUA}

Composto inicialmente por baterias de chumbo - ácido, este sistema de armazenamento de energia teve suas baterias substituídas por baterias de íon de Lítio durante o ano de 2016 (GREENTECH MEDIA, 2015), com a finalidade de obter uma velocidade de resposta maior e, como consequência, atingir um patamar mais elevado de desempenho. Tal motivação se justifica pelo fato de este sistema ser utilizado para prover 
serviços de regulação de frequência, bem como atuar no gerenciamento de energia (YOUNICOS, 2017a).

É importante destacar que o sistema em questão opera interligado a um parque eólico de 153 MW, que pode ser visto na Figura 47, o que o torna o maior sistema de baterias interligado a geração eólica na América do Norte (YOUNICOS, 2017a). As baterias proporcionam 36 MW e 13,2 MWh e estão em operação desde dezembro de 2012, na cidade de Notrees, Texas, EUA, conforme apresenta a Figura 48. A concessionária Duke Energy é proprietária deste sistema de armazenamento e foi a responsável pelo seu desenvolvimento (DOE GLOBAL ENERGY STORAGE DATABASE, 2017).

Figura 47 - Sistema de baterias de $36 \mathrm{MW} /$ 13,2 MWh

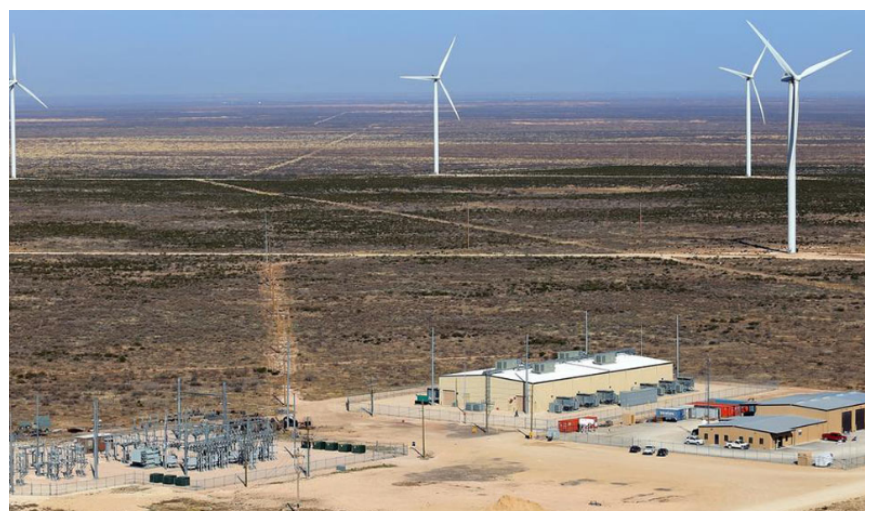

Fonte: (DOE GLOBAL ENERGY STORAGE

DATABASE, 2017)
Figura 48 - Notrees, EUA

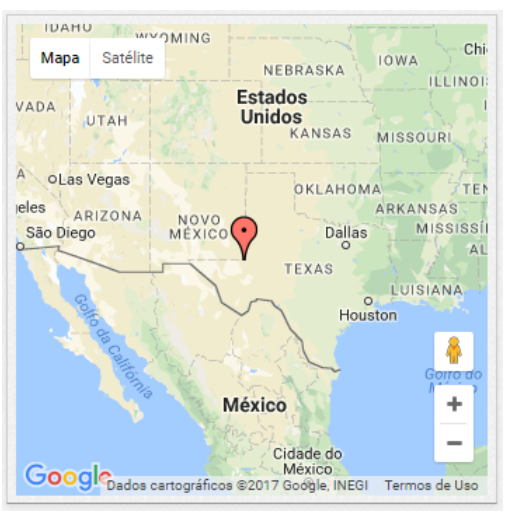

\section{e) Leighton Buzzard, Bedfordshire, Reino Unido}

Desenvolvido pelo operador do sistema de distribuição UK Power Networks, este sistema de baterias apresentado na Figura 49 está localizado no Reino Unido, conforme a Figura 50, e foi implementado como parte do projeto intitulado "Smarter Network Storage" (SNS). Projeto este que tem o intuito de investigar formas economicamente viáveis de aplicações de sistemas armazenadores de energia para auxiliar estratégias do governo britânico de reduzir emissões de carbono (YOUNICOS, 2017b).

Para tanto, este sistema, que é o maior armazenador de energia da Europa, é composto por baterias de íons de Lítio que, juntas, fornecem 6 MW e 10 MWh. Embora sua principal aplicação seja atuar no peak shaving, tal armazenador de energia realiza também outros serviços, como a regulação de frequência. Ademais, o sistema em questão pertence à mesma companhia que o desenvolveu (DOE GLOBAL ENERGY STORAGE DATABASE, 2016c). 
Figura 49 - Sistema de baterias de $6 \mathrm{MW} / 10 \mathrm{MWh}$

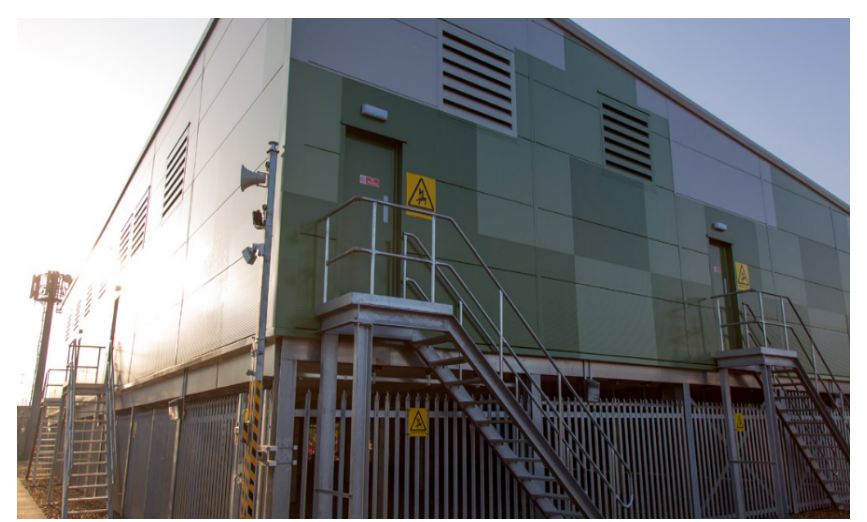

Fonte: (YOUNICOS, 2017b)
Figura 50 - Leighton Buzzard, Reino Unido

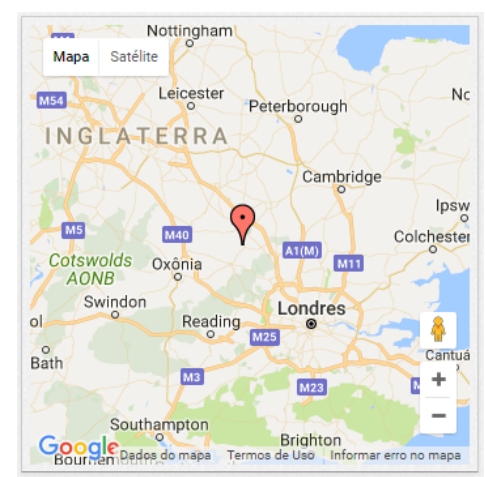

\section{Minamisoma, Fukushima, Japão}

Em operação comercial desde fevereiro de 2016, este sistema de armazenamento aplica baterias de íons de Lítio para aperfeiçoar a relação de oferta e demanda de energia afetada pelas fontes renováveis e mitigar a flutuação de tensão na rede, causada pela variação na geração por fontes renováveis, utilizando a compensação de potência reativa (SOLAR POWER PLANT BUSINESS, 2016).

O sistema, apresentado na Figura 51, faz parte de um projeto da Tohoku Electric Power Company e está instalado no local exposto na Figura 52. De acordo com (TOSHIBA, 2015), o sistema com 40MW de potência e capacidade de 40 MWh era considerado o maior do tipo no Japão, em pesquisa datada de 29 de maio de 2015.

Figura 51 - Sistema de baterias de $40 \mathrm{MW} / 40 \mathrm{MWh}$

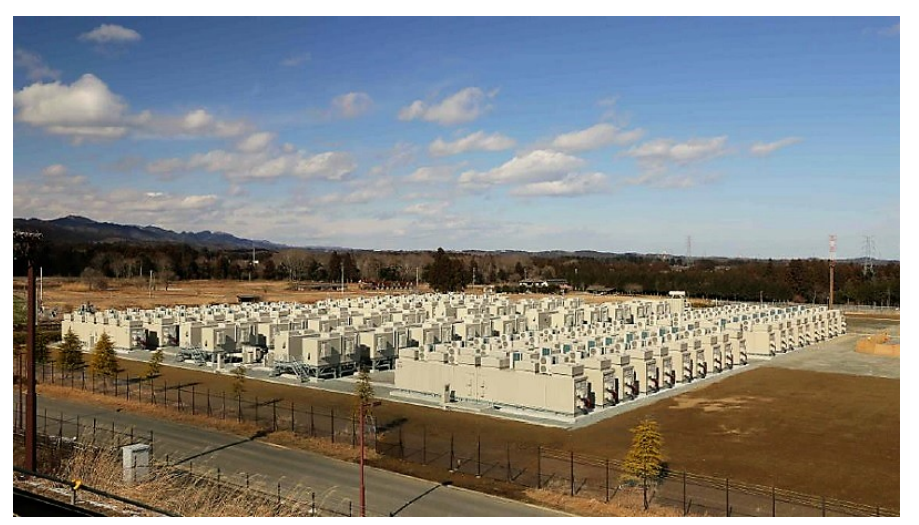

Fonte: (SOLAR POWER PLANT BUSINESS, 2016)
Figura 52 - Minamisoma, Japão

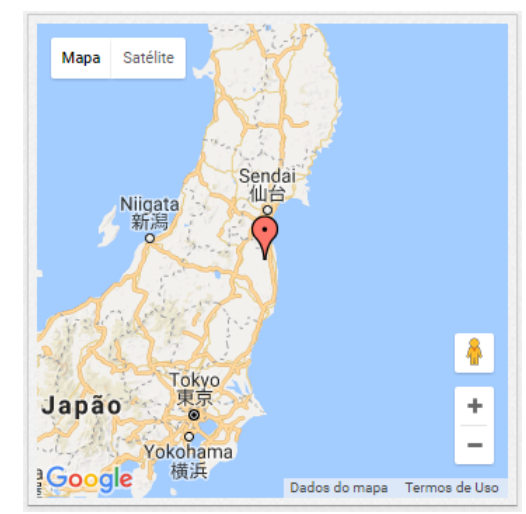




\section{2) Instalações de sistemas de baterias transportáveis}

\section{a) Tempe, Arizona, EUA}

O considerado primeiro sistema de armazenamento de energia multi-modo e transportável, via bateria, foi resultado de investimentos conjuntos entre o Electric Power Research Institute (EPRI) e a concessionária de energia denominada Salt River Project (SRP), com sede localizada em Tempe, no estado do Arizona, EUA. Como parte de um projeto em parceria com o Departamento de Energia dos EUA, o projeto mencionado foi desenvolvido pela então AC Battery Corporation, vendida à OMNION Power Engineering Corporation em dezembro de 2017 (EPRI, 1999).

O sistema, que entrou em operação no ano de 1997, conta com dois modos de operação: modo de qualidade de energia e modo de gerenciamento de energia. A capacidade deste quando operando no modo de qualidade de energia é de $2000 \mathrm{~kW}$ durante 15 segundos. Já quando operando no modo de gerenciamento de energia, este é capaz de suprir $200 \mathrm{~kW}$ e $150 \mathrm{kWh}$ (EPRI, 1999).

Com a finalidade de aumentar, qualidade da energia, de realizar o peak shaving e assim contribuir para a postergação de investimentos em transmissão e distribuição, as baterias utilizadas neste projeto são de Chumbo-ácido inundadas (EPRI, 1999).

A Figura 53 e a Figura 54 apresentam o sistema desenvolvido e a localização da sede da concessionária responsável pelo seu projeto, respectivamente.

Figura 53 - Sistema de baterias multi-modo

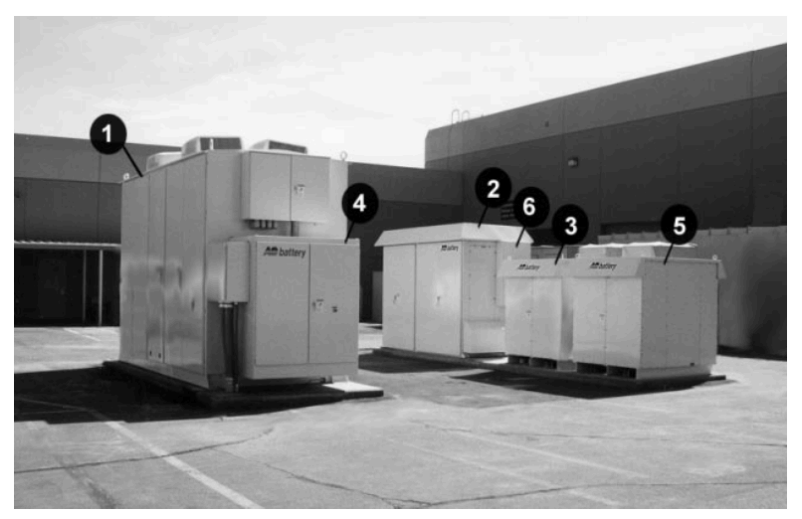

Fonte: (EPRI, 1999)
Figura 54 - Tempe, Arizona, EUA

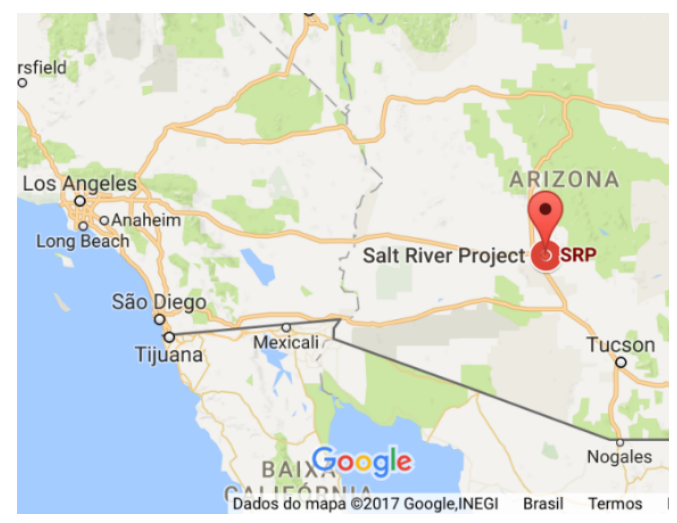




\section{b) Anxi, Fujian, China}

Em operação desde 2012, o sistema móvel de armazenamento de energia que pertence ao Fujian Electric Power Research Institute conta com dois módulos, o primeiro com dois conjuntos de $125 \mathrm{~kW}$ e $250 \mathrm{kWh}$ cada e o segundo com um único conjunto de 125 kW e 375 kWh (DOE GLOBAL ENERGY STORAGE DATABASE, 2016d).

As baterias de fosfato de Lítio e Ferro são responsáveis pelo fornecimento de energia em horário de pico para alguns consumidores industriais ligados à produção de chá, localizados na região indicada na Figura 55 (DOE GLOBAL ENERGY STORAGE DATABASE, 2016d).

Figura 55 - Anxi, Fujian, China

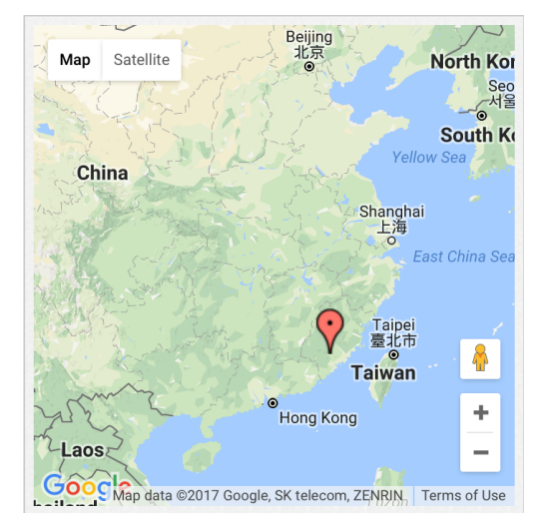

\section{c) $\quad$ Alcalá de Henares, Madrid, Espanha}

Com o objetivo de demonstrar a capacidade que sistemas de armazenamento de energia via baterias possuem de contribuir para a confiabilidade da rede elétrica caracterizada pela grande penetração de fontes renováveis de energia e de suprir energia em situações emergenciais, a concessionária Gás Natural Fenosa, cuja sede é apresentada na Figura 56, em parceria com a Toshiba Corporation iniciou a etapa de testes de um sistema móvel de armazenamento de energia de $500 \mathrm{~kW}$ e capacidade de $775 \mathrm{kWh}$. Esta etapa teve início em dezembro de 2013 e terá duração de cinco anos.

O local de testes inicial é a subestação de distribuição de Alcalá de Henares, na Espanha, conforme ilustra a Figura 57. Entretanto, o sistema composto por baterias de íons de Lítio será testado em vários locais, de modo a permitir o estudo de diversas aplicações. Dentre estas, é possível citar suprimento de energia em locais com alta demanda, peak shaving e controle de tensão e potência provenientes de fontes renováveis de energia (TOSHIBA, 2014). 
Figura 56 - Sede Gás Natural Fenosa

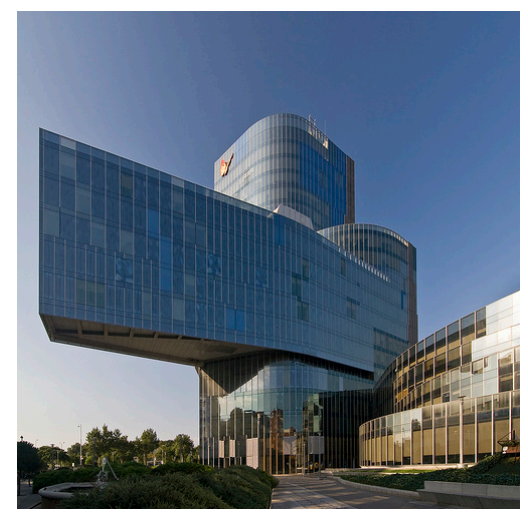

Figura 57 - Alcalá de Henares, Espanha

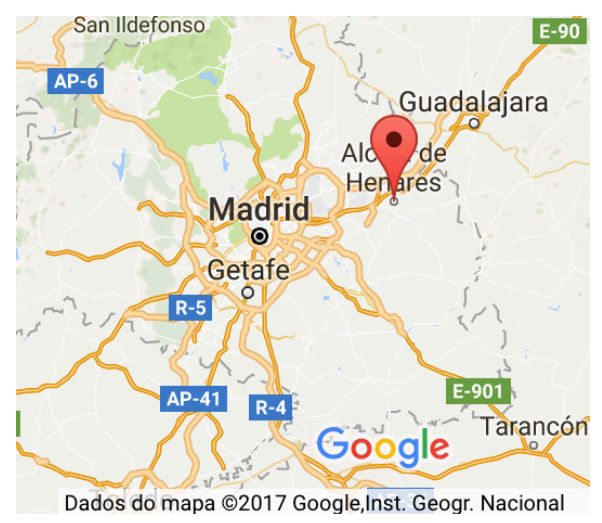

d) Wettringen, Renânia do Norte - Vestfália, Alemanha

Motivada a solucionar os problemas resultantes do aumento de geração fotovoltaica em áreas rurais de forma a não desperdiçar esta energia, amenizar possíveis custos adicionais devidos à imprevisibilidade deste tipo de geração, e a postergar investimentos na infraestrutura da rede elétrica local, a Westnetz, o maior operador de sistemas de distribuição da Alemanha, decidiu por usar um sistema de armazenamento de energia via baterias de íons de Lítio, desenvolvido em parceria com a empresa Parker Hannifin (DOE GLOBAL ENERGY STORAGE DATABASE, 2016e).

O sistema é armazenado em um container de aproximadamente 12 metros de comprimento (PARKER HANNIFIN CORPORATION, 2016), o que possibilita que este seja transportado para diferentes regiões, conforme a necessidade. Além disso, destaca-se que este possui $250 \mathrm{~kW}$ e $1 \mathrm{MWh}$ e entrou em operação em setembro de 2015. Dentre suas aplicações estão a capacidade de operação de forma autônoma e o suporte de tensão.

A Figura 58 e a Figura 59 apresentam o container mencionado e a região em que o sistema se encontra, respectivamente.

Figura 58 - Sistema de baterias de $250 \mathrm{~kW} / 1 \mathrm{MWh}$

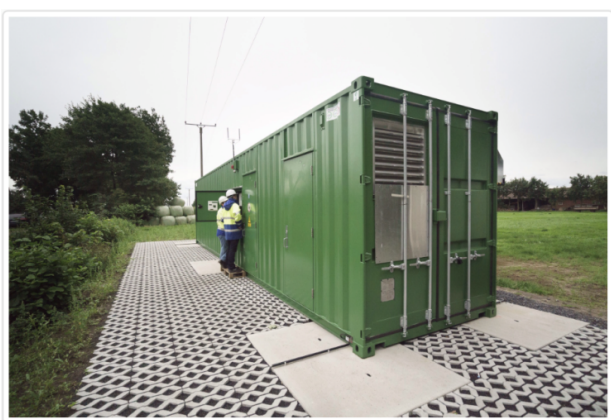

Figura 59 - Wettringen, Alemanha

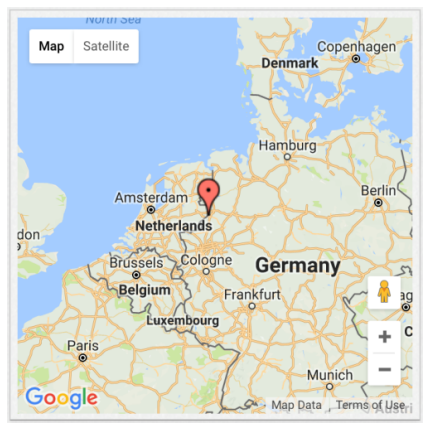

Fonte: (DOE GLOBAL ENERGY STORAGE DATABASE, 2016e) 
e)

Nova Iorque, Nova Iorque, EUA

Um sistema móvel de baterias de íons de Lítio que possui $500 \mathrm{~kW}$ e até $800 \mathrm{kWh}$ foi anunciado em 14 de setembro de 2015 pela Electrovaya (ELECTROVAYA, 2016), empresa responsável pelo fornecimento deste sistema à Con Edison de Nova Iorque, concessionária que fornece eletricidade e gás para consumidores na cidade de Nova Iorque e condado de Westchester, nos EUA (CON EDISON, 2016).

Tais baterias devem ser utilizadas como substitutas de geradores a diesel, até então usados pela Con Edison como meio de fornecimento portátil e temporário de energia. Sendo assim, espera-se que o sistema mencionado, cujo prazo de entrega era o segundo quadrante do ano de 2016, aumente a eficiência e resiliência da rede elétrica quando da ocorrência de interrupções no fornecimento de energia (ELECTROVAYA, 2015).

Menciona-se, adicionalmente, que o prédio em que se encontra sede da Con Edison e a sua localização estão à mostra na Figura 60 e na Figura 61, respectivamente.

Figura 60 - Sede Con Edison

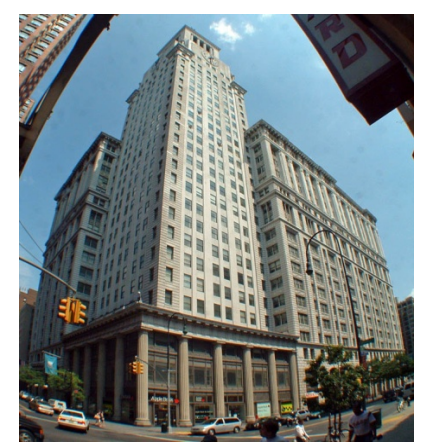

Fonte: (DONOVAN, 2008)
Figura 61 - Localização - Sede Con Edison

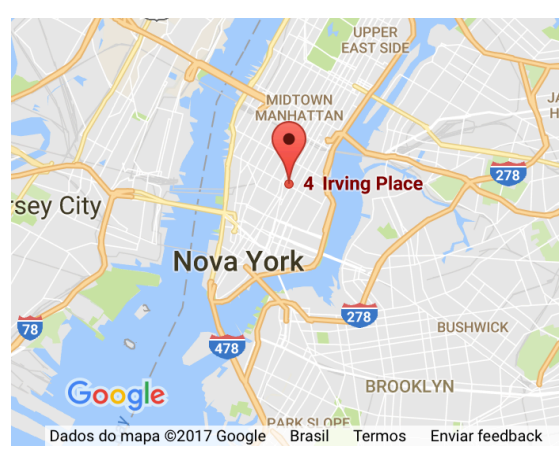

f)

\section{Nova Iorque, Nova Iorque, EUA}

A Con Edison, em parceria com a NRG Energy, está desenvolvendo um sistema móvel de baterias com a finalidade de auxiliar o sistema elétrico durante os meses de verão, quando a demanda por energia aumenta consideravelmente na cidade de Nova Iorque (UTILITY DIVE, 2017). O sistema de 1 MW e 4 MWh será utilizado, segundo (CON EDISON, 2017b; UTILITY DIVE, 2017), como forma de evitar que a rede elétrica fique sobrecarregada durante os períodos de alta demanda de energia e a postergar eventuais investimentos. Além disso, quando não houver este tipo de necessidade, estas irão realizar o peak shaving, gerando benefícios financeiros à companhia proprietária (CON EDISON, 2017c; UTILITY DIVE, 2017). 
É importante enfatizar que o sistema todo será armazenado em 3 compartimentos, conforme ilustra a Figura 7. Dois deles contendo as baterias propriamente ditas e o terceiro contendo os equipamentos elétricos necessários para a operação dessas. Espera-se que tamanha mobilidade conferirá ao sistema a capacidade de este responder a eventos programados com apenas dois dias e meio de antecedência, inicialmente. A expectativa é que este tempo diminua, à medida em que a concessionária adquira experiência e, assim, as baterias possam servir também para atender situações emergenciais (UTILITY DIVE, 2017).

Ainda de acordo com (UTILITY DIVE, 2017), a Con Edison não espera que o retorno financeiro deste projeto de demonstração, denominado Storage On Demand, ultrapasse o seu custo. Entretanto, a companhia visa explorar diversas formas de monetização, isto é, formas de lucrar a partir dos serviços prestados com o uso do sistema de baterias mencionado. Trata-se de uma forma de investigar um possível futuro modelo de mercado, em que o armazenamento de energia pode ser oferecido como serviço. Possibilidade com chances de ser concretizada, tendo em vista a iniciativa governamental de nome "Reforming the Energy Vison" (REV), que acarretará em mudanças regulatórias que promovem o uso mais eficiente da energia, aumento da geração renovável e distribuída de energia e uso de dispositivos de armazenamento (DEPARTMENT OF PUBLIC SERVICES - STATE OF NY, 2017). 